Prepared in cooperation with the

Strategic Environmental Research and Development Program

\title{
SUTRA, a Model for Saturated-Unsaturated, Variable- Density Groundwater Flow with Solute or Energy Transport-Documentation of Generalized Boundary Conditions, a Modified Implementation of Specified Pressures and Concentrations or Temperatures, and the Lake Capability
}

Chapter 52 of

Section A, Groundwater

Book 6, Modeling Techniques

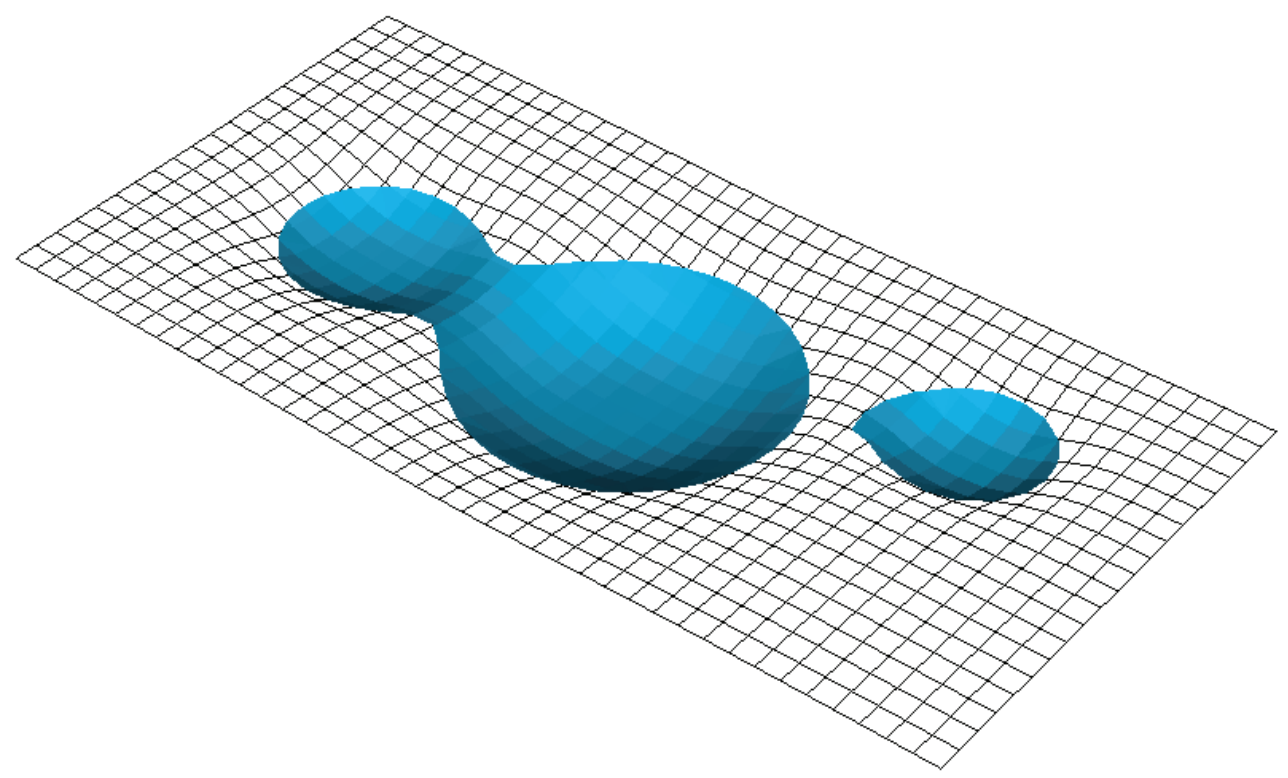

Techniques and Methods 6-A52 
Cover. Illustration of lakes simulated using the SUTRA lake capability. Portions of the top surface of the groundwater model that are covered by lake water are shaded blue. 


\section{SUTRA, a Model for Saturated-}

Unsaturated, Variable-Density

Groundwater Flow with Solute or Energy

Transport-Documentation of Generalized

Boundary Conditions, a Modified

Implementation of Specified Pressures and

Concentrations or Temperatures, and the

Lake Capability

By Alden M. Provost and Clifford I. Voss

Chapter 52 of

Section A, Groundwater

Book 6, Modeling Techniques

Prepared in cooperation with the

Strategic Environmental Research and Development Program

Techniques and Methods 6-A52 


\title{
U.S. Department of the Interior DAVID BERNHARDT, Secretary
}

\author{
U.S. Geological Survey \\ James F. Reilly II, Director
}

\section{U.S. Geological Survey, Reston, Virginia: 2019}

For more information on the USGS - the Federal source for science about the Earth, its natural and living resources, natural hazards, and the environment-visit https://www.usgs.gov or call 1-888-ASK-USGS.

For an overview of USGS information products, including maps, imagery, and publications, visit https://store.usgs.gov.

Any use of trade, firm, or product names is for descriptive purposes only and does not imply endorsement by the U.S. Government.

Although this information product, for the most part, is in the public domain, it also may contain copyrighted materials as noted in the text. Permission to reproduce copyrighted items must be secured from the copyright owner.

Suggested citation:

Provost, A.M., and Voss, C.I., 2019, SUTRA, a model for saturated-unsaturated, variable-density groundwater flow with solute or energy transport-Documentation of generalized boundary conditions, a modified implementation of specified pressures and concentrations or temperatures, and the lake capability: U.S. Geological Survey Techniques and Methods, book 6, chap. A52, 62 p., https://doi.org/10.3133/tm6A52.

ISSN 2328-7055 (online) 


\section{Contents}

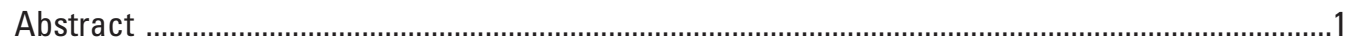

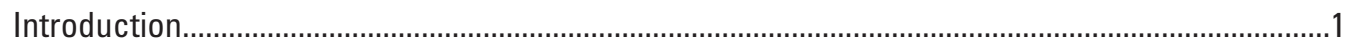

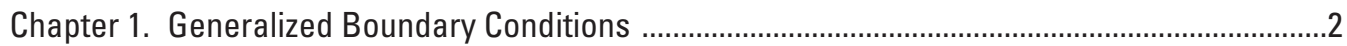

1.1. Piecewise-Linear Form of Generalized-Flow Conditions.................................................2

1.2. Two-Point Specification of Generalized-Flow Conditions .....................................................

1.3. Specification of Inflow and Outflow Concentrations or Temperatures.............................

1.4. Commonly Used Forms of the Generalized-Flow Condition .............................................

1.4.1. Water-Table Elevation........................................................................................

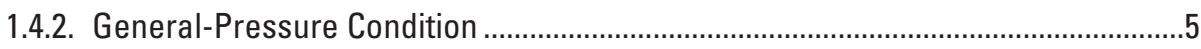

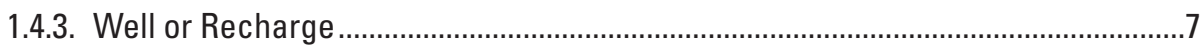

1.4.4. Specified Pressure ..........................................................................................

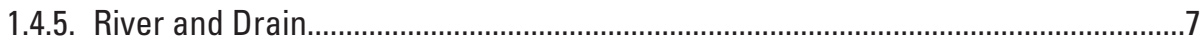

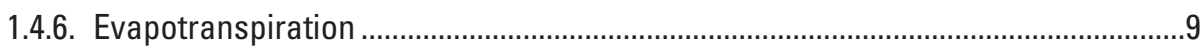

1.4.7. Evapotranspiration: Alternative Formulation for Unsaturated Flow ......................9

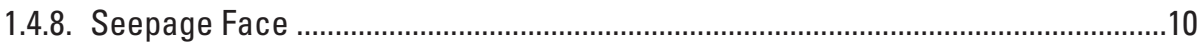

1.5. Linear Form of Generalized-Transport Conditions ........................................................10

1.6. Two-Point Specification of Generalized-Transport Conditions..........................................10

1.7. Commonly Used Forms of the Generalized-Transport Condition......................................11

1.7.1. Heat Transfer Across a Thermal Boundary Layer.................................................11

1.7.2. Solute Mass Transfer Across a Boundary Layer ....................................................12

1.7.3. Specified Source or Sink of Solute Mass or Energy ...........................................12

1.7.4. Specified Concentration or Temperature ..............................................................12

1.8. Budget Output and Boundary-Condition Output Files ...................................................13

1.8.1. The ".bcopg" File for Generalized-Flow Nodes.................................................13

1.8.2. The ".bcoug" File for Generalized-Transport Nodes ............................................13

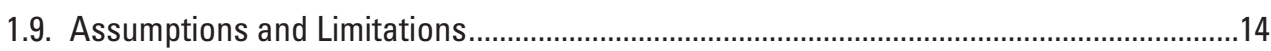

1.10. Example Problem: Seepage Face (Dam with Vertical Sides).........................................14

1.10.1. Physical Setup ..............................................................................................

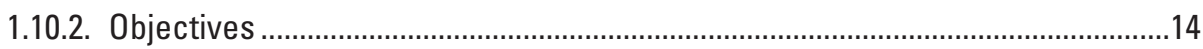

1.10.3. Simulation Setup .............................................................................................. 15

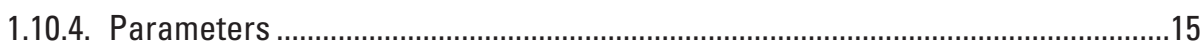

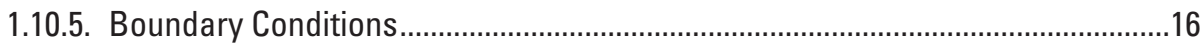

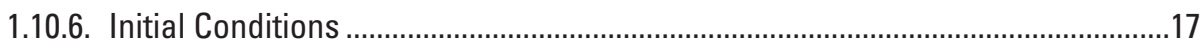

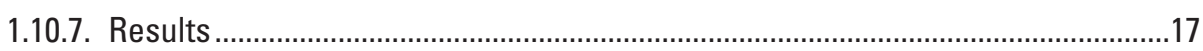

Chapter 2. Modified Implementation of Specified Pressures and Concentrations or

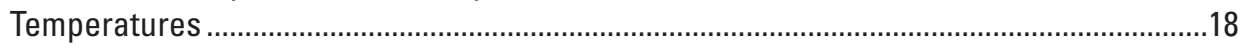

2.1. Specified-Pressure Conditions: Scheme Used with Iterative Solvers ............................18

2.2. Specified-Pressure Conditions: Scheme Used with the Direct Solver ............................19

2.3. Specified-Concentration or Temperature Conditions......................................................19 


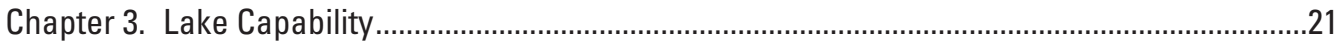

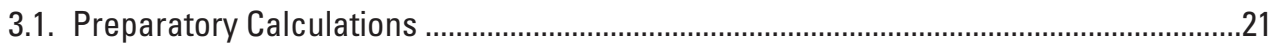

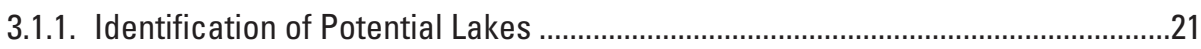

3.1.2. Lake Stage and Area as Functions of Water Volume ..............................................22

3.2. Solution Procedure for Groundwater and Lakes ...........................................................23

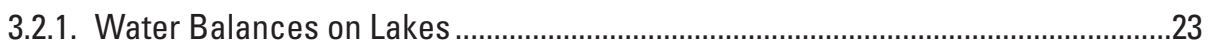

3.2.2. Solute Mass or Energy Balances on Lakes ......................................................24

3.2.3. Effect of Lakes on Groundwater-Flow and Transport Boundary Conditions ........25

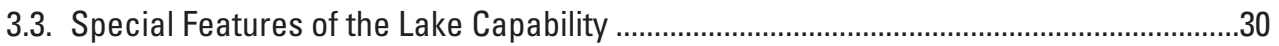

3.3.1. Limiting Where Lakes Can Form .........................................................................30

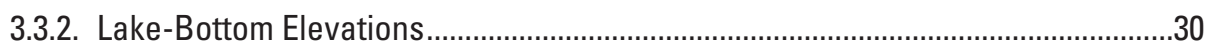

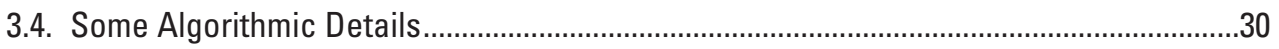

3.4.1. Identifying Potential Lakes Using the Hoshen-Kopelman Algorithm .....................30

3.4.2. Lake Hierarchy as a Binary Tree.......................................................................

3.4.3. Determining the Fate of Spillover Using Steepest Descent .................................32

3.4.4. Drying and Rewetting .......................................................................................33

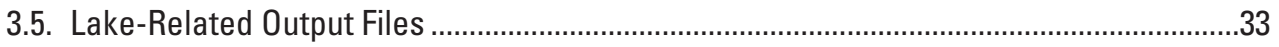

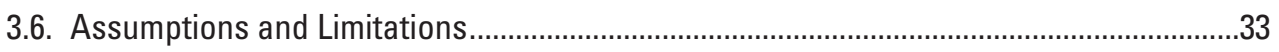

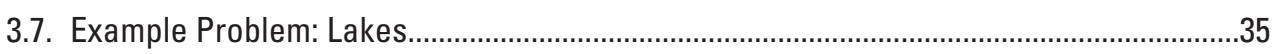

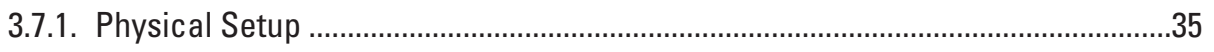

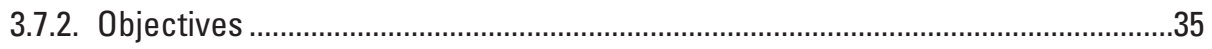

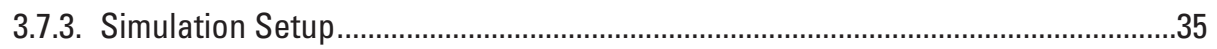

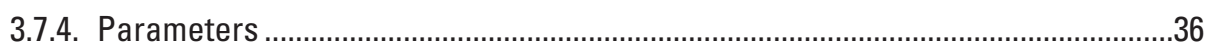

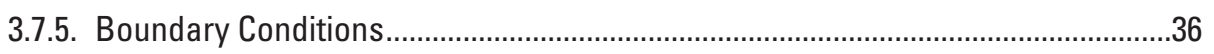

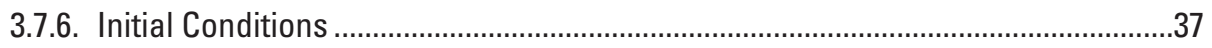

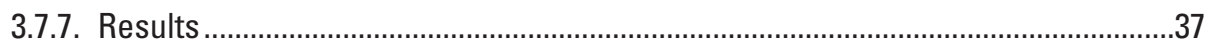

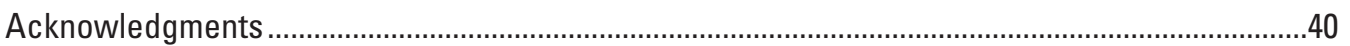

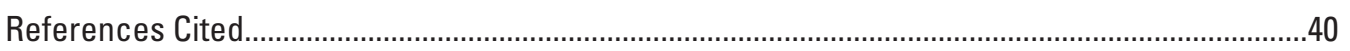

Appendix 1. List of Symbols.................................................................................................

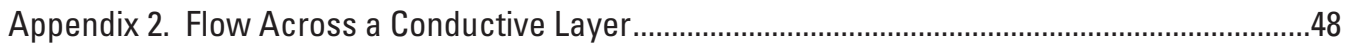

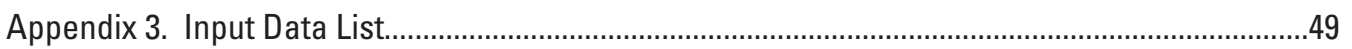




\section{Figures}

1. Seven commonly used forms of the generalized-flow condition

2. For a generalized-flow condition, inflow of fluid mass, 0 , is a linear function of pressure, $p$, subject to optional upper and lower limits on 0 and (or) p ..........................4

3. Two-point representation of a general-pressure boundary condition ...............................6

4. Alternative two-point representations of a specified-pressure boundary condition .......8

5. Two-point representation of a river boundary condition .....................................................

6. Two-point representation of an evapotranspiration boundary condition ...........................9

7. Two-point representation of a seepage-face boundary condition ...................................10

8. Three forms of the generalized-transport condition ...................................................10

9. For a generalized-transport condition, the gain of solute mass or energy, $\mathrm{QU}$, is a linear function of concentration or temperature, U........................................................11

10. Boundary conditions and finite-element mesh for the seepage face example ...............15

11. Near-steady-state SUTRA results for the seepage face example ....................................16

12. Nine potential lakes identified based on a given surface topography ............................22

13. Hierarchy of nine lakes identified based on the topography in figure 12 .......................22

14. Lake cells associated with the nodes in lake 3 identified in figure $12 \ldots \ldots \ldots \ldots \ldots \ldots \ldots \ldots \ldots . . .22$

15. Interaction of a lake with a fluid source or sink at model nodes ..................................26

16. Interaction of a lake with specified pressures at model nodes .....................................27

17. Interaction of a lake with solute or energy sources and sinks at model nodes .............28

18. Interaction of a lake with specified concentrations or temperatures at model nodes ..29

19. The lake capability identifies potential lakes by tracking the formation of distinct clusters of contiguous, submerged nodes on the top surface of the model as the water stage varies from the highest to the lowest elevation on the surface.

20. The middle lake spills into the right-hand lake first because the right-hand sill is

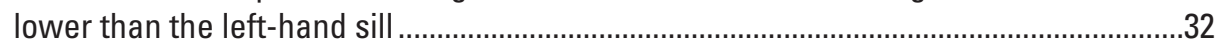

21. In reality, a sufficiently strong source to the middle lake can cause it to spill over

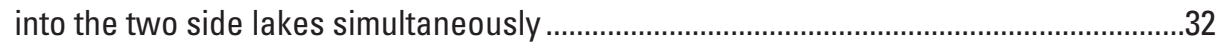

22. Finite-element mesh for the lake example .....................................................................

23. Hierarchy of five lakes identified in the lake example..................................................37

24. Initial groundwater-flow velocity vectors in the top layer of elements for the lake

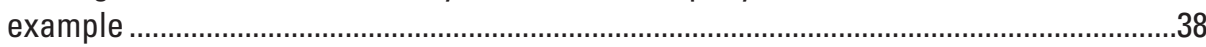

25. Areas of the model surface covered by lake water in the lake example.........................39

26. Lake-water concentration as a function of time in the lake example ............................40

\section{Tables}

1. Summary of input parameter values for commonly used forms of the generalized-flow condition

2. Summary of input parameter values for two commonly used forms of the generalized-transport condition. 


\section{Conversion Factors}

International System of Units to U.S. customary units

\begin{tabular}{|c|c|c|}
\hline Multiply & By & To obtain \\
\hline \multicolumn{3}{|c|}{ Length } \\
\hline meter $(\mathrm{m})$ & 3.281 & foot $(\mathrm{ft})$ \\
\hline kilometer $(\mathrm{km})$ & 0.6214 & mile (mi) \\
\hline \multicolumn{3}{|c|}{ Area } \\
\hline square meter $\left(\mathrm{m}^{2}\right)$ & 0.0002471 & acre \\
\hline square kilometer $\left(\mathrm{km}^{2}\right)$ & 247.1 & acre \\
\hline square centimeter $\left(\mathrm{cm}^{2}\right)$ & 0.001076 & square foot $\left(\mathrm{ft}^{2}\right)$ \\
\hline square meter $\left(\mathrm{m}^{2}\right)$ & 10.76 & square foot $\left(\mathrm{ft}^{2}\right)$ \\
\hline square kilometer $\left(\mathrm{km}^{2}\right)$ & 0.3861 & square mile $\left(\mathrm{mi}^{2}\right)$ \\
\hline \multicolumn{3}{|c|}{ Volume } \\
\hline liter $(\mathrm{L})$ & 0.2642 & gallon (gal) \\
\hline cubic meter $\left(\mathrm{m}^{3}\right)$ & 264.2 & gallon (gal) \\
\hline cubic meter $\left(\mathrm{m}^{3}\right)$ & 35.31 & cubic foot $\left(\mathrm{ft}^{3}\right)$ \\
\hline cubic kilometer $\left(\mathrm{km}^{3}\right)$ & 0.2399 & cubic mile $\left(\mathrm{mi}^{3}\right)$ \\
\hline cubic meter $\left(\mathrm{m}^{3}\right)$ & 0.0008107 & acre-foot (acre-ft) \\
\hline \multicolumn{3}{|c|}{ Flow rate } \\
\hline cubic meter per second $\left(\mathrm{m}^{3} / \mathrm{s}\right)$ & 70.07 & acre-foot per day (acre-ft/d) \\
\hline cubic meter per year $\left(\mathrm{m}^{3} / \mathrm{yr}\right)$ & 0.000811 & acre-foot per year (acre-ft/yr) \\
\hline meter per second $(\mathrm{m} / \mathrm{s})$ & 3.281 & foot per second $(\mathrm{ft} / \mathrm{s})$ \\
\hline $\begin{array}{l}\text { cubic meter per second per square } \\
\text { kilometer }\left[\left(\mathrm{m}^{3} / \mathrm{s}\right) / \mathrm{km}^{2}\right]\end{array}$ & 91.49 & $\begin{array}{l}\text { cubic foot per second per square } \\
\text { mile }\left[\left(\mathrm{ft}^{3} / \mathrm{s}\right) / \mathrm{mi}^{2}\right]\end{array}$ \\
\hline cubic meter per second $\left(\mathrm{m}^{3} / \mathrm{s}\right)$ & 22.83 & million gallons per day (Mgal/d) \\
\hline $\begin{array}{l}\text { cubic meter per day per square } \\
\text { kilometer }\left[\left(\mathrm{m}^{3} / \mathrm{d}\right) / \mathrm{km}^{2}\right]\end{array}$ & 0.0006844 & $\begin{array}{l}\text { million gallons per day per square } \\
\text { mile }\left[(\mathrm{Mgal} / \mathrm{d}) / \mathrm{mi}^{2}\right]\end{array}$ \\
\hline millimeter per year $(\mathrm{mm} / \mathrm{yr})$ & 0.03937 & inch per year (in/yr) \\
\hline \multicolumn{3}{|c|}{ Mass } \\
\hline gram $(\mathrm{g})$ & 0.03527 & ounce, avoirdupois (oz) \\
\hline kilogram (kg) & 2.205 & pound avoirdupois (lb) \\
\hline \multicolumn{3}{|c|}{ Pressure } \\
\hline kilopascal $(\mathrm{kPa})$ & 0.009869 & atmosphere, standard (atm) \\
\hline kilopascal (kPa) & 0.01 & bar \\
\hline kilopascal (kPa) & 0.2961 & inch of mercury at $60^{\circ} \mathrm{F}$ (in $\mathrm{Hg}$ ) \\
\hline kilopascal $(\mathrm{kPa})$ & 0.1450 & pound-force per square inch $\left(\mathrm{lbf} / \mathrm{in}^{2}\right)$ \\
\hline \multicolumn{3}{|c|}{ Density } \\
\hline kilogram per cubic meter $\left(\mathrm{kg} / \mathrm{m}^{3}\right)$ & 0.06242 & pound per cubic foot $\left(\mathrm{lb} / \mathrm{ft}^{3}\right)$ \\
\hline gram per cubic centimeter $\left(\mathrm{g} / \mathrm{cm}^{3}\right)$ & 62.4220 & pound per cubic foot $\left(\mathrm{lb} / \mathrm{ft}^{3}\right)$ \\
\hline \multicolumn{3}{|c|}{ Energy } \\
\hline joule $(\mathrm{J})$ & 0.738 & foot-pound $(\mathrm{ft} \cdot \mathrm{lb})$ \\
\hline
\end{tabular}




\begin{tabular}{lcc}
\hline \multicolumn{1}{c}{ Multiply } & By & To obtain \\
\hline & Specific capacity & \\
\hline liter per second per meter $[(\mathrm{L} / \mathrm{s}) / \mathrm{m}]$ & 4.831 & $\begin{array}{c}\text { gallon per minute per foot }[(\mathrm{gal} / \\
\mathrm{min}) / \mathrm{ft}]\end{array}$ \\
\hline \multicolumn{3}{l}{ Hydraulic conductivity } \\
\hline meter per day $(\mathrm{m} / \mathrm{d})$ & 3.281 & foot per day $(\mathrm{ft} / \mathrm{d})$ \\
\hline & Hydraulic gradient & \\
\hline meter per kilometer $(\mathrm{m} / \mathrm{km})$ & 5.27983 & foot per mile $(\mathrm{ft} / \mathrm{mi})$ \\
\hline
\end{tabular}

Temperature in degrees Celsius $\left({ }^{\circ} \mathrm{C}\right)$ may be converted to degrees Fahrenheit $\left({ }^{\circ} \mathrm{F}\right)$ as follows:

${ }^{\circ} \mathrm{F}=\left(1.8 \times{ }^{\circ} \mathrm{C}\right)+32$.

Temperature in degrees Fahrenheit $\left({ }^{\circ} \mathrm{F}\right)$ may be converted to degrees Celsius $\left({ }^{\circ} \mathrm{C}\right)$ as follows:

${ }^{\circ} \mathrm{C}=\left({ }^{\circ} \mathrm{F}-32\right) / 1.8$. 



\title{
SUTRA, a Model for Saturated-Unsaturated, Variable- Density Groundwater Flow with Solute or Energy Transport-Documentation of Generalized Boundary Conditions, a Modified Implementation of Specified Pressures and Concentrations or Temperatures, and the Lake Capability
}

\author{
By Alden M. Provost and Clifford I. Voss
}

\begin{abstract}
Version 3.0 of the SUTRA groundwater modeling program offers three new capabilities: generalized boundary conditions, a modified implementation of specified pressures and concentrations or temperatures, and lakes. Two new types of "generalized" boundary conditions facilitate simulation of a wide range of hydrologic processes that interact with the groundwater model, such as rivers, drains, and evapotranspiration. For generalized-flow boundary conditions, gain (inflow) or loss (outflow) of fluid mass varies linearly with pressure, subject to optional upper and lower limits on flow and (or) pressure. For generalized-transport boundary conditions, gain or loss of solute mass or energy varies linearly with concentration or temperature, respectively. Two of the original types of SUTRA boundary conditions - specified-pressure and specified-concentration or temperaturehave been modified such that user-specified, conductance-like factors (known as GNUP and GNUU in previous versions of SUTRA) are no longer required. The new lake capability works with all types of SUTRA boundary conditions, including the new generalized boundary conditions, to enable simulation of the interaction of groundwater flow and transport with lake water "ponded" on the surface of a three-dimensional model. SUTRA uses the topography of the top surface of the model, or, optionally, user-specified lake-bottom elevations, to identify potential lakes automatically. Increases and decreases in lake stage can cause lakes to coalesce and divide, respectively. The lake capability may be used with saturated or unsaturated flow and solute or energy transport.
\end{abstract}

\section{Introduction}

This report complements the main SUTRA documentation (Voss and Provost, 2002). The report documents three new capabilities in SUTRA Version 3.0: generalized boundary conditions, a modified implementation of specified pressures and concentrations or temperatures, and lakes. Throughout this report, the terms "fluid" and "water" are used interchangeably to mean "water, including any dissolved solute." The generic term "flow" refers to movement of fluid mass within the groundwater model, into or out of the model from or to an external source or sink, between groundwater and lakes, or between lakes.

Two new types of "generalized" boundary conditions facilitate simulation of a wide range of hydrologic processes that interact with the groundwater system, such as rivers, drains, and evapotranspiration. For "generalized-flow" conditions, gain (inflow) or loss (outflow) of fluid mass varies linearly with pressure, subject to optional upper and lower limits on flow and (or) pressure. For "generalized-transport" conditions, gain or loss of solute mass or energy varies linearly with concentration or temperature, respectively. The two new types of conditions are specified in datasets 21A and 21B of the ".inp" (main input) file and datasets 7A and 7B of the optional ".bcs" (time-dependent boundary condition) files.

The implementation of specified-pressure and specified-concentration or specified-temperature boundary conditions is modified in this version of SUTRA. Previously, the user was required to provide appropriate values for two conductance-like factors-GNUP and GNUU. These factors are no longer required as input and have been removed from dataset 5 of the ".inp" file. 
The lake capability introduced in this version of SUTRA simulates the evolution of lakes as they exchange fluid mass and solute mass or thermal energy with groundwater, with each other, and with external sources or sinks. Given the topography of the top surface of the model, or, optionally, user-specified lake-bottom elevations, SUTRA identifies the lakes that can form by "ponding" of water on the top surface. Increases and decreases in lake stage can cause lakes to coalesce and divide, leading to a hierarchy of "parent" and "child" lakes that is automatically determined by SUTRA at the start of the simulation. On each time step, SUTRA solves the groundwater-flow and transport equations and updates lake stages and lake-water concentrations or temperatures. Lakes influence the groundwater simulation by interacting with user-specified flow and transport boundary conditions on the top surface of a model. The lake capability may be used with saturated or unsaturated flow, solute or energy transport, and all types of SUTRA boundary conditions, including the new generalized boundary conditions.

A list of input datasets created or modified to support the new and modified boundary conditions and the lake capability is given in appendix 3. A complete, up-to-date description of all SUTRA input datasets is maintained on the U.S. Geological Survey (USGS) Web site at https://doi.org/10.5066/P9PPEHHM.

\section{Chapter 1. Generalized Boundary Conditions}

Prior to Version 3.0, SUTRA supported only the following four types of boundary conditions, which are applied at nodes:

1. Sources and sinks of fluid mass,

2. Sources and sinks of solute mass or thermal energy,

3. Specified pressures, and

4. Specified concentrations or temperatures.

These four types, which are still supported in SUTRA 3.0, allow users to represent a variety of hydrologic processes that interact with the groundwater system, such as pumping or injection of water, recharge, pressure due to surface water of known depth and density, addition of tracer, and variations in surface temperature.

To facilitate representation of a wider range of physical process, SUTRA 3.0 offers two additional types of boundary conditions, which are also applied at nodes:

1. Generalized-flow conditions - sources and sinks of fluid mass that depend on pressure, and,

2. Generalized-transport conditions - sources and sinks of solute mass or energy that depend on concentration or temperature, respectively.

The two new types of boundary conditions are "generalized" in the sense that they include the four original types as special cases while offering additional capabilities. Like the four original types, the two new types can be made time-dependent using “bcs" input files.

Like sources and sinks of fluid mass and specified pressures, generalized-flow conditions require specification of concentrations or temperatures associated with fluid inflows to the model. In addition, generalized-flow conditions require specification of concentrations or temperatures associated with fluid outflows from the model. The latter specification enables simulation of processes such as evaporation, in which fluid may leave the model at a concentration or temperature different from that of the groundwater.

\subsection{Piecewise-Linear Form of Generalized-Flow Conditions}

Figure 1 shows schematic representations of seven idealized, pressure-dependent boundary conditions: general pressure, well or recharge, specified pressure, river, drain, evapotranspiration (ET), and seepage face. By specifying such functions using the generalized-flow boundary condition, the user can create these and other boundary-condition variations. The first six conditions are analogous to commonly used head-dependent conditions described by Harbaugh (2005). These conditions represent boundary-condition processes that may be specified at any node in the finite-element model mesh. By convention, fluid-mass gain by (inflow to) the model is positive and fluid-mass loss (outflow) is negative.

In each case in figure 1, the relation between flow, $Q[\mathrm{M} / \mathrm{s}]$, into or out of the model at the boundary-condition node, and simulated pressure, $p\left[\mathrm{M} /\left(\mathrm{L} \cdot \mathrm{s}^{2}\right)\right]$, at the node is piecewise-linear; it is defined by a combination of horizontal, vertical, and (or) sloping straight-line segments. For a general-pressure condition (fig. $1 A$ ), the sloping segment of the graph characterizes a conductive connection between the simulated pressure at the boundary-condition node and a specified external pressure. For a 


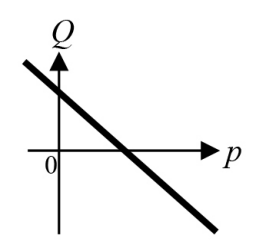

$A$ general pressure

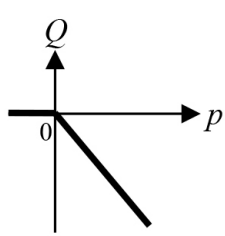

$E$ drain

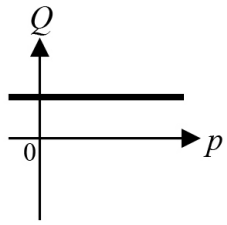

$B$ well or recharge

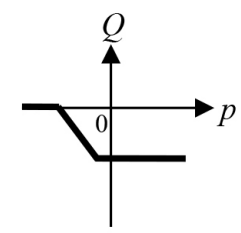

$F$ evapotranspiration

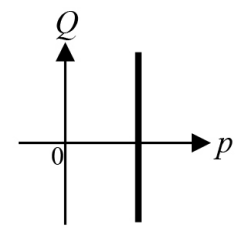

C specified pressure

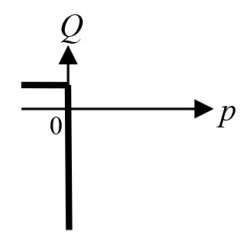

$G$ seepage face

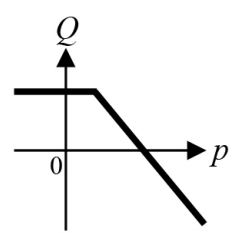

$D$ river
Figure 1. Seven commonly used forms of the generalizedflow condition: $A$, general pressure; $B$, well or recharge; $C$, specified pressure; $D$, river; $E$, drain; $F$, evapotranspiration; and $G$, seepage face. $Q$ is the gain of fluid mass at the node where this boundary condition is specified [M/s] (see appendix 2), and $p$ is simulated pressure at that node $\left[\mathrm{M} /\left(\mathrm{L} \cdot \mathrm{S}^{2}\right)\right]$. The symbol " 0 " represents the origin, $(p, 0)=(0,0)$.

well or recharge condition (fig. $1 B$ ), flow is specified independently of pressure, as indicated by the horizontal line in the graph. For a specified-pressure condition (fig. 1C), pressure is specified independently of flow, as indicated by the vertical line in the graph. For a river condition (fig. $1 D$ ), the conductive connection between the boundary-condition node and the external pressure imposed by the overlying river water is conceptualized as occurring through a river bed. The horizontal segment of the plot indicates that, for a given river stage, the rate of seepage from the river becomes independent of pressure when the water table is below the river bed (Harbaugh, 2005). (The correspondence between water-table elevation and pressure assumed in formulating some generalized-flow conditions is discussed in section 1.4.1., "Water-Table Elevation.") A drain condition (fig. 1E) is a special case of a river condition in which surface water does not accumulate in the channel and recharge of surface water to the groundwater cannot occur. For an evapotranspiration (ET) condition (fig. 1F), the sloping segment of the graph characterizes the change in the rate of fluid loss by ET as the pressure (and, hence, the water-table elevation) changes. When the water table is above a certain depth, the rate of fluid loss by ET is at its maximum possible value, and when the water table is below a certain depth (the "extinction depth"), the rate of fluid loss by ET is zero, as indicated by the horizontal segments of the graph. (An alternative interpretation of figure $1 F$ is presented in section 1.4.7. "Evapotranspiration: Alternative Formulation for Unsaturated Flow.") For a seepage-face condition, as defined for SUTRA (fig. 1G), the vertical segment of the graph below the horizontal axis represents conditions along the lower portion of the seepage face, where the pressure is constrained to be zero (atmospheric pressure) and water discharges from the model. The vertical segment of the graph above the horizontal axis represents conditions along the seepage face where the pressure is constrained to be zero and water recharges the model. (Recharge along a seepage face can occur along its uppermost portion when the face is not vertical.) The horizontal segment of the graph represents recharge at a specified rate $(p<0)$ in model regions above the uppermost seepage face where unsaturated conditions prevail. If the face is vertical, the recharge rate is zero. Each of the conditions illustrated in figure 1 is discussed in more detail in section 1.4. "Commonly Used Forms of the Generalized-Flow Condition."

\subsection{Two-Point Specification of Generalized-Flow Conditions}

A generalized-flow condition at a node requires specification of a linear dependence of flow (fluid mass gain), $Q$, on simulated pressure at the node, $p$. Optional upper and (or) lower limits can be set on flow and (or) pressure. Figure 2 illustrates the two-point scheme used to specify both the sloping linear segment and the optional limits for a generalized-flow condition. User-specified points $\left(p_{1}, Q_{1}\right)$ and $\left(p_{2}, Q_{2}\right)$ define the linear relation between $Q$ and $p$. These also serve as points at which the user can optionally limit either $Q$ or $p$ (but not both at the same point). The values $p_{1}$ and $p_{2}$ can be used as lower and upper limiting values of $p$, respectively. The values $Q_{1}$ and $Q_{2}$ can be used as upper and lower limiting values of $Q$, respectively. All of the boundary conditions shown in figure 1 are created by the user setting appropriate values of $\left(p_{1}, Q_{1}\right)$ and $\left(p_{2}, Q_{2}\right)$ and optionally specifying limits at these points, thereby defining the piecewise-linear relation for each particular condition.

For most realistic hydrologic processes that might be represented by a generalized-flow boundary condition, the linear segment will have a negative slope as shown in figure 1; as simulated pressure at the node increases relative to the external pressure, the flow at the node decreases (fluid mass gain from an external source becomes less positive, or fluid mass loss to an external sink becomes more negative). Thus, SUTRA requires $p_{2}>\mathrm{p}_{1}$ and $Q_{2} \leq Q_{1}$, which implies a negative or zero slope.

For the sake of notational simplicity, the symbols $p_{1}, p_{2}, Q_{1}$, and $Q_{2}$ are used throughout Chapter 1 to represent the user-specified pressures and flows that define a generalized-flow boundary condition. Note that in input datasets that define 


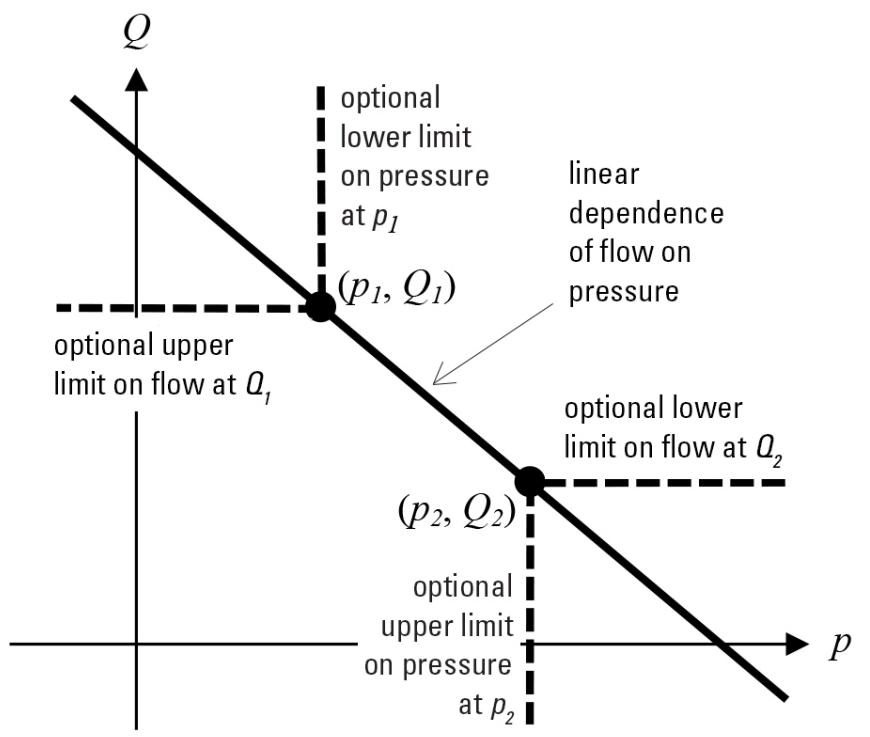

Figure 2. For a generalized-flow condition, inflow of fluid mass, $Q$, is a linear function of pressure, $p$, subject to optional upper and lower limits (dashed lines) on $Q$ and (or) $p$. By convention, positive values of $Q$ denote inflows and negative values denote outflows. generalized-flow conditions (".inp" dataset 21A and ".bcs" dataset 7A), $p_{1}, p_{2}, Q_{1}$, and $Q_{2}$ are represented by the more descriptive symbols $p_{B G 1}, p_{B G 2}, Q_{P B G 1}$, and $Q_{P B G 2}$, respectively.

\subsection{Specification of Inflow and Outflow Concentrations or Temperatures}

For all types of flow-related SUTRA boundary conditions, including generalized-flow conditions, the user specifies the concentration or temperature of any inflow to the model that might occur at each boundary node. For a specified-source/sink or specified-pressure condition at a node, any outflow automatically has the groundwater concentration or temperature computed at the node. Generalized-flow conditions offer more flexibility by allowing the user to set the outflow concentration or temperature. Two options are available for specifying the value of the outflow concentration or temperature. The first option is to specify the value directly. For example, to simulate ET of pure water from solute-laden groundwater, the outflow concentration would be set to zero. The second option is to specify the outflow value relative to the value computed by SUTRA at the boundary node. The relative value can be positive, zero, or negative. A positive
greater than (less than) the value computed by SUTRA at the (negative) relative value indicates a concentration or temperature greater than (less than) the value computed by SUTRA at the boundary node. For example, to simulate groundwater discharge to a drain, the outflow concentration would be set to a relative value of zero so that the discharging water has the same concentration as the groundwater at the boundary node.

\subsection{Commonly Used Forms of the Generalized-Flow Condition}

The generalized-flow condition provides a framework for defining commonly used boundary conditions on groundwater flow. Guidance on how to formulate a generalized-flow condition for the forms shown in figure 1 is provided below. Input parameter values for general-pressure conditions, rivers, drains, ET, and seepage faces are summarized in table 1. Although specified-pressure and pressure-independent conditions, such as recharge and wells, are most easily handled using other types of SUTRA boundary conditions, instructions for formulating such conditions within the generalized-flow framework are given in the main text.

\subsubsection{Water-Table Elevation}

In the discussion below, the river, drain, and ET conditions are conceptualized in terms of water-table elevation. In a drain, for example, flow is zero when the water table drops below the drain elevation. However, because a SUTRA generalized-flow condition expresses flow as a function of pressure at the boundary-condition node, water-table elevation must be estimated as a function of pressure at the boundary-condition node. For this purpose, the pressure profile below land surface is assumed to be hydrostatic:

$$
p(z)=p_{w t}+\rho g\left(z_{w t}-z\right)
$$

where $p(z)$ is the estimated pressure at a particular boundary-condition node, which is at elevation $z$ [L], $p_{w t}$ is the pressure at the water table, which is at elevation $z_{w t}[\mathrm{~L}], \rho\left[\mathrm{M} / \mathrm{L}^{3}\right]$ is fluid density, and $g\left[\mathrm{~L} / \mathrm{s}^{2}\right]$ is the acceleration of gravity. Assuming the pressure at the water table is zero $\left(p_{w t}=0\right)$, rearrangement of equation (1) yields an approximate relation between water-table elevation, $z_{w t}$, and simulated pressure, $p$, at the boundary-condition node:

$$
z_{w t}=z+\frac{p}{\rho g}
$$


Table 1. Summary of input parameter values for commonly used forms of the generalized-flow condition. Each form is discussed in detail and symbols are defined in the main text.

\begin{tabular}{|c|c|c|c|c|c|}
\hline Special cases ${ }^{1}$ & $p_{1}$ & $Q_{1}$ & $p_{2}$ & $\mathrm{Q}_{2}$ & Notes \\
\hline General pressure & $p_{\text {ext }}$ & $Q_{f d}$ & $>p_{\text {ext }}$ & $\frac{C_{l a y}}{g}\left(p_{e x t}-p_{2}\right)+Q_{f d}$ & $\begin{array}{l}\text { If free drainage is negligible compared to pressure- } \\
\text { driven flow, } Q_{f d}=0 \text {. See equations (3)-(8). Note that } \\
\quad C_{\text {lay }} \geq 0\end{array}$ \\
\hline \multirow[t]{2}{*}{ River, Drain } & \multirow[t]{2}{*}{$p_{e x t}$} & \multirow[t]{2}{*}{$Q_{\max }$} & \multirow[t]{2}{*}{$>p_{\text {ext }}$} & \multirow[t]{2}{*}{$\frac{C_{\text {lay }}}{g}\left(p_{\text {ext }}-p_{2}\right)+Q_{\max }$} & $\begin{array}{l}\text { For a river, use } p_{\text {ext }}=\rho g d_{r i v} \text { and } Q_{\max }=Q_{f d}+Q_{r i v} \text {. } \\
\quad \text { Set an upper limit on flow at } Q_{l} \text {. } \\
\text { For a drain, use } p_{e x t}=0 \text { and } Q_{\max }=0 \text {. Set an upper } \\
\quad \text { limit on flow at } Q_{l} \text {. }\end{array}$ \\
\hline & & & & & See equations (3)-(8) and (9)-(11). Note that $C_{\text {lay }} \geq 0$. \\
\hline \multirow[t]{2}{*}{$\begin{array}{l}\text { Evapo- } \\
\text { transpiration }\end{array}$} & \multirow[t]{2}{*}{$-\rho g d_{e x}$} & \multirow[t]{2}{*}{0} & \multirow[t]{2}{*}{$-\rho g d_{\max }$} & \multirow[t]{2}{*}{$q_{E T}^{\max } A$} & $\begin{array}{l}\text { Set upper and lower limits on flow at } Q_{1} \text { and } Q_{2,} \text {, respec- } \\
\text { tively. Note that } d_{e x}>0, d_{\max } \geq 0 \text {, and } q_{E T}^{m a x}<0> \\
\text { by convention, and } d_{e x}>d_{\max } \text {. }\end{array}$ \\
\hline & & & & & See equations (13) and (14). \\
\hline \multirow[t]{2}{*}{ Seepage face } & \multirow[t]{2}{*}{$<0$} & \multirow[t]{2}{*}{$Q_{i n f}$} & 0 & \multirow[t]{2}{*}{$Q_{i n f}$} & $\begin{array}{l}\text { Set an upper limit on pressure at } p_{2} \text {. For a vertical seepage } \\
\quad \text { face, } Q_{\text {inf }}=0 \text {. }\end{array}$ \\
\hline & & & & & See equation (15). \\
\hline
\end{tabular}

When $p<0, p=0$, or $p>0$ at the boundary-condition node, the water-table elevation is below, exactly at, or above the boundary-condition node, respectively.

The river, drain, and ET forms of the generalized-flow condition are simplified representations of real hydrologic processes. Although SUTRA is capable of simulating detailed saturation profiles for saturated-unsaturated flow, the river, drain, and ET conditions described below do not make use of the details of unsaturated zone physics. Rather, they use equation (2) to formulate approximate, piecewise-linear relations between flow and pressure at boundary-condition nodes. The user should remain mindful of this approximation when constructing models and interpreting results. (In the case of ET, an alternative formulation that does take into account variable saturation is presented in section 1.4.7, "Evapotranspiration: Alternative Formulation for Unsaturated Flow.")

\subsubsection{General-Pressure Condition}

A general-pressure condition is implemented by specifying two points, $\left(p_{l}, Q_{1}\right)$ and $\left(p_{2}, Q_{2}\right)$, with no limits on $p$ or $Q$ (fig. 3). The concentrations or temperatures associated with possible inflow and outflow at the general-pressure node are set by the user according to the hydrologic-geochemical process being represented. For outflow, the concentration or temperature is typically chosen to be that of the groundwater, unless a chemical or physical process somehow modifies it.

The common case in which the boundary condition represents flow across a conductive layer is described below. Within the conductive layer, permeability, fluid density and viscosity, and gravity are assumed to be uniform. Flow is driven by the hydraulic head difference across the layer; under hydrostatic conditions (no head difference), no flow crosses the layer. Because SUTRA calculates flows in terms of pressure rather than head, this concept and the equations below are presented in terms of pressure. Details of the derivation are presented in appendix 2. 
The expression for flow, $Q[\mathrm{M} / \mathrm{s}]$, across the layer consists of two terms that reflect the two forces-pressure and gravity - that drive the flow:

$$
Q=\frac{C_{\text {lay }}}{g}\left(p_{\text {ext }}-p\right)+Q_{f d}
$$

The first term on the right-hand side of equation (3) represents flow driven by the pressure difference between the boundary node at pressure $p$ and an external point (on the other side of the layer) at pressure $p_{e x t}$. The conductance of the layer, $C_{l a y}$ $\left[\mathrm{L}^{2} / \mathrm{s}\right]$, is defined by

$$
C_{\text {lay }}=\frac{K A}{L}
$$

where

$$
K=\frac{k \rho g}{\mu}
$$

is the hydraulic conductivity $[\mathrm{L} / \mathrm{s}]$ of the layer, $L[\mathrm{~L}]$ is its thickness, $k\left[\mathrm{~L}^{2}\right]$ is its permeability, $\rho$ is fluid density $\left[\mathrm{M} / \mathrm{L}^{3}\right]$, $\mu$ is fluid viscosity $[\mathrm{M} /(\mathrm{L} \cdot \mathrm{s})], g\left[\mathrm{~L} / \mathrm{s}^{2}\right]$ is the acceleration of gravity, and $A\left[\mathrm{~L}^{2}\right]$ is the area of the conductive layer through which flow passes to the boundary node (see fig. B.1 in Voss and Provost, 2002). The second term on the right-hand side of equation (3), $Q_{f d}[\mathrm{M} / \mathrm{s}]$, represents gravity-driven flow (that is, the rate of free drainage) that would occur if there were no pressure difference across the conductive layer. This is given by

$$
Q_{f d}=K A \rho\left(\frac{g_{n}}{g}\right)
$$

where $g_{n}\left[\mathrm{~L} / \mathrm{s}^{2}\right]$ is the component of gravity across (normal to) the layer. If the layer is inclined at an angle $\theta$ above the horizontal, $g_{n} / g=\cos \theta$; if the layer is horizontal, $g_{n} / g=1$; and if the layer is vertical, $g_{n} / g=0$. If pressure within the layer is hydrostatic $\left(p=p_{e x t}+\rho g_{n} L\right)$, the driving forces due to pressure and gravity cancel each other exactly in equation (3), and no flow crosses the layer $(Q=0)$.

Any two points that lie on the line represented by equation (3) may be used to define a general-pressure condition that represents flow through a conductive layer as described above. One may set, for example,

$$
p_{1}=p_{e x t}, \quad Q_{1}=Q_{f d}, \quad p_{2}>p_{e x t}, \quad \text { and } \quad Q_{2}=\frac{C_{l a y}}{g}\left(p_{e x t}-p_{2}\right)+Q_{f d}
$$

If free drainage is negligible compared to pressure-driven flow across the layer (or zero, as for a vertical conductive layer), then $Q_{f d} \approx 0$, and equation (7) may be approximated by

$$
p_{1}=p_{\text {ext }}, \quad Q_{1}=0, \quad p_{2}>p_{\text {ext }}, \quad \text { and } \quad Q_{2}=\frac{C_{\text {lay }}}{g}\left(p_{\text {ext }}-p_{2}\right)
$$




\subsubsection{Well or Recharge}

The simplest way to represent a pressure-independent fluid source or sink, such as recharge or a pumping well, is through “.inp" dataset 17 and, for time-dependent conditions, the corresponding ".bes" dataset 3 . However, such a condition can also be formulated as a special case of a general-pressure condition with $Q_{1}=Q_{2}$ so that flow does not vary with pressure. Flow (fluid mass gain) is negative for a pumping well and positive for an injection well or recharge. The concentration or temperature associated with inflow is set to that of the water being recharged or injected. The concentration or temperature associated with outflow is set to that of the groundwater. Evaporation of pure (solute-free) water from solute-laden groundwater can be simulated by setting the outflow concentration to zero.

\subsubsection{Specified Pressure}

The simplest way to represent a specified-pressure boundary condition is through ".inp" dataset 19 and, for time-dependent conditions, the corresponding ".bcs" dataset 5. However, the generalized-flow framework allows two alternative formulations for specified-pressure boundary conditions. The first alternative (fig. $4 A$ ) is to set $p_{1}$ and $p_{2}$ nearly equal so that the slope is very large. This is essentially how specified-pressure conditions were formulated in earlier versions of SUTRA. The disadvantage of this method is that the slope must be chosen by trial and error such that SUTRA computes the pressure and the corresponding flow to approximately equal precision. For details, see section 3.5 and the input data listing for ".inp" dataset 5, both in the main SUTRA documentation (Voss and Provost, 2002). The second alternative (fig. $4 B$ ) is to set a limit on pressure at $p=p_{1}$, set $p_{2}$ greater than $p_{1}$, and set $Q_{1}$ and $Q_{2}$ to values that will never be attained in the simulation, so that $p$ is always held at its limiting value.

\subsubsection{River and Drain}

A river boundary condition represents the hydraulic connection, through the river bed, between the boundary-condition node at the base of the river bed and the overlying river water. When the pressure computed at the boundary-condition node is negative, the water-table elevation is below the river bed, and the rate of leakage through the river bed no longer depends on pressure (Harbaugh, 2005). Thus, the river condition is a variation on the general-pressure condition (3) in which $p_{\text {ext }}=\rho g d_{r i v}$ is the pressure exerted by the overlying river water, where $d_{r i v}[\mathrm{~L}]$ is the depth of the river water, atmospheric pressure is zero, and an upper limit is set on flow (fig. 5). The maximum flow rate, $Q_{\max }[\mathrm{M} / \mathrm{s}]$, is the sum of two contributions:

$$
Q_{\text {max }}=Q_{f d}+Q_{r i v}
$$

where $Q_{f d}$ is the free drainage given by equation (6), and $Q_{r i v}[\mathrm{M} / \mathrm{s}]$ is the flow driven by the additional head supplied by the overlying river water,

$$
Q_{r i v}=K A \rho\left(\frac{d_{r i v}}{L}\right)
$$

Thus, for a river condition, one may set

$$
p_{1}=p_{\text {ext }}, \quad Q_{1}=Q_{\max }, \quad p_{2}>p_{\text {ext }}, \quad \text { and } \quad Q_{1}=\frac{C_{\text {lay }}}{g}\left(p_{\text {ext }}-p_{2}\right)+Q_{\max }
$$

with $p_{\text {ext }}=\rho g d_{r i v}, Q_{\max }$ given by equation (9), and a limit on $Q$ set at $Q_{1}$.

The drain boundary condition at a node is a special case of the river condition in which no water collects in the channel $\left(p_{e x t}=0\right)$ and fluid mass can only be lost from the drain node; groundwater recharge is prohibited from a drain $\left(Q_{\max }=0\right)$. A river-type boundary condition can also be used to approximate the hydraulic behavior of a perforated or porous pipe buried beneath the ground. In that case, the pipe wall is analogous to the river bed. 


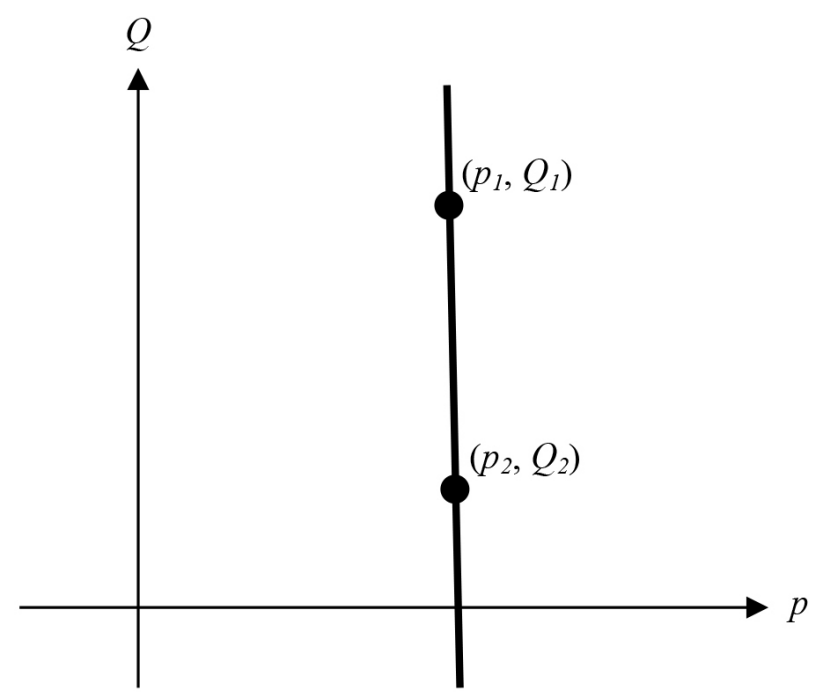

$A$

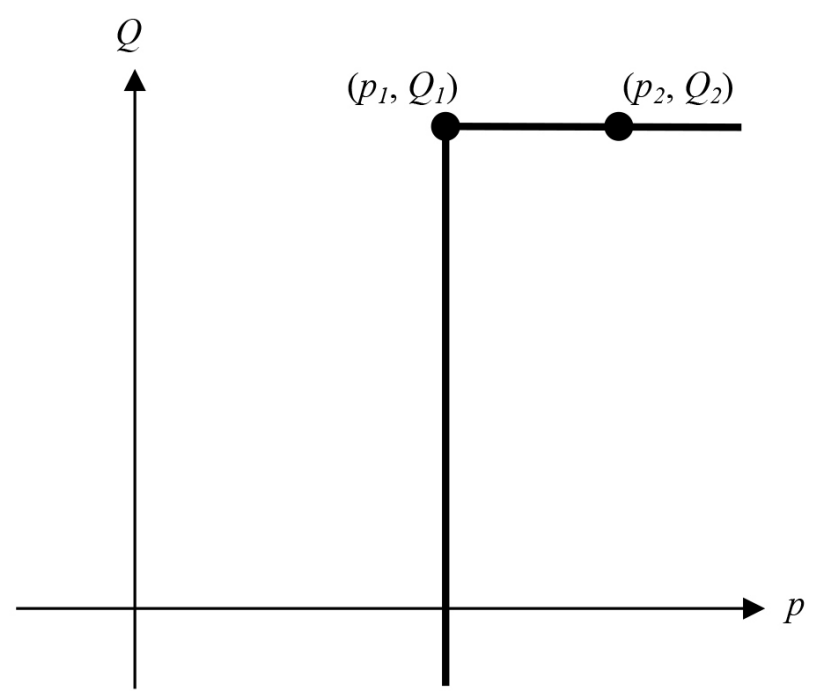

$B$

Figure 4. Alternative two-point representations of a specified-pressure boundary condition. $A$, The values of $p_{1}$ and $p_{2}$ are nearly equal, so the slope is very large. $B$, A limit is set at $p=p_{1}, p_{2}$ is set greater than $p_{1}$, and $Q_{1}$ and $Q_{2}$ are set to a very large value outside the expected range of flows, so the limit on $p$ is always active.

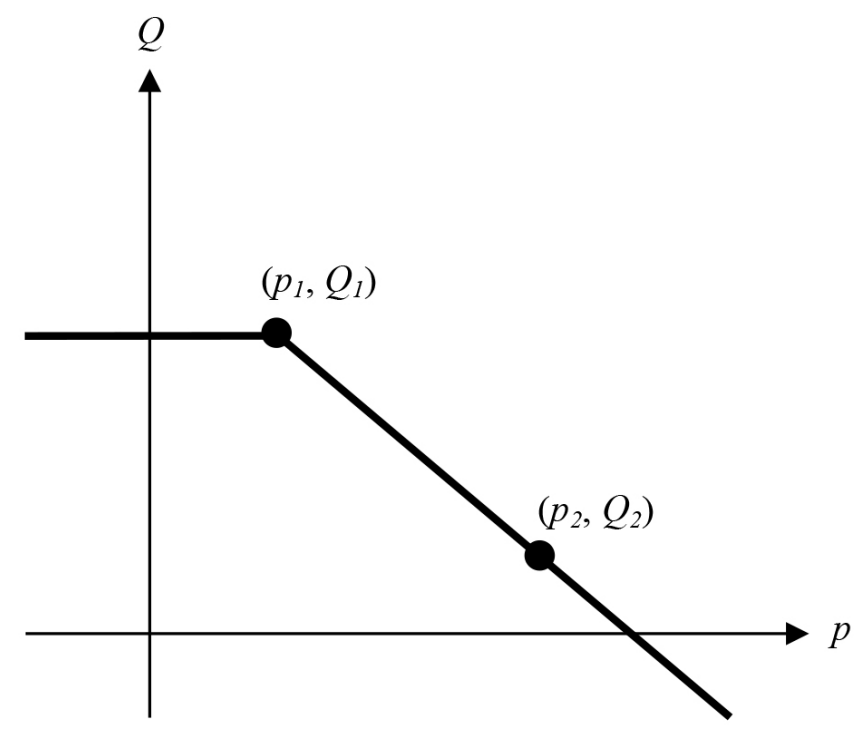

Figure 5. Two-point representation of a river boundary condition. An upper limit of $Q_{1}$ is set on $Q$ when the pressure becomes low enough that the water-table elevation is below the river bed, and the rate of leakage through the river bed no longer depends on pressure. A drain boundary condition is similar, but with $p_{1}=0$ and $Q_{1}=0$. Parameter values for rivers and drains are summarized in table 1. 


\subsubsection{Evapotranspiration}

By analogy with the head-dependent evapotranspiration (ET) condition described by Harbaugh (2005), the rate of fluid loss, $Q$, due to ET at an ET boundary-condition node depends linearly on simulated pressure, $p$, at the node when the water-table elevation is between an upper and a lower bound, that is, when

$$
z-d_{e x} \leq z_{w t} \leq z-d_{\max }
$$

where $z$ is the elevation of the ET boundary-condition node at land surface and $z_{w t}$ is the water-table elevation estimated using equation (2). The upper bound on $z_{w t}$ corresponds to the depth, $d_{\max }[\mathrm{L}]$, above which the rate of fluid loss is at its maximum (most negative) value, and the lower bound corresponds to the "extinction depth," $d_{e x}[\mathrm{~L}]$, below which the rate of fluid loss is zero. Depths are defined as positive distances from land surface, and $d_{e x}>d_{\max }$. Using equation (2), equation (12) can be reexpressed in terms of pressure:

$$
-\rho g d_{e x} \leq p \leq-\rho g d_{\max }
$$

resulting in a piecewise-linear dependence of $Q$ on $p$ (fig. 6). Thus, the ET condition can be implemented by setting

$$
p_{1}=-\rho g d_{e x}, \quad Q_{1}=0, \quad p_{2}=-\rho g d_{\max }, \quad \text { and } \quad Q_{2}=q_{E T}^{\max } A
$$

where $q_{E T}^{\max }$ is the maximum (most negative) ET flux $\left[\mathrm{M} /\left(\mathrm{L}^{2} \cdot \mathrm{s}\right)\right]$ and $A$ is the area $\left[\mathrm{L}^{2}\right]$ associated with the ET boundary-condition node. In accordance with SUTRA convention, $q_{E T}^{\max }$ is defined as negative because it represents a loss of fluid from the model.

For solute transport, the concentration of the evapotranspired (outflowing) water is typically assumed to be zero, although any desired value can be specified. For energy transport, the temperature associated with the evapotranspired water depends on the process being simulated. If only transpiration by plants

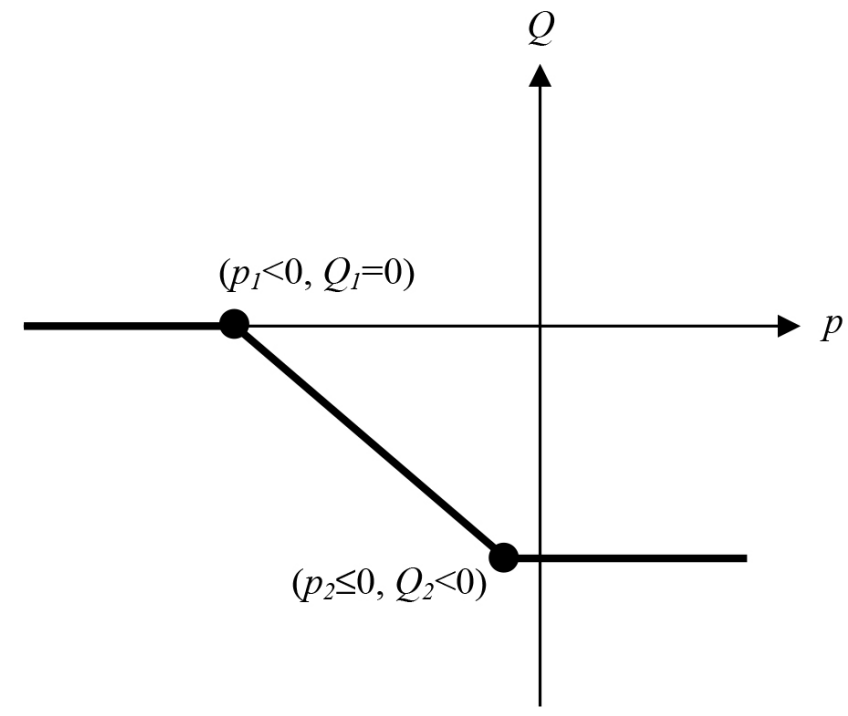

Figure 6. Two-point representation of an evapotranspiration (ET) boundary condition. The upper limit of $Q_{1}=0$ corresponds to the pressure $p_{1}$ at which the water-table elevation is below the extinction depth. The lower limit of $Q_{2}$ represents the maximum rate of fluid loss due to ET, which is achieved when the water-table elevation is above a specified depth at or below land surface. Parameter values are summarized in table 1. (An alternative interpretation is presented in section 1.4.7, "Evapotranspiration: Alternative Formulation for Unsaturated Flow.") (not evaporation) is being simulated, setting the temperature of the transpired water to that of the groundwater may be the most appropriate choice. If only direct evaporation (not transpiration) is being simulated, the latent heat of vaporization, $\Delta H_{v a p}[\mathrm{E} / \mathrm{M}]$, can be taken into account by setting the associated outflow temperature to a relative value of $\Delta H_{v a p} / c_{w}$, where $c_{w}\left[\mathrm{E} /\left(\mathrm{M} \cdot{ }^{\circ} \mathrm{C}\right)\right]$ is the specific heat of water. (Relative specification of outflow temperatures is discussed is section 1.3, "Specification of Inflow and Outflow Concentrations or Temperatures.") The concentration or temperature associated with inflow is irrelevant in the case of ET, since inflow cannot occur.

\subsubsection{Evapotranspiration: Alternative Formulation for Unsaturated Flow}

In the formulation of the ET condition presented in section 1.4.6, the loss of water due to ET represents the total loss integrated over the depth of the root zone. As an approximation, this total loss of water is assigned to the node at the top surface of the model. Such an approximation is especially useful when the details of the unsaturated zone are considered unimportant and the flow system is modeled as saturated. In that case, the simulated pressure at the top-surface node provides an estimate of the water-table elevation according to (2).

If unsaturated flow is being simulated explicitly, an ET condition can be applied at multiple nodes at or below the 
top surface of the model, allowing the ET flux at each ET node to depend on simulated pressure at the node, which is indicative of saturation at the node. In that case, each ET node is assigned its own piecewise-linear $Q$ versus $p$ function (fig. 6).

Negative pressures correspond to unsaturated conditions. Pressure $p_{1}$ is the (negative) pressure below which roots are unable to extract groundwater. As pressure increases above $p_{l}$, saturation increases, and therefore so does the rate of water loss due to ET. Pressure $p_{2}$ is the (negative) pressure above which roots extract groundwater at the maximum possible rate. Note that in this alternative formulation, the loss of water due to ET can be distributed over multiple nodes at different depths, with a different rate of loss at each node.

\subsubsection{Seepage Face}

A vertical seepage face discharges to atmospheric pressure below the water table and acts as a no-flux boundary above the water table (Freeze and Cherry, 1979). Wherever the portion of the face above the water table is not vertical, the possibility of infiltration exists, and the face need not act as a no-flux boundary there.

A seepage-face boundary condition (fig. 7) can be implemented by setting

$$
p_{1}<0, \quad Q_{1}=Q_{i n f}, \quad p_{2}=0, \quad \text { and } \quad Q_{2}=Q_{i n f}
$$

where $Q_{i n f}$ is the infiltration rate $[\mathrm{M} / \mathrm{s}]$ when the boundary node is unsaturated $(p<0)$. A limit is imposed on pressure at point 2. For a vertical seepage face, $Q_{i n f}=0$. The infiltration rate is commonly set to zero even when the seepage face is not vertical.

\subsection{Linear Form of Generalized-Transport Conditions}

Figure 8 shows schematic representations of three idealized concentration- or temperature-dependent boundary conditions: general concentration or temperature, specified source or sink of solute mass or energy, and specified concentration or temperature. In each case, the relation between the gain of solute or energy, $Q^{U}\left[\mathrm{M}_{\mathrm{s}} / \mathrm{s}\right.$ or E/s $]$, and concentration or temperature, $U\left[\mathrm{M}_{\mathrm{s}} / \mathrm{M}\right.$ or $\left.{ }^{\circ} \mathrm{C}\right]$, is linear. By convention, gain of solute or energy by the model is positive and loss of solute or energy by the model is negative.

\subsection{Two-Point Specification of Generalized- Transport Conditions}

A generalized-transport condition requires specification of a linear dependence of the solute or energy gain, $Q^{U}$, on concentration or temperature, $U$. Figure 9 illustrates how two

Figure 8. Three forms of the generalized-transport condition: $A$, general concentration or temperature; $B$, specified source or sink of solute mass or energy; and $C$, specified concentration or temperature.

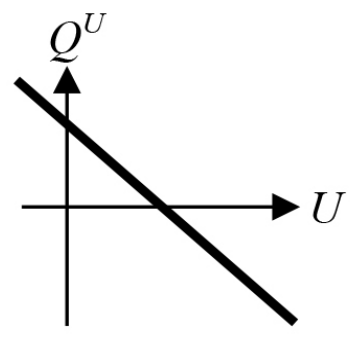

A

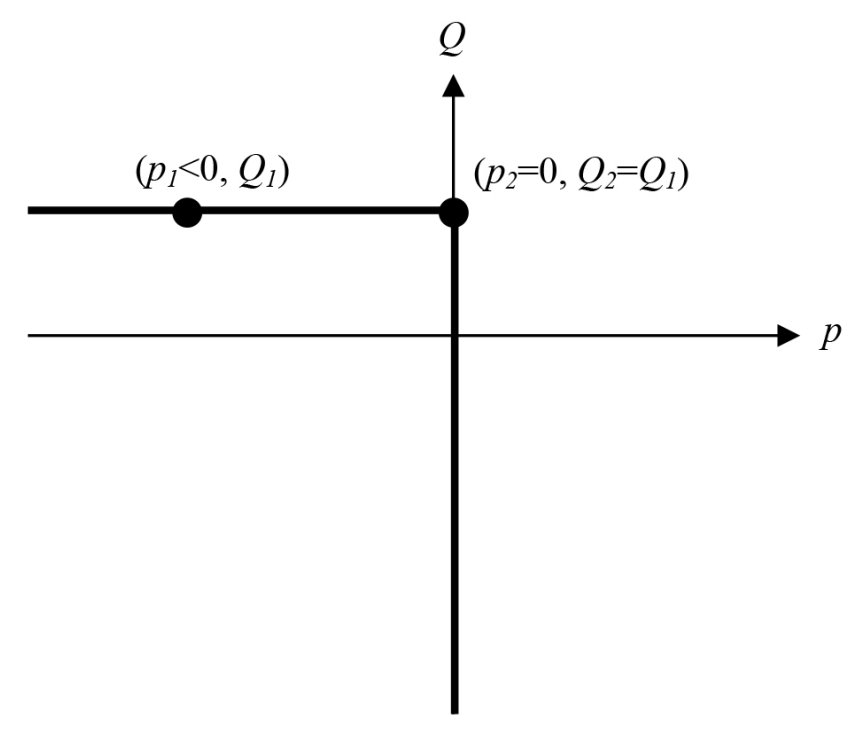

Figure 7. Two-point representation of a seepage-face boundary condition. An upper limit of $p_{2}=0$ is set on $p$, and $Q_{1}$ and $Q_{2}$ are both set to the unsaturated infiltration rate. For the vertical seepage face described by Freeze and Cherry (1979), the unsaturated infiltration rate is zero. Parameter values are summarized in table 1.

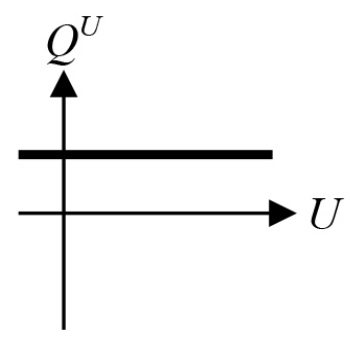

$B$

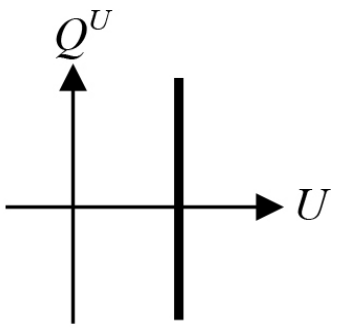

C 
user-specified points, $\left(U_{1}, Q_{1}^{U}\right)$ and $\left(U_{2}, Q_{2}^{U}\right)$, define the line. Unlike generalized-flow conditions, generalized-transport conditions do not allow specification of bounds on $Q^{U}$ or $U$.

For the sake of notational simplicity, the symbols $U_{1}, U_{2}$, $Q_{1}^{U}$ and $Q_{2}^{U}$ are used throughout Chapter 1 to represent the user-specified concentrations or temperatures and rates of gain or loss of solute or energy that define a generalized-transport boundary condition. In input datasets that define generalizedtransport conditions (".inp" dataset 21B and ".bes" dataset 7B), $U_{1}, U_{2}, Q_{1}^{U}$ and $Q_{2}^{U}$ are represented by the more descriptive symbols $U_{B G 1}^{\prime}, U_{B G 2}, Q_{U B G 1}^{U}$, and $Q_{U B G 2}^{U}$, respectively.

\subsection{Commonly Used Forms of the Generalized- Transport Condition}

The generalized-transport condition provides a framework for defining commonly used boundary conditions on solute or energy transport. Guidance on how to formulate a generalized-transport condition for two particular forms is provided below. Input parameter values are summarized in table 2. Although specified-concentration, specifiedtemperature, and concentration- or temperature-independent conditions are most easily handled using other types of SUTRA boundary conditions, instructions for formulating such conditions within the generalized-transport framework are given in the main text.

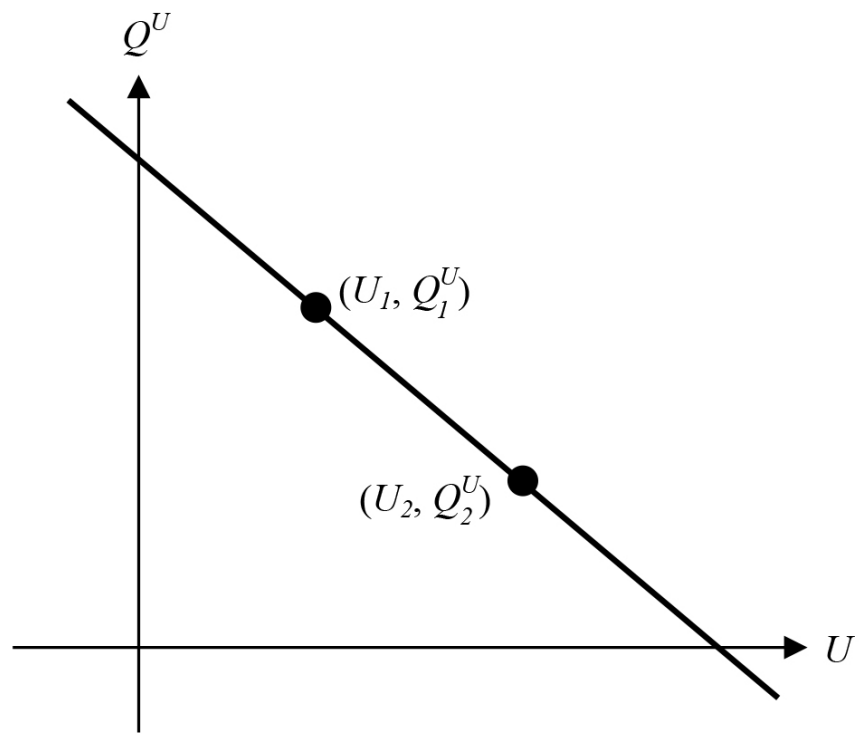

Figure 9. For a generalized-transport condition, the gain of solute mass or energy, $Q^{U}$, is a linear function of concentration or temperature, $U$. By convention, positive values of $Q^{U}$ denote gains and negative values denote losses. Parameter values for heat and solute transport across boundary layers are summarized in table 2.

Table 2. Summary of input parameter values for two commonly used forms of the generalized-transport condition. Each form is discussed in detail and symbols are defined in the main text.

\begin{tabular}{|c|c|c|c|c|c|}
\hline Special cases $^{1}$ & $U_{1}$ & $\mathbf{Q}^{\nu}{ }_{1}$ & $U_{2}$ & $\mathbf{Q}_{2}^{\nu}$ & Notes \\
\hline $\begin{array}{l}\text { Thermal boundary } \\
\text { layer }\end{array}$ & 0 & $h_{T} A T_{e x t}$ & $T_{e x t}$ & 0 & $\begin{array}{l}\text { This formulation can be used if } T_{\text {ext }} \neq 0 \text {. Otherwise, any two points that give the } \\
\text { desired slope can be used to define the linear relation between } Q^{U} \text { and } U \text {. } \\
\text { See equations (16) and (17). }\end{array}$ \\
\hline $\begin{array}{l}\text { Concentration } \\
\text { boundary layer }\end{array}$ & 0 & $h_{M} A \rho C_{e x t}$ & $C_{e x t}$ & 0 & $\begin{array}{l}\text { This formulation can be used if } C_{\text {ext }} \neq 0 \text {. Otherwise, any two points that give the } \\
\text { desired slope can be used to define the linear relation between } Q^{U} \text { and } U \text {. }\end{array}$ \\
\hline
\end{tabular}

See equations (18) and (19).

$\overline{ }{ }^{\top}$ Representation of concentration or temperature-independent sources and sinks and specified concentrations or temperatures using generalized-transport conditions is discussed in the main text. However, the simplest way to implement concentration or temperature-independent sources and sinks is to use ".inp" dataset 18 and ".bcs" dataset 4, and the simplest way to implement specified concentrations or temperatures is to use ".inp" dataset 20 and ".bcs" dataset 6.

\subsubsection{Heat Transfer Across a Thermal Boundary Layer}

If a thermal boundary layer exists adjacent to the model boundary, the rate of heat transfer from an external point to a boundary node (for example, from the atmosphere to land surface) is proportional to the heat-transfer coefficient, the available area of the layer across which the heat transfer occurs, and the temperature difference across the layer:

$$
Q^{U}=h_{T} A\left(T_{e x t}-T\right)
$$

where $Q^{U}$ is the rate of heat transfer $[\mathrm{E} / \mathrm{s}], h_{T}$ is the heat-transfer coefficient $\left[\mathrm{E} /\left(\mathrm{L}^{2 \cdot{ }^{\circ}} \mathrm{C} \cdot \mathrm{s}\right)\right], A$ is the area $\left[\mathrm{L}^{2}\right]$ associated with the generalized-transport boundary condition node, $T_{\text {ext }}$ is the temperature $\left[{ }^{\circ} \mathrm{C}\right]$ at the external point, and $T$ is the temperature $\left[{ }^{\circ} \mathrm{C}\right]$ at 
the node. A straightforward way to implement this type of boundary condition is to specify the two intercepts of the line represented by equation (16) by setting

$$
T_{1}=0, \quad Q_{1}^{U}=h_{T} A T_{\text {ext }}, \quad T_{2}=T_{\text {ext }}, \quad \text { and } \quad Q_{2}^{U}=0
$$

However, any two distinct points that lie on the desired line may be used. The user may specify one point and choose the second point such that the desired slope is obtained.

\subsubsection{Solute Mass Transfer Across a Boundary Layer}

Solute mass transfer across a boundary layer is analogous to the case of a thermal boundary layer described above. The rate of mass transfer from an external point to the generalized-transport boundary condition node is proportional to the masstransfer coefficient, the available area of the layer across which the solute transfer occurs, and the concentration difference across the layer:

$$
Q^{U}=h_{M} A \rho\left(C_{e x t}-C\right)
$$

where $Q^{U}$ is the rate of solute mass transfer $\left[\mathrm{M}_{\mathrm{s}} /\left(\mathrm{L}^{2} \cdot \mathrm{s}\right)\right], h_{M}$ is the mass-transfer coefficient $[\mathrm{L} / \mathrm{s}], A$ is the area $\left[\mathrm{L}^{2}\right]$ associated with the boundary-condition node, $\rho$ is the average fluid density $\left[\mathrm{M} / \mathrm{L}^{3}\right]$ within the boundary layer, and $C_{\text {ext }}$ and $C$ are the mass fractions $\left[\mathrm{M}_{\mathrm{s}} / \mathrm{M}\right]$ of solute at the external point and the boundary-condition node, respectively.

A straightforward way to implement this type of boundary condition is to specify the two intercepts of the line represented by equation (18) by setting

$$
C_{1}=0, \quad Q_{1}^{U}=h_{M} A \rho C_{e x t}, C_{2}=C_{e x t}, \text { and } Q_{2}^{U}=0
$$

However, any two distinct points that lie on the desired line may be used.

Note that although no explicit bounds are set on $C$, concentrations generated by the boundary condition (18) are inherently limited when there are no other sources of solute. Consider, for example, a block of salt dissolving into the groundwater. The maximum solute concentration is $C_{\text {sat }}$, the concentration of saturated brine, and the rate of dissolution is given by equation (18) with $C_{\text {ext }}=C_{\text {sat }}$. Assuming $C$ is initially less than $C_{\text {sat }}$, the rate of dissolution is initially positive; salt dissolves into the groundwater. As $C$ increases, the rate of dissolution decreases, approaching zero as $C$ approaches $C_{\text {sat }}$. Thus, in the absence of other sources of solute, $C$ will never exceed $C_{s a t}$, so the concentration is inherently limited by the form of the boundary condition (equation 18).

\subsubsection{Specified Source or Sink of Solute Mass or Energy}

The simplest way to represent a concentration- or temperature-independent source or sink of solute mass or energy is through ".inp" dataset 18 and, for time-dependent conditions, the corresponding ".bes" dataset 4. However, such a condition can also be formulated as a special case of a general concentration or temperature condition with $Q_{1}^{U}=Q_{2}^{U}$. By convention, gains of solute or energy are positive and losses are negative.

\subsubsection{Specified Concentration or Temperature}

The simplest way to represent a specified-concentration or temperature boundary condition is through ".inp" dataset 20 and, for time-dependent conditions, the corresponding ".bcs" dataset 6 . However, the generalized-transport framework allows an alternative formulation for specified concentration or temperature that is analogous to the formulation of specified pressure depicted in figure $4 A$ : $U_{1}$ is set nearly equal to $U_{2}$ so that the slope is very large. This is essentially how specified-concentration or temperature conditions were formulated in earlier versions of SUTRA. The disadvantage of this method is that the slope must be chosen by trial and error such that SUTRA computes the concentration or temperature and the corresponding solute or energy gain to approximately equal precision. For details, see section 3.5 and the input data listing for ".inp" dataset 5, both in the main SUTRA documentation (Voss and Provost, 2002). 


\subsection{Budget Output and Boundary-Condition Output Files}

Fluid and solute or energy budget information is calculated and reported for generalized-flow and generalized-transport conditions, just as it is for the original four types of SUTRA boundary conditions (Voss and Provost, 2002, section 5.8). Budget information is written to the ".Ist" output file.

In addition, two new files are available for output of information about generalized-flow and generalized-transport conditions: the ".bcopg" and ".bcoug" files, respectively. These files are similar in form to the ".bcof", ".bcos", ".bcop", and ".bcou" files that report information about the original four types of SUTRA boundary conditions.

\subsubsection{The ".bcopg" File for Generalized-Flow Nodes}

The ".bcopg" file contains the following information on generalized-flow nodes:

- Node number.

- Where the condition was defined (“.inp” file, subroutine BCTIME, or “.bcs” file).

- “.bcs” identifier (if defined in a “.bcs” file).

- Resultant fluid source/sink rate (the rate at which fluid enters or leaves the system at that node to satisfy the generalizedflow condition).

- Concentration or temperature of the resultant fluid source/sink.

- Resultant source/sink of solute or energy (the rate at which solute mass or energy enters or leaves the system as a result of fluid inflow/outflow at that node).

- Computed pressure.

- Pressure at the first of two points used to define the relation between flow and pressure.

- Flow at the first of two points used to define the relation between flow and pressure.

- Pressure at the second of two points used to define the relation between flow and pressure.

- Flow at the second of two points used to define the relation between flow and pressure.

- Limit on pressure or flow (if any) set at the first point, and whether the limit is active.

- Limit on pressure or flow (if any) set at the second point, and whether the limit is active.

- Solute concentration or temperature associated with fluid outflow from that node, and whether it is specified directly ("DIR") or relative to the value computed at the node ("REL").

\subsubsection{The ".bcoug" File for Generalized-Transport Nodes}

The ".bcoug" file contains the following information on generalized-transport nodes:

- Node number.

- Where the condition was defined (“.inp” file, subroutine BCTIME, or “.bcs” file).

- “.bcs" identifier (if defined in a ".bcs" file).

- Resultant solute or energy source/sink rate (the rate at which solute or energy enters or leaves the system at that node to satisfy the generalized-transport condition).

- Computed concentration or temperature.

- Concentration or temperature at the first of two points used to define the relation between solute mass gain/loss and concentration or energy gain/loss and temperature, respectively. 
- Solute mass or energy gain/loss at the first of two points used to define the relation between solute mass gain/loss and concentration or energy gain/loss and temperature, respectively.

- Concentration or temperature at the second of two points used to define the relation between solute mass gain/loss and concentration or energy gain/loss and temperature, respectively.

- Solute mass or energy gain/loss at the second of two points used to define the relation between solute mass gain/loss and concentration or energy gain/loss and temperature, respectively.

\subsection{Assumptions and Limitations}

The following is a summary of the assumptions and limitations inherent in SUTRA's generalized boundary conditions:

- Like other types of SUTRA boundary conditions, generalized boundary conditions are applied at model nodes. (See p. 2.)

- For generalized-flow conditions, the dependence of the gain or loss of fluid mass on pressure is linear or piecewise-linear. (See section 1.1.)

- For generalized-transport conditions, the dependence of the gain or loss of solute mass or energy on concentration or temperature is linear. (See section 1.5.)

- The "river," "drain," and "ET" forms of the generalized-flow condition described in sections 1.4.5 and 1.4.6 represent hydrologic processes in a simplified way that depends on the assumption that the pressure profile in the vicinity of the boundary-condition node is approximately hydrostatic, allowing the water-table elevation to be estimated from the pressure computed at the node. The alternative formulation of ET presented in section 1.4.7 does not depend on this assumption. (See section 1.4.1.)

- The "general-pressure" form of the generalized-flow condition is based on the assumption of uniform and isotropic physical properties within the conductive layer. (See appendix 2.)

- The "heat transfer" and "solute mass transfer" forms of the generalized-transport condition are based on the assumption that a boundary layer exists, and that the rate of heat or solute-mass transfer across the boundary layer is proportional to the product of a heat- or mass-transfer coefficient and the concentration or temperature difference across the layer.

\subsection{Example Problem: Seepage Face (Dam with Vertical Sides)}

\subsubsection{Physical Setup}

This problem involves two-dimensional (2D), constant-density groundwater flow through a 10-meter-wide and 10-meterhigh dam with vertical sides under steady-state conditions (fig. 10). The water level is held even with the top of the dam on the upstream side, where hydrostatic conditions prevail, and water does not accumulate on the downstream side, where water exits through a seepage face (fig. 11).

The problem is nonlinear and may be solved by approaching the steady state gradually with a series of time steps. Initially, the dam is fully saturated with water, and at time zero, water begins to seep out from the downstream side of the dam and flow in through the upstream side. As the water-table elevation within the dam decreases, inflows and outflows become nearly equal and steady state is approached. A total simulation time of approximately $82 . \mathrm{hr}$ is selected, which is sufficient time for the problem to essentially reach steady state at the scale simulated. Near-steady-state simulation results are compared with predictions based on Dupuit's formula for discharge through the dam (Muskat, 1937) and Polubarinova-Kochina's (1962) semianalytical solution for the height of the seepage face.

\subsubsection{Objectives}

1. Demonstrate the use of a generalized-flow boundary condition to simulate a seepage face.

2. Compare SUTRA results with analytical and semianalytical solutions. 
Figure 10. Boundary conditions and finite-element mesh for the seepage face example (dam with vertical sides; $m$, meter).

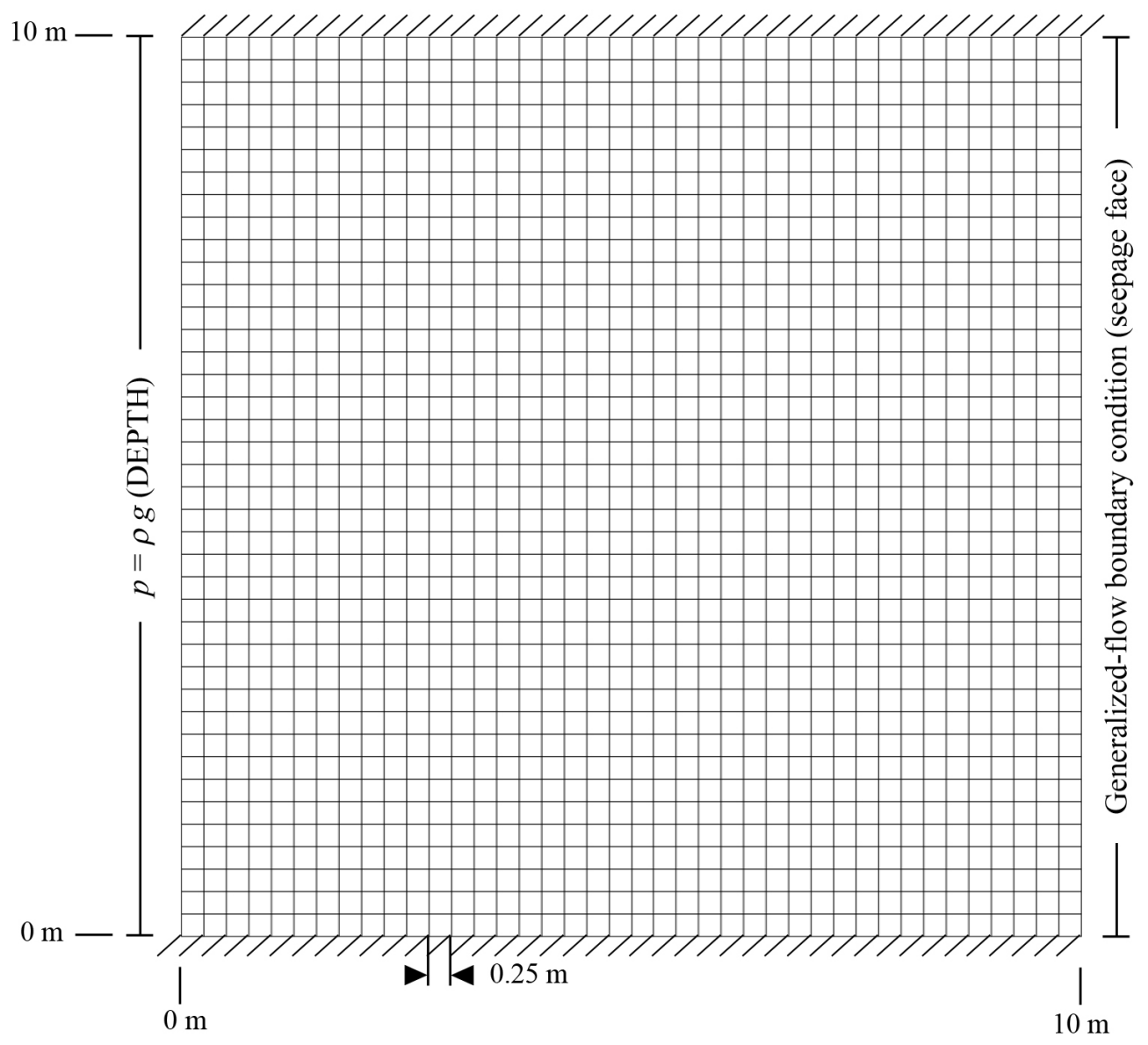

\subsubsection{Simulation Setup}

The mesh (fig. 10) consists of 40 by 40 elements, each of size $0.25 \mathrm{~m}$ by $0.25 \mathrm{~m}$, resulting in a total of 1,681 nodes $(\mathrm{NN}=$ $1,681)$ and 1,600 elements $(\mathrm{NE}=1,600)$. The mesh thickness, $B$, represents $1.0 \mathrm{~m}$ of the dam thickness, which extends infinitely in the direction perpendicular to the mesh. The initial time step is $\Delta t_{\mathrm{o}}=1 \mathrm{~s}$, with time steps increasing by a factor of 1.5 on each subsequent step up to a maximum time step of $\Delta t=3600 \mathrm{~s}(1 \mathrm{hr})$. The simulation consists of 100 time steps. The total simulation time is approximately $2.9 \times 10^{5} \mathrm{~s}(82 . \mathrm{hr})$. Nonlinearity iterations are used to improve convergence to steady state. Convergence of nonlinearity iterations is controlled by the tolerance for pressure, RPMAX, which is set to $100 . \mathrm{kg} /\left(\mathrm{m} \cdot \mathrm{s}^{2}\right.$ ) (equivalent to approximately $0.01 \mathrm{~m}$ of freshwater head). As few as one and as many as eight nonlinearity iterations are used on each time step, with later time steps generally requiring fewer iterations.

The left vertical boundary, which is held at hydrostatic pressure, acts as a source of fluid. The right vertical boundary, along which a seepage face forms, acts as a sink of fluid. No flow occurs across the top and bottom boundaries. Formulation of the boundary conditions is described in the section 1.10.5, "Boundary conditions."

\subsubsection{Parameters}

$$
\alpha=1.0 \times 10^{-8} \mathrm{~m} \cdot \mathrm{s}^{2} / \mathrm{kg}
$$

$$
\beta=4.47 \times 10^{-10} \mathrm{~m} \cdot \mathrm{s}^{2} / \mathrm{kg}
$$

(The $\alpha$ and $\beta$ values imply that $S_{o p}=9.0447 \times 10^{-9} \mathrm{~m} \cdot \mathrm{s}^{2} / \mathrm{kg}$.)

$$
\begin{aligned}
& k=1.0 \times 10^{-12} \mathrm{~m}^{2} \\
& \varepsilon=0.1 \\
& \rho=1000 . \mathrm{kg} / \mathrm{m}^{3} \\
& \mu=1.0 \times 10^{-3} \mathrm{~kg} /(\mathrm{m} \cdot \mathrm{s}) \\
& g=9.81 \mathrm{~m} / \mathrm{s}^{2}
\end{aligned}
$$




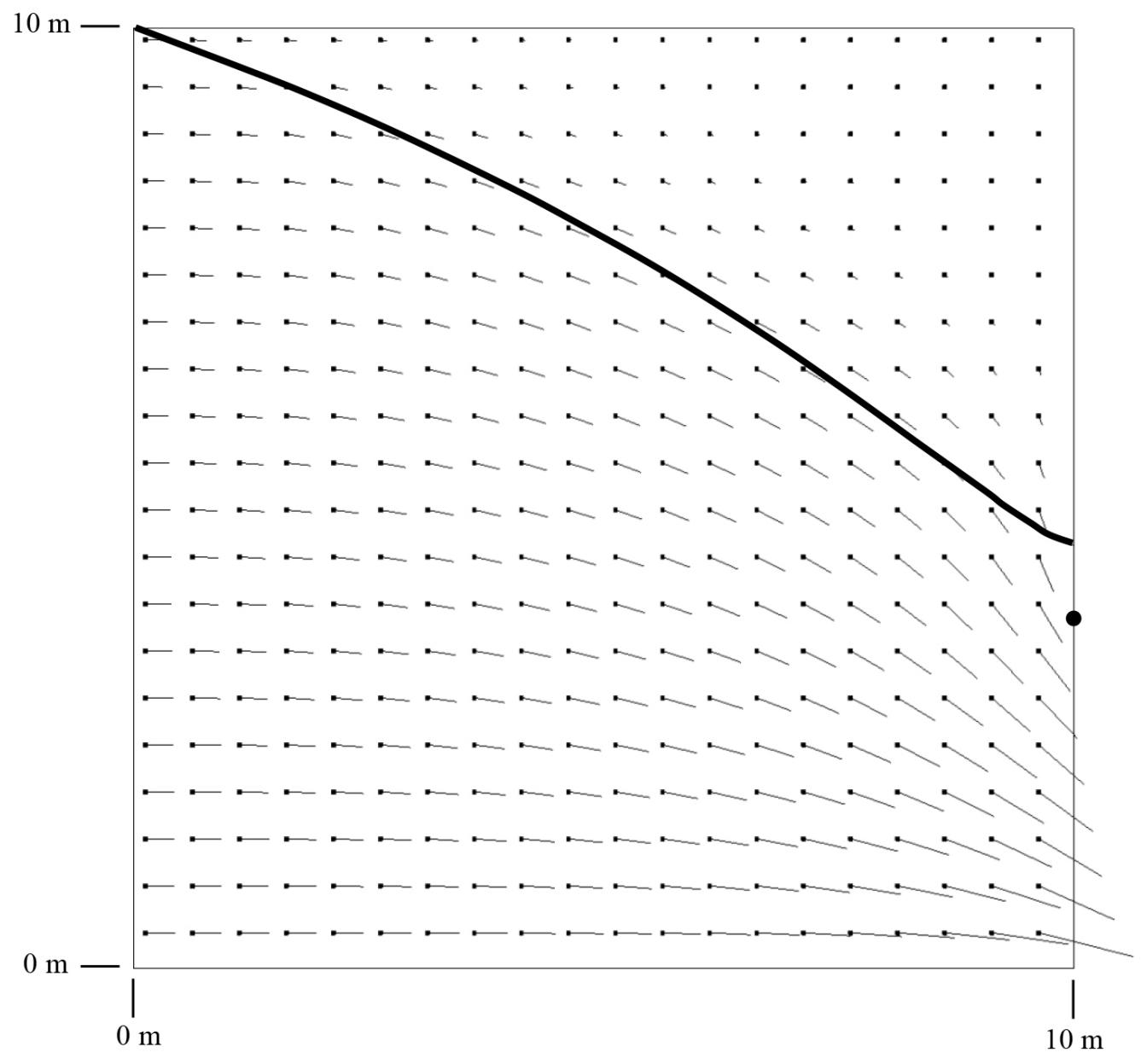

Figure 11. Near-steadystate SUTRA results for the seepage face example (dam with vertical sides). The thick line indicates the numerically simulated position of the water table $(p=0)$. The intersection of the thick line with the right vertical boundary indicates the numerically simulated top of the seepage face. The black circle indicates the top of the seepage face predicted by the semianalytical solution of Polubarinova-Kochina (1962). Dots indicate element centers from which flow-velocity vectors (thin line segments) emanate. Vector length is proportional to velocity magnitude. Vectors are plotted for every second element in each coordinate direction. $(\mathrm{m}$, meter)

$$
\begin{aligned}
& S_{w}=\left\{\begin{array}{l}
1 \text { for } p \geq 0 \\
0.3+0.7\left[1+\left(5 \times 10^{-5} p\right)^{2}\right]^{-0.5} \text { for } p<0
\end{array}\right. \\
& k_{r}=\left(\frac{S_{w}-0.3}{0.7}\right)^{0.5}\left(1-\left\{1-\left(\frac{S_{w}-0.3}{0.7}\right)^{2}\right\}^{0.5}\right)^{2} \quad \begin{array}{l}
\text { Unsaturated properties functions } \\
\text { of Van Genuchten }(1980) \\
\text { with } S_{\text {wres }}=0.3, a=5 \times 10^{-5} \mathrm{~m} \cdot \mathrm{s}^{2} / \mathrm{kg}, \\
\text { and } n=2 . \text { See eqns. }(2.8) \text { and }(2.21) \text { of } \\
\text { Voss and Provost }(2002) .
\end{array}
\end{aligned}
$$

Here, $\alpha$ and $\beta$ are compressibilities of the porous matrix and the fluid, respectively, $S_{o p}$ is specific pressure storativity, $k$ is permeability, $\varepsilon$ is porosity, $\rho$ is fluid density, $\mu$ is fluid viscosity, $g$ is the acceleration of gravity, $S_{w}$ is water saturation, $S_{\text {wres }}$ is residual water saturation, $a$ and $n$ are Van Genuchten model parameters, and $k_{r}$ is relative permeability. These physical properties are defined and discussed in more detail in Voss and Provost (2002).

\subsubsection{Boundary Conditions}

No flow occurs across the top and bottom boundaries. Hydrostatic pressure is specified at all nodes along the left vertical boundary. At the node in the upper-left corner, pressure is held at zero.

All nodes along the right vertical boundary are generalized-flow boundary-condition nodes set up such that a seepage face can form to allow water to exit, and no flow crosses the vertical boundary above the seepage face. This condition is set up as described in the section 1.4.8, "Seepage Face," and figure 7. The two points in the two-point specification are $\left(p_{l}, Q_{1}\right)=(-1 ., 0$.) and $\left(p_{2}, Q_{2}\right)=\left(0 ., 0\right.$.), and an upper bound of zero is set on pressure by setting a limit at $p_{2}$. Thus, the seepage face is a zeropressure boundary, and above the seepage face is a no-flux boundary. 


\subsubsection{Initial Conditions}

Initially, hydrostatic pressure is set at each node. At all nodes along the top boundary, initial pressures are set at zero, so the simulation begins fully saturated.

\subsubsection{Results}

Figure 11 shows the simulated, near-steady-state water table and flow field after approximately 82 . hr of simulated time. Along the right vertical boundary, no flow crosses the boundary above the water table, and below the water table water discharges through the seepage face. The slight decrease in the slope of the water table as it nears the right vertical boundary is due to the fact that at that boundary the simulated water table must coincide exactly with a node at which $p=0$ is specified; the water table cannot fall between two nodes at that boundary. The intersection of the water table with the right vertical boundary marks the top of the seepage face. The semianalytical solution of Polubarinova-Kochina (1962), which does not account for flow through the unsaturated zone, predicts a slightly lower seepage face height (fig. 11, black circle). The semianalytical seepage face height (approximately $3.7 \mathrm{~m}$ ) was determined from figure 2 of Polubarinova-Kochina (1962) for parameter values $l=10 \mathrm{~m}$, $H=10 \mathrm{~m}$, and $h=0 \mathrm{~m}$, where $l, H$, and $h$ are the dam width, the height of the water on the upstream side, and the height of the water on the downstream side, respectively.

The Dupuit formula for discharge, $Q_{d a m}\left[\mathrm{~m}^{3} / \mathrm{s}\right.$ per meter of thickness], through a dam with vertical sides (Muskat, 1937),

$$
Q_{d a m}=\frac{k \rho^{2} g}{2 l \mu}\left(H^{2}-h^{2}\right)
$$

is based on the Dupuit-Forcheimer assumptions of horizontal flow and a hydraulic gradient equal to the slope of the water table. Nevertheless, equation (20) is an exact expression for discharge through the dam (see, for example, Polubarinova-Kochina, 1962) if it is assumed that no flow occurs through the unsaturated zone. For this example, the discharge predicted by equation (20) is $4.905 \times 10^{-5} \mathrm{~m}^{3} / \mathrm{s}$ per meter of dam thickness. This is 6 percent less than the discharge simulated by SUTRA, which is $5.228 \times 10^{-5} \mathrm{~m}^{3} / \mathrm{s}\left(5.228 \times 10^{-2} \mathrm{~kg} / \mathrm{s}\right)$ per meter of dam thickness and includes flow through the unsaturated zone. 


\section{Chapter 2. Modified Implementation of Specified Pressures and Concentrations or Temperatures}

In versions of SUTRA prior to Version 3.0, the implementation of specified-pressure and specified-concentration or temperature boundary conditions required the user to provide values for the factors GNUP and GNUU in dataset 5 of the ".inp" input file. Beginning with SUTRA Version 3.0, these types of boundary conditions are implemented without the use of GNUP or GNUU, and the latter have been removed from dataset 5. Modified input instructions are provided in appendix 3.

The SUTRA iterative and direct solvers handle storage of the coefficient matrix differently. Therefore, different numerical schemes for specified pressures are used with the two types of solvers, as described below. SUTRA automatically chooses the appropriate numerical scheme, depending on the types of solvers used.

\subsection{Specified-Pressure Conditions: Scheme Used with Iterative Solvers}

Specifying pressure $p_{i}^{B C}$ at boundary node $i$ results in an associated gain of fluid mass, $Q_{i}^{P B C}$, at that node. Addition of $Q_{i}^{P B C}$ as a source/sink term to the right-hand side of the discretized flow equation for node $i$ gives

$$
a_{i i} p_{i}+\sum_{j \neq i} a_{i j} p_{j}=b_{i}+Q_{i}^{P B C}
$$

where $a_{i i}$ is the diagonal element of the coefficient matrix in the absence of the specified-pressure condition, $a_{i j}$ are the offdiagonal elements, $b_{i}$ is the right-hand side in the absence of the specified-pressure condition, $p_{i}$ is the computed pressure at node $i, p_{j}$ is the computed pressure at neighboring node $j$, and the summation is over the neighbors of node $i$, not including itself. Equation (21) above is equivalent to (3.39) in the main SUTRA documentation (Voss and Provost, 2002), except that the latter is expressed in terms of head to simplify the presentation.

In previous versions of SUTRA, $Q_{i}^{P B C}$ was expressed as

$$
Q_{i}^{P B C}=v_{p}\left(p_{i}^{B C}-p_{i}\right)
$$

which, when substituted into equation (21), yielded the discretized flow equation

$$
\left(a_{i i}+v_{p}\right) p_{i}+\sum_{j \neq i} a_{i j} p_{j}=b_{i}+v_{p} p_{i}^{B C}
$$

at node $i$. The symbol $v_{p}$ represents the factor GNUP, which was set large enough so that equation (23) effectively reduced to $p_{i} \approx p_{i}^{B C}$; the user chose GNUP such that the computed value of $p_{i}$ matched $p_{i}^{B C}$ to about the first half of the available doubleprecision digits (making the simulated pressure match the specified pressure for the first six or seven digits). The other half of the available precision was used by SUTRA to compute $Q_{i}^{P B C}$ using equation (22) after the discretized flow equation was solved.

In the new scheme used with iterative solvers in SUTRA 3.0, $Q_{i}^{P B C}$ is calculated from a rearrangement of equation (21) with $p_{i}=p_{i}^{B C}$ :

$$
Q_{i}^{P B C}=a_{i i} p_{i}^{B C}+\sum_{j \neq i} a_{i j} p_{j}-b_{i}
$$

As before, $Q_{i}^{P B C}$ is calculated in a postprocessing step after the discretized flow equation has been solved for pressure.

Three alternatives for incorporating specified-pressure conditions into the discretized flow equation are:

a. A specified pressure at node $i$ could be enforced by simply replacing equation (21) with the equation $p_{i}=p_{i}^{B C}$. This straightforward approach would, however, introduce asymmetry into the matrix and overwrite the original values of $a_{i i}, a_{i j}$, and $b_{i}$, which are needed to evaluate $Q_{i}^{P B C}$ using equation (24). Therefore, this approach would be incompatible with the CG solver, which requires a symmetric matrix, and additional storage would be required to save the original values of $a_{i i}$, $a_{i j}$, and $b_{i}$.

b. To instead preserve matrix symmetry if it exists, and to minimize the additional storage required, one could use an extremely large value of GNUP in equation (23). This approach, however, is likely to result in loss of precision when 
recovering the original values of $a_{i i}$ and $b_{i}$ from $a_{i i}+v_{p}$ and $b_{i}+v_{p} p_{i}^{B C}$, respectively, because it would typically involve adding and subtracting numbers of vastly different magnitudes.

c. The approach used with iterative solvers in SUTRA 3.0 is to enforce specified-pressure conditions by multiplying the diagonal term in equation (21) by an extremely large number, $\eta_{p}$, (set by SUTRA, with no user input required) and replacing the right-hand side with $\eta_{p} a_{i i} p_{i}^{B C}$ to give.

$$
\eta_{p} a_{i i} p_{i}+\sum_{j \neq i} a_{i j} p_{j}=\eta_{p} a_{i i} p_{i}^{B C}
$$

For extremely large $\eta_{p}$, the summation term is negligible, and equation (25) is effectively equivalent to $p_{i}=p_{i}^{B C}$. The original values of $a_{i j}$ are retained in the matrix, and the value of $a_{i i}$ can be recovered with negligible loss of precision by dividing $\eta_{p} a_{i i}$ by $\eta_{p}$. Thus, only $b_{i}$ in equation (21) need be saved in additional storage.

The scheme described above is incompatible with the direct solver, which overwrites the coefficient matrix during the solution process. Therefore, SUTRA uses this scheme only with the iterative matrix solvers. Because this scheme does not introduce asymmetry into the matrix, it is compatible with the CG solver, which requires a symmetric matrix.

\subsection{Specified-Pressure Conditions: Scheme Used with the Direct Solver}

Equation (21) is the discretized flow equation for node $i$ (the node of interest at which a specified-pressure condition is being enforced), and there exists an analogous equation (with or without a specified-pressure source term, as appropriate) for every node in the model. For node $i$ and nodes that are neighbors of node $i$, the discretized flow equations include the simulated pressure at node $i, p_{i}$.

The scheme for specified-pressure nodes that is used with the SUTRA direct solver involves substituting the specified pressure at node $i, p_{i}^{B C}$, directly for the simulated pressure at node $i, p_{i}$, wherever the latter appears in the discretized flow equation for every node except node $i$. At node $i$, equation (21) is formulated under the temporary assumption that $Q_{i}^{P B C}=0$. Upon solving the system of discretized flow equations just described, the resulting pressure at node $i$ is denoted by $p_{i}^{(0)}$, and equation (21) can be written as

$$
a_{i i} p_{i}^{(0)}+\sum_{j \neq i} a_{i j} p_{j}=b_{i}
$$

Combining equation (26) with equation (24) then gives

$$
Q_{i}^{P B C}=a_{i i}\left(p_{i}^{B C}-p_{i}^{(0)}\right)
$$

which is used in a postprocessing step to compute $Q_{i}^{P B C}$. Because the direct solver overwrites $a_{i j}$, the value of $a_{i i}$ is saved in additional storage for use in equation (27). After the matrix problem is solved and $Q_{i}^{P B C}$ is evaluated, the value of $p_{i}^{(0)}$ is no longer needed and is replaced in the $p$-solution vector by $p_{i}^{B C}$, the desired value of $p_{i}$.

SUTRA uses this scheme only with the direct solver. Because this scheme introduces asymmetry into the matrix, it is incompatible with the CG solver, although it could, in principle, be used with the GMRES and ORTHOMIN solvers.

\subsection{Specified-Concentration or Temperature Conditions}

The scheme for handling specified-concentration or temperature conditions is entirely analogous to the direct-solver scheme for handling specified-pressure conditions described just above. For transport, this scheme is used with all of SUTRA's matrix solvers, including the direct solver, except CG (which cannot be used for transport in any case).

The specified concentration or temperature at boundary node $i, U_{i}^{B C}$, is substituted directly for $U_{i}$, wherever the latter appears in the matrix equations, except in the equation for node $i$. At node $i$, the concentration or temperature is solved for under the temporary assumption that $Q_{i}^{U B C}=0$, where $Q_{i}^{U B C}$ is the gain of solute mass or energy at node $i$ resulting from the specifiedconcentration or temperature condition. If the resulting concentration or temperature at node $i$ is denoted by $U_{i}^{(0)}$, the corresponding equation is 


$$
\tilde{a}_{i i} U_{i}^{(0)}+\sum_{j \neq i} \tilde{a}_{i j} U_{j}=\tilde{b}_{i}
$$

where " $\sim$ " indicates that the matrix and right-hand side terms are for the transport equation. Combining equation (28) with the analog of equation (24),

$$
Q_{i}^{U B C}=\tilde{a}_{i i} U_{i}^{B C}+\sum_{j \neq i} \tilde{a}_{i j} U_{j}-\tilde{b}_{i}
$$

then gives

$$
Q_{i}^{U B C}=\tilde{a}_{i i}\left(U_{i}^{B C}-U_{i}^{(0)}\right)
$$

which is used in a postprocessing step to compute $Q_{i}^{U B C}$. The value of $\tilde{a}_{i i}$ is saved for use in equation (30) when the direct solver is used. After the matrix problem is solved and $Q_{i}^{U B C}$ is evaluated, the value of $U_{i}^{(0)}$ is no longer needed and is replaced in the $U$-solution vector by $U_{i}^{B C}$, the desired value of $U_{i}$. 


\section{Chapter 3. Lake Capability}

The lake capability introduced in SUTRA Version 3.0 simulates the evolution of lakes on the surface of a three-dimensional (3D) model as the lakes exchange fluid mass and solute mass or thermal energy with groundwater, with each other, and with external sources or sinks. Lakes influence the groundwater simulation by interacting with user-specified flow and transport boundary conditions on the top surface of the model. Lakes can increase boundary-condition pressures, intercept or supply recharge, and receive groundwater discharge and runoff. As lakes expand and contract during the simulation, the presence or absence of lake water can control whether a given boundary condition is applied or not applied, giving the user considerable control over how fluid and solute or energy enters or exits the model in the presence or absence of lakes. Exchanges of water between lakes, with groundwater, and with external sources and sinks can represent a variety of physical processes that include spillover from an adjacent lake, groundwater base flow, direct precipitation into lakes, evaporation of lake water, and surfacewater runoff into lakes.

Given the topography of the top surface of the model, or, optionally, user-specified lake-bottom elevations, SUTRA identifies the lakes that can form by "ponding" of water on the top surface. Increases and decreases in lake stage can cause lakes to coalesce and divide, leading to a hierarchy of possible "parent" and "child" lakes that is automatically determined by SUTRA at the start of the simulation. On each time step of a transient simulation, SUTRA solves the groundwater flow and transport equations and updates lake stages and lake-water concentrations or temperatures. The calculations, which are described in more detail below, conserve water mass and solute mass or thermal energy within each lake, the groundwater system, and the SUTRA model as a whole.

\subsection{Preparatory Calculations}

At the start of a simulation that involves lakes, SUTRA performs a number of preparatory calculations that pertain to lakes. These calculations include identification of potential lakes and determination of stage and area as functions of water volume for each lake.

\subsubsection{Identification of Potential Lakes}

The surface topography on which lake water can "pond" is determined by the elevations of the nodes on the top surface of the SUTRA model, or, optionally, by user-specified lake-bottom elevations. The lake capability can be used with 3D SUTRA meshes that are REGULAR, BLOCKWISE, or LAYERED. Each of these three types of mesh consists of layers of nodes (Voss and Provost, 2002). LAYERED meshes need not be logically rectangular but must have the same (regular or irregular) twodimensional structure within each layer. SUTRA infers the location of the top layer from the node numbering, which is assumed to conform to the convention used in SutraGUI (Winston and Voss, 2004). The lake capability cannot presently be used with 3D IRREGULAR meshes, nor with 2D meshes of any type.

To illustrate how SUTRA determines the set of potential lakes, consider the example shown in figure 12. To simplify the explanation, the topography in this example varies along only one grid direction, effectively reducing the problem to two dimensions, and the node numbering includes only surface nodes.

SUTRA identifies potential lakes by starting with the surface node that has the highest elevation and working down through surface nodes in order of decreasing elevation, finding the topographic ridges, or "sills," that separate lakes. When the lake stage drops below a sill, a lake splits into two lakes.

In this example, the search begins with the water stage set at 1.0 (the highest elevation, which is found at nodes 1 and 31 ). For this lake stage, all the lake water is coalesced in one lake, which is designated as lake 1 . When the stage drops below an elevation of 0.9 (node 6), lake 1 divides into two lakes: lake 2 on the right (nodes 7-30) and lake 3 on the left (nodes 2-5).

The next division occurs when the stage drops below 0.8 (node 26). Then lake 2 divides into lake 4 (nodes 8-25) and lake 5 (nodes 27-30). Similar divisions occur as the stage decreases through elevations of 0.7 (node 12) and 0.6 (node 20).

The nine potential lakes identified in figure 12 form a hierarchy of "parents" and "children" that is represented by an inverted tree in figure 13. As the stage decreases, parent lakes split into children. Children of the same parent lake are called "siblings." As the stage increases, sibling lakes coalesce into their parents. SUTRA assumes that the hierarchy of lakes is represented by a binary tree; each parent has exactly two children. Implications of this assumption are discussed in section 3.4.2, "Lake Hierarchy as a Binary Tree." The algorithm used to identify potential lakes is discussed in more detail in section 3.4.1, "Identifying Potential Lakes Using the Hoshen-Kopelman Algorithm." The "basin" of a lake is defined as the collection of all surface nodes that belong to that lake or any of its descendants in the binary tree.

Water balances are maintained on "active" lakes. A lake is considered active if it is not coalesced with its sibling or split into its children. If a lake is coalesced with its sibling, the lake and its sibling are both full, and a single water balance is 
maintained on the resulting parent lake. Thus, the original lake and its sibling become inactive, and the parent lake becomes active. If a lake is split into its two children, a separate water balance is maintained on each child lake. Thus, the parent lake becomes inactive and the child lakes become active.

\subsubsection{Lake Stage and Area as Functions of Water Volume}

Each surface node is overlain by a "lake cell" that can hold lake water. The volume of water in a lake is the sum of the volumes of water in all the lake cells within that lake. For the purpose of volume calculations, the lake-bottom elevation is assumed to be uniform within each lake cell, as shown in figure 14 .

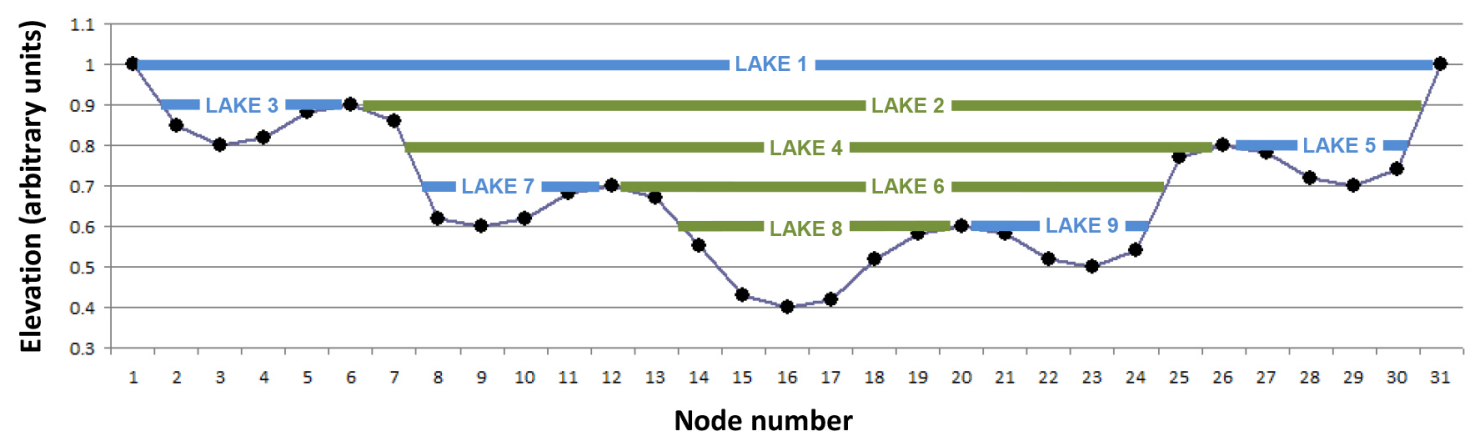

Figure 12. Nine potential lakes identified based on a given surface topography. Although the lake capability is designed to work only with three-dimensional SUTRA models, this schematic representation is presented in two dimensions to clearly illustrate how lakes are identified. The node numbering includes only surface nodes (black dots). Blue and green horizontal lines show the stages at which the various lakes come into existence by splitting of larger lakes as the stage decreases. Two different colors are used to help distinguish adjacent ("sibling") lakes.

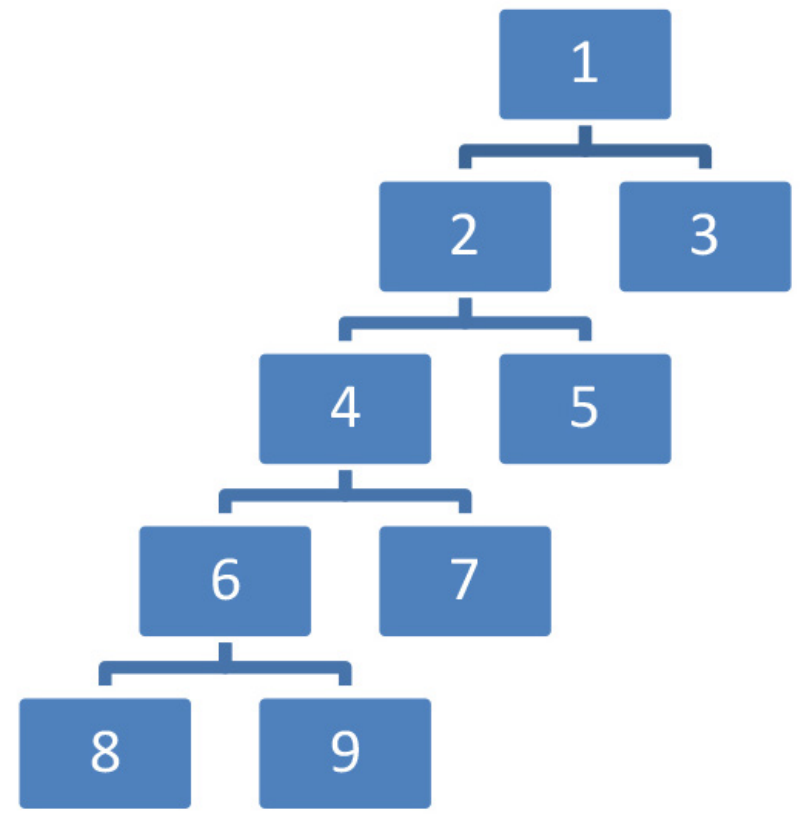

Figure 13. Hierarchy of nine lakes identified based on the topography in figure 12. Moving down the tree as stage decreases, lake 1 divides into lakes 2 and 3, lake 2 divides into lakes 4 and 5 , and so forth. Moving up the tree as stage increases, lakes 8 and 9 coalesce into lake 6 , lakes 6 and 7 coalesce into lake 4 , and so forth. Lake 6 is the "parent" of lakes 8 and 9; lakes 8 and 9 are "siblings," as they are both "children" of lake 6 .

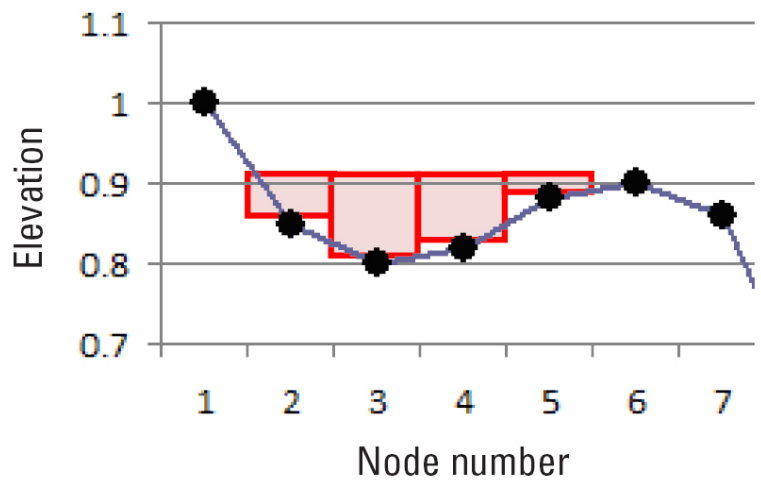

Figure 14. Lake cells (outlined in red and filled with pink) associated with the nodes (black dots) in lake 3 identified in figure 12. For the purpose of volume calculations, the lake-bottom elevation is assumed to be uniform within each lake cell. Straightline segments connecting nodes are included only to guide the eye in viewing the surface topography and are not used in volume calculations. 
The rate at which the lake stage increases as the volume of water in the lake increases is inversely proportional to the surface area of the lake. For the purpose of lake-stage calculations, the surface area of the lake is the sum of the areas associated with all the submerged lake cells in the lake. Whenever an additional lake cell is submerged, the lake area increases by the area of that lake cell. Thus, lake stage is a continuous, piecewise-linear function of volume, with a decrease in slope occurring each time an additional lake cell is submerged. Each lake has its own stage-volume function, which is computed automatically by SUTRA.

\subsection{Solution Procedure for Groundwater and Lakes}

When the lake capability is used in a transient-flow, transient-transport SUTRA simulation, the following sequence of calculations is performed on each time step or nonlinearity iteration:

- Solve the groundwater-flow equation (Voss and Provost, 2002, equations (2.24) and (4.112)), taking into account all sources and sinks of groundwater, including exchanges of water with lakes via groundwater-flow boundary conditions. Lake stages are from the previous time step or nonlinearity iteration.

- Solve the groundwater-transport equation (Voss and Provost, 2002, equations (2.52) and (4.145)), taking into account all sources and sinks of solute mass or thermal energy, including exchanges of solute mass or energy with lakes via groundwater-flow and transport boundary conditions. Lake concentrations or temperatures are from the previous time step or nonlinearity iteration.

- Solve the set of water-mass and solute or energy balance equations for the lakes (described in section 3.2.1, "Water Balances on Lakes," and section 3.2.2, "Solute Mass or Energy Balances on Lakes"), taking into account all sources and sinks of lake water and solute or energy, including exchanges with the groundwater-flow system. To conserve water mass and solute mass or energy in the simulation, exchanges are consistent with those used in solving the groundwater-flow and groundwater-transport equations. The result of solving the balance equations is an update of lake volumes, stages, and concentrations or temperatures.

When the lake capability is used in a steady-flow, steady-transport simulation, SUTRA uses the lake stages and concentrations or temperatures specified by the user or saved in the restart information from a previous simulation to formulate boundary conditions for the groundwater flow and transport equations. Lakes are not updated. This simulation mode is useful for computing initial conditions for transient simulations. The lake capability is not programmed for use in the steady-flow, transienttransport simulation mode in this version of SUTRA.

\subsubsection{Water Balances on Lakes}

After the groundwater flow and transport equations have been solved, exchanges of fluid between lakes and groundwater are computed at all boundary-condition nodes that interact with lakes. Exchanges of fluid with groundwater, other lakes, and external sources and sinks are then summed for each active lake (that is, each lake that is not coalesced with its sibling or split into its children). Rates of fluid exchange with groundwater, other lakes, and external sources and sinks are assumed to remain constant throughout each time step. The net inflows or outflows to or from lakes over a time step can cause splitting or coalescence of lakes.

\subsubsection{Spillover, Coalescence, and Splitting of Lakes}

If a lake receives a net inflow of water, its stage increases. If the lake fills completely, that is, if its stage rises to the elevation of the topographic sill that separates the lake from its sibling lake, any further net inflow spills over into the sibling lake (or an active descendant thereof, as described in section 3.4.3, "Determining the Fate of Spillover Using Steepest Descent"). Spillover occurs by a surface-water process that is not explicitly modeled and is assumed to occur instantaneously; excess water is simply reallocated from the lake to its sibling. If both the lake and its sibling fill completely, they coalesce into their parent lake.

If a lake experiences a net outflow of water, its stage decreases. If the stage of a lake decreases to the elevation of the topographic sill that separates its child lakes, any further net outflow causes the lake to split into its children. If the stage decreases below the elevation of the lowest surface node in the lake, the lake dries out completely. Complete drying and subsequent rewetting are described in section 3.4.4, "Drying and Rewetting." 


\subsubsection{Equations Governing the Mass of Water in a Lake}

During a given time step, the mass of water in each active lake varies linearly with time:

$$
M_{l}=M_{l}^{0}+F_{l}^{\text {net }}\left(t-t_{0}\right)
$$

where

$$
\begin{aligned}
& M_{l}=\text { mass of water in lake } l \text { at time } t[\mathrm{M}], \\
& M_{l}^{0}=\text { mass of water in lake } l \text { at time } t_{0}[\mathrm{M}], \\
& t=\text { current time [s], } \\
& t_{0}=\text { time at which the last breakpoint occurred [s], and } \\
& F_{l}^{\text {net }}=\text { net rate of inflow of water to or outflow of water from lake } l[\mathrm{M} / \mathrm{s}] \text {. }
\end{aligned}
$$

The net rate of inflow or outflow of water, $F_{l}^{\text {net }}$, is the sum of the sources and sinks associated with spillover to or from other lakes, groundwater-flow boundary conditions (which can act as external sources and sinks when intercepted by a lake), and removal of lake water due to lake-area limitations (see section 3.3.1, "Limiting Where Lakes Can Form"):

$$
F_{l}^{n e t}=\sum_{k=1}^{N A L} F_{k, l}^{s p i l l}-F_{l, l^{\prime}}^{s p i l l}+F_{l}^{b c, \text { in }}+F_{l}^{b c, \text { out }}+F_{l}^{\text {lim }}
$$

where

$$
\begin{aligned}
& N A L=\text { number of active lakes, } \\
& F_{k, l}^{\text {spill }}=\text { rate of spillover from lake } k \text { to lake } l[\mathrm{M} / \mathrm{s}], \\
& F_{l, l^{\prime}}^{\text {spill }}=\text { rate of spillover from lake } l \text { to its sibling, lake } l \text {, }[\mathrm{M} / \mathrm{s}], \\
& F_{l}^{b c, \text { in }}=\text { rate of inflow to lake } l \text { from groundwater-flow boundary conditions }[\mathrm{M} / \mathrm{s}], \\
& F_{l}^{b c, \text { out }}=\text { rate of outflow from lake } l \text { to groundwater-flow boundary conditions }[\mathrm{M} / \mathrm{s}] \text {, and } \\
& F_{l}^{l i m}=\text { rate of outflow from lake } l \text { due to lake-area limitations }[\mathrm{M} / \mathrm{s}] .
\end{aligned}
$$

Rates of inflow to lake $l$ are positive and rates of outflow from lake $l$ are negative by definition in equation (32), except rates of spillover. Spillover represents outflow from one lake and inflow into another. Therefore, rates of spillover are defined as positive, and $F_{l, l^{\prime}}^{\text {spill }}$ is included in equation (32) with a negative sign to indicate an outflow from lake $l$. Note that a lake can receive spillover from its own sibling or from siblings of inactive lakes further up the hierarchy (as described in section 3.4.3, "Determining the Fate of Spillover Using Steepest Descent").

\subsubsection{Calculation of Water Volume from Water Mass in a Lake}

The volume of water in each lake, which in turn determines the stage, is computed from the mass of water under the approximation that lake water has the density of water at the base concentration or temperature, RHOW0 (specified in dataset 9 of the ".inp" input file). This greatly simplifies the lake calculations by making water volume a linear function of water mass and decoupling the water balances from the solute-mass or thermal-energy balances. In systems in which lake-water density departs significantly from RHOW0, the error introduced in the volumetric calculations may not be negligible. However, this approximation does not compromise the conservation of mass in each lake, the groundwater-flow system, or the model as a whole.

\subsubsection{Solute Mass or Energy Balances on Lakes}

Lakes are treated as well-mixed tanks; water entering a lake from various sources instantaneously mixes with the water already in the lake. The equation that governs the evolution of concentration or temperature in lake $l$ under these conditions is

$$
M_{l} u_{l}=M_{l}^{0} u_{l}^{0}+G_{l}^{n e t}\left(t-t_{0}\right)
$$

and 


$$
G_{l}^{\text {net }}=\sum_{k=1}^{N A L} F_{k, l}^{\text {spill }} u_{k}-F_{l, l^{\prime}}^{\text {spill }} u_{l}+F_{l}^{\text {lim }} u_{l}+F_{l}^{b c, \text { in }} u_{l}^{b c, \text { in }}+F_{l}^{b c, \text { out }} u_{l}+G_{l}^{b c, \text { in }}+G_{l}^{b c, \text { out }}
$$

where

$$
\begin{aligned}
& u_{l}=\text { concentration or thermal energy content in lake } l\left[\mathrm{M}_{\mathrm{s}} / \mathrm{M} \text { or E/M }\right], \\
& u_{k}=\text { concentration or thermal energy content in lake } k\left[\mathrm{M}_{\mathrm{s}} / \mathrm{M} \text { or E/M }\right], \\
& u_{l}^{b c, \text { in }}=\text { concentration or thermal energy content of inflows to lake } l \text { from groundwater-flow boundary conditions }\left[\mathrm{M}_{\mathrm{s}} / \mathrm{M}\right. \\
& \text { or E/M }], \\
& G_{l}^{b c, \text { in }}=\text { rate of inflow of solute mass or energy to lake } l \text { from groundwater-transport boundary conditions }\left[\mathrm{M}_{\mathrm{s}} / \mathrm{s}\right. \text { or E/s], } \\
& \text { and } \\
& G_{l}^{b c, \text { out }}=\text { rate of outflow of solute mass or energy from lake } l \text { to groundwater-transport boundary conditions }\left[\mathrm{M}_{\mathrm{s}} / \mathrm{s}\right. \text { or } \\
& \text { E/s }] .
\end{aligned}
$$

For solute-transport simulations, $u$ represents solute concentration $\left[\mathrm{M}_{\mathrm{s}} / \mathrm{M}\right]$. For energy-transport simulations, $u$ represents thermal energy content $[\mathrm{E} / \mathrm{M}]$, which is defined as $u=c_{w} T$, where $c_{w}$ is the specific heat $\left[\mathrm{E} /\left(\mathrm{M} \cdot{ }^{\circ} \mathrm{C}\right)\right]$ of the water and $T$ is its temperature $\left[{ }^{\circ} \mathrm{C}\right]$. Rates of inflow to lake $l$ are positive and rates of outflow from lake $l$ are negative by definition in equation (33), except rates of spillover, as discussed in section 3.2.1.2, "Equations Governing the Mass of Water in a Lake."

\subsubsection{Effect of Lakes on Groundwater-Flow and Transport Boundary Conditions}

Lakes influence the groundwater-flow and transport simulation by modifying the flows, pressures, and concentrations or temperatures associated with boundary-condition nodes on the top surface of the model. The way a lake interacts with a boundary-condition node depends on the type of boundary condition.

When lake water overlies a node at which a source or sink of fluid mass, solute mass, or energy is specified, the lake intercepts the source or sink; fluid, solute, or energy is added to or removed from the lake water instead of the groundwater. The details of this type of interaction are described in sections 3.2.3.1, "Interaction with Fluid Sources and Sinks," and 3.2.3.5, "Interaction with Sources and Sinks of Solute Mass or Energy."

When lake water overlies a node at which pressure, concentration, or temperature is specified, the lake water modifies the boundary pressure, concentration, or temperature that controls the flow of water, solute, or energy in or out of the groundwater system, and the lake water supplies or receives the resultant inflow or outflow. The details of this type of interaction are described in sections 3.2.3.2, "Interaction with Specified Pressures," and 3.2.3.6, "Interaction with Specified Concentrations or Temperatures."

Note that in the case of a specified source or sink, the lake exchanges fluid, solute, or energy directly with the source or sink at a rate specified by the user. By contrast, in the case of a specified pressure, concentration, or temperature, the lake exchanges fluid, solute, or energy with the groundwater at a rate computed by SUTRA.

Generalized boundary conditions (described earlier in this report) include specified-source/sink and specified-pressure/concentration/temperature conditions as special cases. Therefore, in specifying how each generalized boundary condition behaves when interacting with a lake, the user has two options. One option is to set the generalized boundary condition to behave like a specified source or sink by allowing the lake to intercept the source or sink of fluid, solute, or energy. This option can be used to simulate, for example, evaporation of pure water from solute-laden lake water at a user-specified rate. The other option is to set the generalized boundary condition to behave like a specified pressure, concentration or temperature by exchanging fluid, solute, or energy with the lake. This option can be used to simulate, for example, groundwater discharge across a conductive lake bed into a lake at a rate controlled by the pressure exerted by the overlying lake water. The two options are described in detail in section 3.2.3.3, "Interaction with Generalized-Flow Conditions."

Boundary-condition nodes on the top surface of the model that are not overlain by lake water interact with the groundwater model in the same way as in previous versions of SUTRA (Voss and Provost, 2002). However, such nodes can also contribute water to lakes via runoff. The rate of runoff is related to the rate of groundwater recharge or discharge at the node via a userspecified ratio, as described in more detail in section 3.2.3.4, "Runoff to Lakes."

The presence or absence of lake water can also optionally control whether a given boundary condition is applied or not applied by SUTRA. Only boundary-condition nodes at which lakes are allowed to form (see section 3.3.1) can be affected by the presence or absence of lake water. This feature, together with the interactions between lakes and active boundary-condition nodes described above, allows considerable flexibility in formulating lake-related boundary conditions of practical interest. In the discussion that follows, each node in question is assumed to be an active boundary-condition node on the top surface of the model, unless specified otherwise. 


\subsubsection{Interaction with Fluid Sources and Sinks}

Associated with each fluid source or sink node (".inp" dataset 17 and ".bcs" dataset 3 ) is a user-specified rate of inflow or outflow, $Q_{I N}[\mathrm{M} / \mathrm{s}]$. By definition, the value of $Q_{I N}$ is positive for inflow to and negative for outflow from the model. Figure 15 shows how $Q_{I N}$ enters or exits the model, depending on whether or not the node is submerged by a lake.

If the node is submerged by a lake (figs. $16 \mathrm{~A}$ and $16 \mathrm{~B}$ ), $Q_{I N}$ is added to or withdrawn from the lake. This allows direct addition of water to lakes, as by precipitation, or direct removal of water from lakes at the lake-water concentration or temperature, as by pumpage directly from the lake.

If the node is not submerged by a lake (figs. $16 C$ and $16 D$ ), $Q_{I N}$ is added to or withdrawn from the groundwater system. In addition, runoff at a rate of $\varphi\left|Q_{I N}\right|$ is added to the lake in whose basin the node resides, where $\varphi$ is the user-specified runoff expressed as a fraction of recharge or discharge. In the case of recharge $\left(Q_{I N}>0\right)$, the magnitude of the total inflow to the groundwater-lake system is $(1+\varphi) \mid Q_{I N}$, and in the case of discharge $\left(Q_{I N}<0\right)$, the magnitude of the total outflow from the groundwaterlake system is $(1-\varphi)\left|Q_{I N}\right|$. Runoff is described in more detail in section 3.2.3.4, "Runoff to Lakes."

Water added to the groundwater flow system or lake from outside the model has the user-specified concentration or temperature assigned to the boundary node. Water withdrawn from a lake has the concentration or temperature of the lake water. Groundwater discharge and any associated runoff has the concentration or temperature computed at the boundary node.

\subsubsection{Interaction with Specified Pressures}

Associated with each specified-pressure node (“.inp” dataset 19 and ".bcs" dataset 5) is a user-specified pressure, $p_{B C}$ $\left[\mathrm{M} /\left(\mathrm{L} \cdot \mathrm{s}^{2}\right)\right]$, and a resultant rate of fluid mass gain, $Q_{P B C}[\mathrm{M} / \mathrm{s}]$. By definition, the value of $Q_{P B C}$ is positive for inflow to and negative for outflow from the model. Figure 16 shows how $Q_{P B C}$ enters or exits the model, depending on whether or not the node is submerged by a lake.

If the node is submerged by a lake (figs. $17 A$ and $17 B$ ), the user-specified pressure $p_{B C}$ is augmented by adding the pressure associated with the overburden of lake water. The overburden pressure is the product of the depth and density of the lake water and the acceleration of gravity. The resultant groundwater recharge or discharge, $Q_{P B C}$, is supplied or received by the lake.

If the node is not submerged by a lake (figs. $17 C$ and $17 D$ ), the boundary pressure remains at its user-specified value, $p_{B C}$. The resultant groundwater recharge or discharge, $Q_{P B C}$, is supplied or received by an external source or sink. In addition, runoff at a rate of $\varphi\left|Q_{P B C}\right|$ is added to the lake in whose basin the node resides, where $\varphi$ is the user-specified runoff expressed as a fraction of recharge or discharge. In the case of recharge $\left(Q_{P B C}>0\right)$, the magnitude of the total inflow to the groundwater-lake system is $(1+\varphi)\left|Q_{P B C}\right|$, and in the case of discharge $\left(Q_{P B C}<0\right)$, the magnitude of the total outflow from the groundwater-lake system is $(1-\varphi)\left|Q_{P B C}\right|$. Runoff is described in more detail in section 3.2.3.4, "Runoff to Lakes."

Water added to the groundwater flow system or lake from outside the model has the user-specified concentration or temperature for inflow assigned to the boundary node. Groundwater recharge from the lake has the concentration or temperature of the lake water. Groundwater discharge and any associated runoff has the concentration or temperature computed at the boundary node.

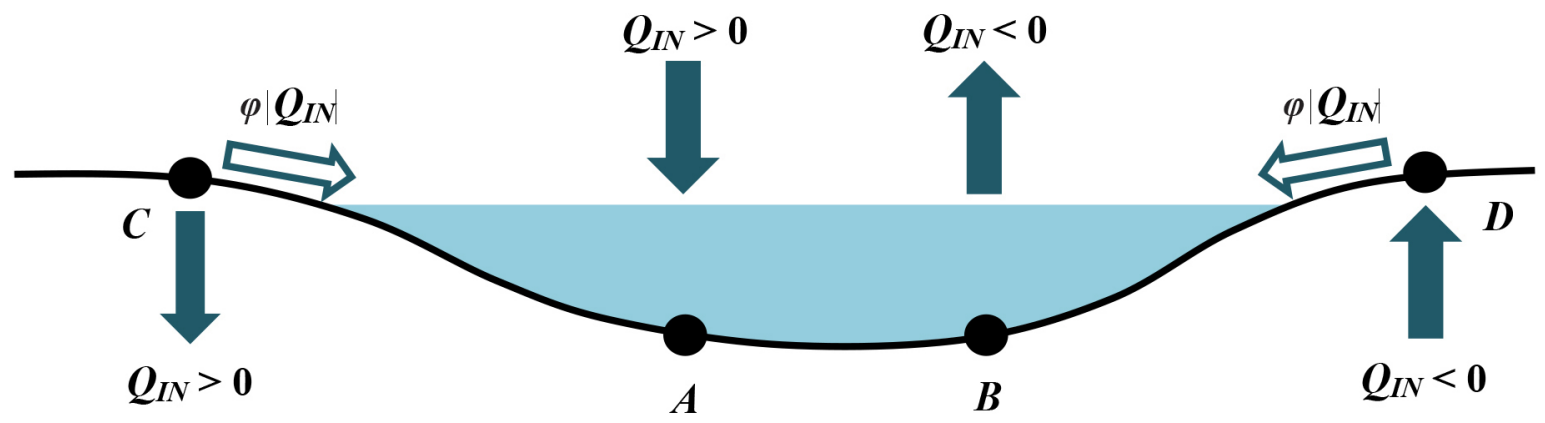

Figure 15. Interaction of a lake (light blue) with a fluid source (inflow) or sink (outflow) at model nodes (black circles). Solid arrows represent the specified inflow or outflow, $Q_{I N^{\prime}}$ to or from the aquifer or lake at each node. Four cases are illustrated: $A$, inflow at a submerged node; $B$, outflow at a submerged node; $C$, inflow at a nonsubmerged node; and $D$, outflow at a nonsubmerged node. At submerged nodes $A$ and $B, Q_{I N}$ (solid arrow) is added to or withdrawn from the lake. At nonsubmerged nodes $C$ and $D, Q_{I N}$ (solid arrow) is added to or withdrawn from the aquifer. Also, the nonsubmerged nodes contribute runoff (outlined arrow) to the lake at a non-negative rate that is determined by the user-specified ratio, $\varphi$, of runoff to specified inflow or outflow: runoff $=\varphi\left|Q_{I N}\right|$. 


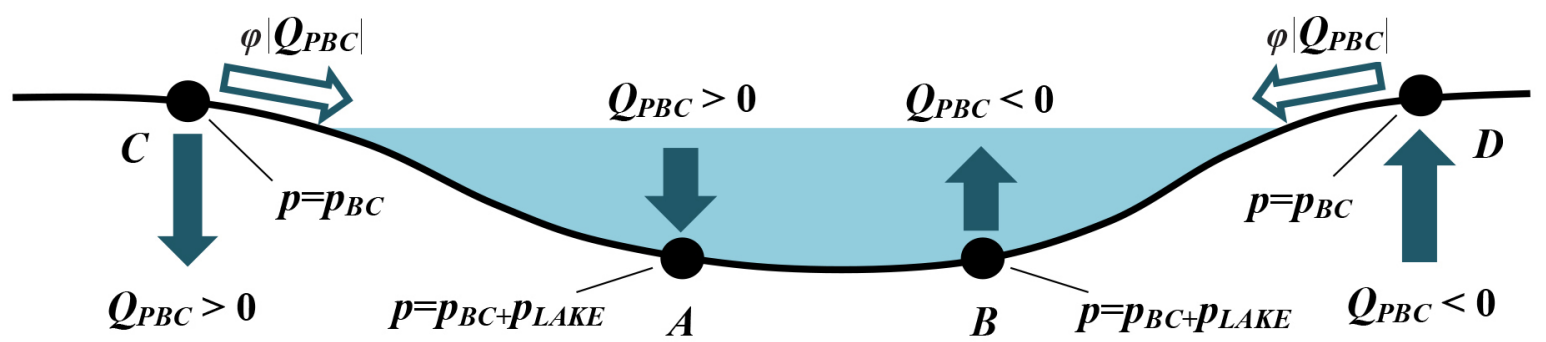

Figure 16. Interaction of a lake (light blue) with specified pressures at model nodes (black circles). Solid arrows represent the resultant inflow or outflow, $Q_{P B C^{\prime}}$ to or from the aquifer at each node. Four cases are illustrated: $A$, inflow at a submerged node; $B$, outflow at a submerged node; $C$, inflow at a nonsubmerged node; and $D$, outflow at a nonsubmerged node. At submerged nodes $A$ and $B, Q_{P B C}$ (solid arrow) is supplied or received by the lake, and the lake modifies the user-specified boundary pressure, $p_{B C^{\prime}}$ by adding the pressure $p_{L A K E}$ associated with the overburden of lake water. At nonsubmerged nodes $C$ and $D, Q_{P B C}$ (solid arrow) is controlled by the user-specified boundary pressure $p_{B C}$ Also, the nonsubmerged nodes contribute runoff (outlined arrow) to the lake at a non-negative rate that is determined by the user-specified ratio, $\varphi$, of runoff to inflow or outflow to or from the aquifer: runoff $=\varphi\left|Q_{P B C}\right|$.

\subsubsection{Interaction with Generalized-Flow Conditions}

The interaction of lakes with generalized-flow conditions is analogous to their interaction with either fluid sources and sinks or specified pressures. The type of interaction is chosen by the user in the ".lkbc" input file, which is summarized in section 3.2.3.8, "Application of Boundary Conditions: The ".lkbc" Input File." The input format for the ".lkbc" file is described in detail in appendix 3.

Associated with each generalized-flow node (“.inp” dataset 21A and ".bcs" dataset 7A) are user-specified pressures, $p_{B G 1}$ and $p_{B G 2}\left[\mathrm{M} /\left(\mathrm{L} \cdot \mathrm{s}^{2}\right)\right]$, and rates of inflow or outflow, $Q_{P B G 1}$ and $Q_{P B G 2}[\mathrm{M} / \mathrm{s}]$, that define the piecewise-linear relationship between computed pressure and inflow or outflow of fluid at the node. (Input parameters $p_{B G 1}, p_{B G 2}, Q_{P B G 1}$, and $Q_{P B G 2}$ represent the same quantities as the symbols $p_{1}, p_{2}, Q_{1}$, and $Q_{2}$, respectively, which are used throughout Chapter 1 for the sake of notational simplicity.) For a given pressure $p$ computed by SUTRA at the generalized-flow node, $Q_{P B G}[\mathrm{M} / \mathrm{s}]$ is the resultant rate of inflow or outflow at the node. By definition, the value of $Q_{P B G}$ is positive for inflow to and negative for outflow from the model. The type of interaction chosen by the user affects how $Q_{P B G}$ is apportioned between the lake and the groundwater and whether $p_{B G 1}$ and $p_{B G 2}$ are modified by the presence of the lake, as described below.

\subsection{Interaction Analogous to a Fluid Source or Sink}

If the interaction of lakes with a generalized-flow condition is specified to be analogous to the interaction of lakes with a fluid source or sink condition, $Q_{P B G}$ is apportioned between the lake (as runoff) and the groundwater recharge to or the discharge from the model. This is done in the same manner that $Q_{I N}$ is apportioned between the lake and the groundwater recharge/ discharge for a fluid source or sink (fig. 16). Pressures $p_{B G 1}$ and $p_{B G 2}$ are unaffected by the lake. This facilitates simulation of processes such as evaporation from the lake.

Water added to the groundwater flow system or lake from outside the model has the user-specified concentration or temperature for inflow assigned to the boundary node. Groundwater discharge and any associated runoff, or water withdrawn from a lake, has the user-specified concentration or temperature for outflow assigned to the boundary node. For example, the outflow concentration can be set to zero to simulate evaporation of pure water from solute-laden lake water.

\subsection{Interaction Analogous to a Specified Pressure}

If the interaction of lakes with a generalized-flow condition is specified to be analogous to their interaction with a specifiedpressure condition, pressures $p_{B G 1}$ and $p_{B G 2}$ are increased by the pressure associated with the overburden of lake water. The resultant flow, $Q_{P B G}$, enters or exits the groundwater-flow system in the same manner as $Q_{P B C}$ does for a specified pressure (fig. 17). This facilitates simulation of processes such as discharge of groundwater across a conductive lake bed and into a lake.

Water added to the groundwater flow system or lake from outside the model has the user-specified concentration or temperature for inflow assigned to the boundary node. Groundwater recharge from the lake has the concentration or temperature of the lake water. Groundwater discharge and any associated runoff has the user-specified concentration or temperature for outflow assigned to the boundary node. 


\subsubsection{Runoff to Lakes}

Although the SUTRA lake capability does not simulate the dynamics of stream and overland flow explicitly, the effects of such runoff to lakes in SUTRA are represented in an approximate way. At each active boundary node on the top surface of the model, runoff to lakes is related to the rate of groundwater recharge or discharge via a user-specified factor, $\varphi$, which is runoff expressed as a fraction of recharge or discharge. Thus, if the gain of fluid mass is $Q$ (which is positive for recharge and negative for discharge), the rate of runoff is $\varphi|Q|$. Runoff is assigned to the lake in whose basin the boundary node resides. If the lake to which runoff is assigned is inactive (that is, if it is split into its children), runoff is assigned to a descendant of that lake that is identified using a discrete steepest-descent algorithm described in section 3.4.3, "Determining the Fate of Spillover Using Steepest Descent." Thus, runoff follows the steepest downhill direction until it encounters either lake water or a completely dry lake bottom. Runoff is assumed to reach the lake instantaneously, which is usually a reasonable assumption for a groundwater model, as surface water typically redistributes more quickly than groundwater.

In the case of recharge (for example, fig. 16C), runoff can be conceptualized as originating from an external fluid source that is divided into recharge and runoff. In the case of discharge (for example, fig. 16D), a portion of the discharge can be conceptualized as being diverted to runoff, with the remainder going to an external sink. The user may specify a different fraction $\varphi$ for recharge than for discharge at a given node. Although SUTRA does not restrict the allowable values of $\varphi$, a non-negative value is typically desired so that runoff is non-negative (into, not out of, the lake). If runoff is being diverted from groundwater discharge, a value of $\varphi$ less than or equal to 1 is typically desired so that the diverted runoff does not exceed $100 \%$ of the discharge.

\subsubsection{Interaction with Sources and Sinks of Solute Mass or Energy}

Associated with each solute-mass or energy source or sink node (".inp" dataset 18 and ".bcs" dataset 4) is a user-specified rate of inflow or outflow of solute mass or energy, $Q_{\text {UINC }}\left[\mathrm{M}_{\mathrm{s}} / \mathrm{s}\right.$ or E/s]. The value of $Q_{\text {UINC }}$ is positive for inflow to and negative for outflow from the model. Figure 17 shows how $Q_{\text {UINC }}$ enters or exits the model, depending on whether or not the node is submerged by a lake.

If the node is submerged by a lake (figs. $18 \mathrm{~A}$ and $18 \mathrm{~B}$ ), $Q_{\text {UINC }}$ is added to or removed from the lake. This provides a mechanism for adding or removing solute mass or energy directly to or from lakes. If the node is not submerged by a lake (figs. $18 C$ and $18 D), Q_{U I N C}$ is added to or removed from the groundwater-flow system at that node.

\subsubsection{Interaction with Specified Concentrations or Temperatures}

Associated with each specified-concentration or temperature node (".inp" dataset 20 and ".bcs" dataset 6) is a user-specified concentration or temperature, $U_{B C}\left[\mathrm{M}_{\mathrm{s}} / \mathrm{M}\right.$ or $\left.{ }^{\circ} \mathrm{C}\right]$ and a resultant gain of solute mass or energy $Q_{U B C}^{U}\left[\mathrm{M}_{\mathrm{s}} / \mathrm{s}\right.$ or E/s]. The value of $Q_{U B C}^{U}$ is positive for inflow to and negative for outflow from the model. Figure 18 shows how $Q_{U B C}^{U}$ enters or exits the model, depending on whether or not the node is submerged by a lake.

If the node is submerged by a lake (figs. $19 \mathrm{~A}$ and 19B), the boundary concentration or temperature is changed from $U_{B C}$ to the lake concentration or temperature, and the resultant flow into or out of the groundwater-flow system, $Q_{U B C}^{U}$, is supplied or received by the lake. If the node is not submerged by a lake (figs. 19C and 19D), the boundary concentration or temperature remains at $U_{B C}$, and $Q_{U B C}^{U}$ is added to or removed from the groundwater-flow system at that node.

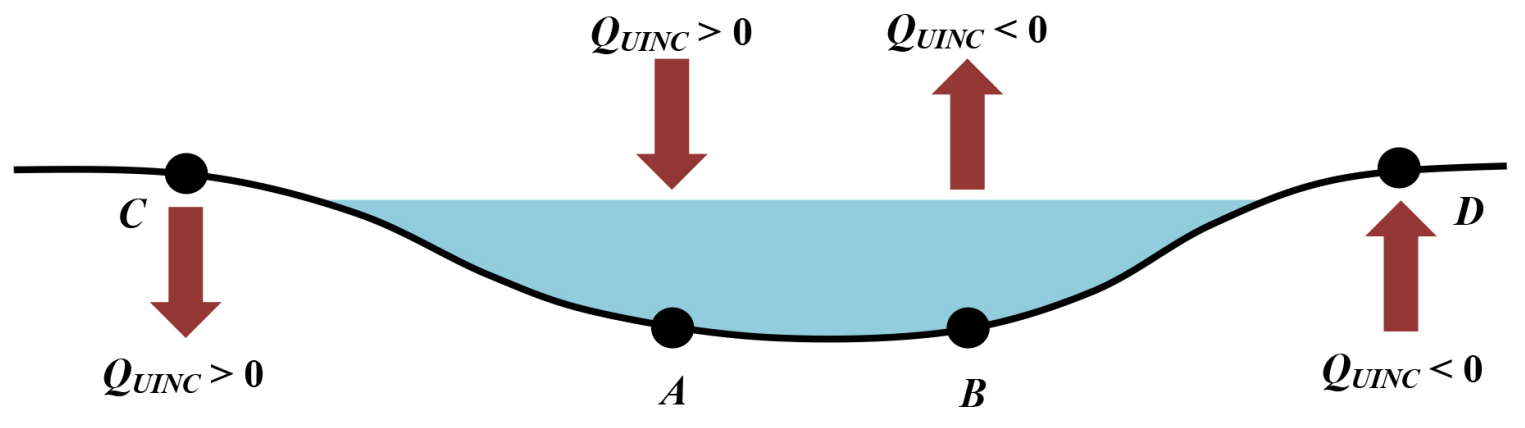

Figure 17. Interaction of a lake (light blue) with solute or energy sources and sinks at model nodes (black circles). Arrows represent the specified source or sink of solute or energy, $Q_{U I N C^{\prime}}$ to or from the aquifer or lake at each node. Four cases are illustrated: $A$, source at a submerged node; $B$, sink at a submerged node; $C$, source at a nonsubmerged node; and $D$, sink at a nonsubmerged node. At submerged nodes $A$ and $B, Q_{\text {UINC }}$ (arrow) is added to or withdrawn from the lake. At nonsubmerged nodes $C$ and $D, Q_{\text {UINC }}$ (arrow) is added to or removed from the aquifer. 


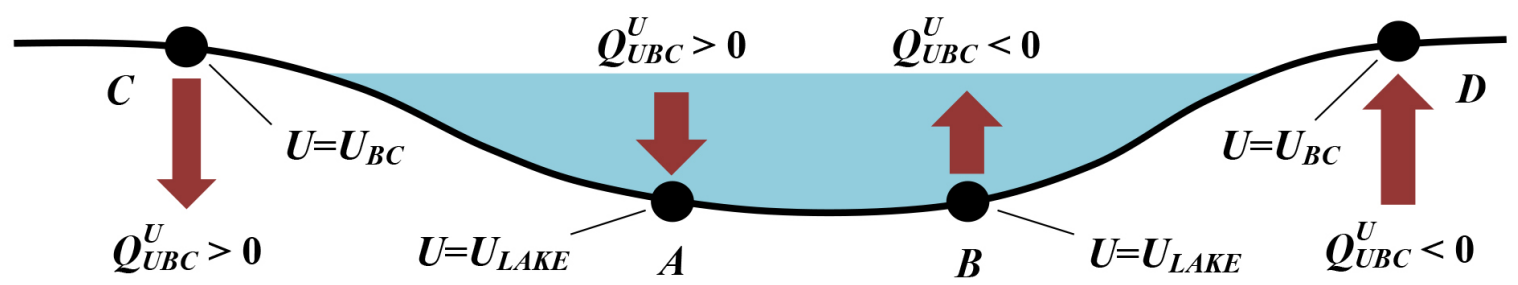

Figure 18. Interaction of a lake (light blue) with specified concentrations or temperatures at model nodes (black circles). Arrows represent the resultant source or sink of solute or energy, $Q_{U B C}^{U}$, to or from the aquifer at each node. Four cases are illustrated: $A$, source at a submerged node; $B$, sink at a submerged node; $C$, source at a nonsubmerged node; and $D$, sink at a nonsubmerged node. At submerged nodes $A$ and $B, Q_{U B C}^{U}$ (arrow) is supplied or received by the lake and is controlled by the lake concentration or temperature, $U_{\text {LAKE }}$ At nonsubmerged nodes $C$ and $D, Q_{U B C}^{U}$ (arrow) is controlled by the user-specified boundary concentration or temperature, $U_{B C}$.

\subsubsection{Interaction with Generalized-Transport Conditions}

The interaction of lakes with generalized-transport conditions is analogous to their interaction with either sources and sinks of solute or energy or specified concentrations or temperatures. The type of interaction is chosen by the user in the ".lkbc" input file, which is summarized in section 3.2.3.8, "Application of Boundary Conditions: The ".lkbc" Input File." The input format for the ".lkbc" file is described in detail in appendix 3.

Associated with each generalized-transport node (".inp" dataset 21B and ".bcs" dataset 7B) are user-specified concentrations or temperatures, $U_{B G 1}$ and $U_{B G 2}\left[\mathrm{M}_{\mathrm{s}} / \mathrm{M}\right.$ or $\left.{ }^{\circ} \mathrm{C}\right]$, and rates of gain or loss of solute mass or energy, $Q_{U B G 1}^{U}$ and $Q_{U B G 2}^{U}$, that define the linear relationship between computed concentration or temperature and the rate of gain or loss of solute or energy at the node. (Input parameters $U_{B G 1}, U_{B G 2}, Q_{U B G 1}^{U}$, and $Q_{U B G 2}^{U}$ represent the same quantities as the symbols $U_{1}, U_{2}$, $Q_{1}^{U}$, and $Q_{2}^{U}$, respectively, which are used throughout Chapter 1 for the sake of notational simplicity.) For a given concentration or temperature $U$ computed by SUTRA at the generalized-flow node, $Q_{U B G}^{U}\left[\mathrm{M}_{\mathrm{s}} / \mathrm{s}\right.$ or E/s $]$ is the resultant rate of gain or loss of solute mass or energy. The value of $Q_{U B G}^{U}$ is positive for inflow to and negative for outflow from the model. The type of interaction chosen by the user affects how $Q_{U B G}^{U}$ is apportioned between the lake and the groundwater and whether $U_{B G 1}, U_{B G 2}$, $Q_{U B G 1}^{U}$, and $Q_{U B G 2}^{U}$ are modified by the presence of the lake, as described below.

\subsection{Interaction Analogous to a Source or Sink of Solute or Energy}

If the interaction of lakes with a generalized-transport condition is specified to be analogous to their interaction with a source or sink of solute or energy, $Q_{U B G}^{U}$ enters or exits the model in the same manner that $Q_{U I N C}$ does for a source or sink of solute or energy (fig. 18). Concentrations or temperatures $U_{B G 1}$ and $U_{B G 2}$ are unaffected by the lake. This allows simulation of heat transfer between a lake and the atmosphere across a thermal boundary layer, for example, with the heat transfer being driven by the temperature difference between the lake water and the atmosphere.

\subsection{Interaction Analogous to a Specified Concentration or Temperature}

If the interaction of lakes with a generalized-transport condition is specified to be analogous to their interaction with a specified concentration or temperature, $U_{B G 1}$ and $U_{B G 2}$ depend on whether or not lake water is present. The resultant flow, $Q_{U B G}^{U}$, enters or exits the groundwater-flow system in the same manner that $Q_{U B C}^{U}$ does for a specified concentration or temperature (fig. 19).

If the node is submerged by a lake, SUTRA automatically sets the point $\left(U_{B G 1}, Q_{U B G 1}^{U}\right)$ to $\left(U_{L A K E}, 0\right)$, and adjusts the point $\left(U_{B G 2}, Q_{U B G 2}^{U}\right)$ such that the original slope of the $Q^{U}$-versus- $U$ line (fig. 9) is preserved. Thus, the resultant gain of solute or energy by the groundwater-flow system, $Q_{U B G}^{U}$, which is supplied or received by the lake, becomes zero when $U=U_{L A K E}$. This allows simulation of heat transfer between a lake and groundwater across a thermally conductive lake bed and (or) a thermal boundary layer, for example, with the heat transfer being driven by the temperature difference between the lake water and the groundwater at the boundary node.

\subsubsection{Application of Boundary Conditions: the ".Ikbc" Input File}

The presence or absence of lake water can optionally control whether a given boundary condition is applied or not applied. Consider, for example, a model in which the recharge rate due to precipitation is specified across the top of the model, but the recharge rate is different for precipitation that falls on a lake than it is for precipitation that falls on the land surface. One set of fluid-source boundary conditions specified at all the top-surface nodes provides the recharge to the land surface. This set is not 
applied when lake water is present and is applied when lake water is absent; it is applied only when the land surface is exposed. A second set of fluid-source boundary conditions specified at all the top-surface nodes provides the recharge to lakes. This second set is applied when lake water is present and is not applied when lake water is absent; it is applied only when the land surface is inundated. Thus, at any given fluid-source node at any given time, the recharge rate is either the value for lakes or the value for the land surface, depending on whether or not lake water is present.

SUTRA boundary-condition nodes are grouped by type and given default parameter values in ".inp" datasets 17-21. Timevarying parameter values that override the default values are specified in ".bcs" datasets 2-7, which can be distributed over multiple ".bcs" files. Specification of the way lakes control the application of boundary conditions follows a parallel structure in the ".lkbc" input file. For each of the six types of boundary condition, default specifications that apply to all boundary conditions of that type are listed first. These are followed by optional specifications for individual ".bes" files that override the default specifications. Thus, by organizing boundary conditions in multiple ".bes" files, one can effectively construct boundary conditions that change type and (or) parameter values depending on whether or not lake water is present.

Specifications for each of the six types of boundary condition include how the presence or absence of lake water affects the application status of boundary conditions of that type. For the generalized-flow and generalized-transport types, the user also specifies whether lakes interact with that type of boundary condition analogously to a source or sink, or analogously to a specified pressure, concentration, or temperature. The input format for the ".lkbe" file is described in detail in appendix 3.

\subsection{Special Features of the Lake Capability}

This section describes features that give the user additional control over the formation of lakes.

\subsubsection{Limiting Where Lakes Can Form}

In some applications, it may be desirable to simulate lakes over only a portion or portions of the surface of the model. To allow this, the subset of top-surface nodes at which lakes may form are listed in the optional ".lkar" input file. Input data formats for the ".Ikar" file are listed in appendix 3. If the optional ".Ikar" file is omitted, all nodes on the top surface of the model are eligible to form lakes. If the optional "Ikar" file is specified, then if the lowest-elevation node in the basin of a lake is disqualified from lake formation, lake water cannot accumulate in that basin, so that entire basin is disqualified from lake formation. Top-surface nodes at which lakes may form must form one contiguous region; they cannot be separated into two or more separate regions in which lakes may form. The contiguous region may contain "holes" in which lakes are not allowed to form, but there must be only one contiguous region so that potential lakes are all contained within a single hierarchy.

When a lake expands such that it reaches the outer boundary of the model or a node at which lakes are not allowed to form, the lake volume (stage) is not allowed to increase, and any excess inflow is assumed to "spill over" out of the model. The amount of spillover out of the model is reported in the budget information, as summarized in section 3.5, "Lake-Related Output Files."

\subsubsection{Lake-Bottom Elevations}

The lake capability identifies potential lakes and their hierarchy automatically, as described in section 3.1.1, "Identification of Potential Lakes." If the surface topography includes numerous small undulations, a very large number of potential lakes can result. To keep the number of lakes and their hierarchy manageable, lake-bottom elevations can be specified by the user in the optional ".lkar" file. This feature allows the user to supply lake-bottom elevations that have been smoothed in a preprocessing step, if desired, to eliminate small undulations. Optionally, the user can choose to have SUTRA use the top-surface node elevations of the groundwater model as the lake-bottom elevations by default.

\subsection{Some Algorithmic Details}

This section describes in greater detail some of the procedures used by the lake capability and their ramifications for SUTRA models involving lakes.

\subsubsection{Identifying Potential Lakes Using the Hoshen-Kopelman Algorithm}

The SUTRA lake capability identifies potential lakes by starting with the highest elevation in the grid and working its way down, finding the "sills" at which lakes divide. On a 2D elevation grid that represents the top surface of a 3D model, the lakes 
that form at a given water stage correspond to contiguous "clusters" of submerged lake cells on the "lattice" formed by the grid. When the stage is lowered and a lake splits, the number of clusters increases.

Consider, for example, the regular, rectangular grid shown in figure 19. The nodes in the grid vary in elevation (arbitrary units), and numerals indicate the cluster (lake) number with which each node is identified. In figure $20 \mathrm{~A}$, the water stage is at 1.0 - the elevation of the highest node in the grid. Thus, all nodes are submerged, and all belong to one large cluster (cluster 1). When the stage is lowered below 0.7 (the highest sill elevation), cluster 1 divides into two distinct clusters, 2 and 3 (fig. 20B). As the water stage is lowered further, clusters continue to divide until finally all possible clusters (lakes) have been identified. The final array (fig. 20C) corresponds to a lake hierarchy that is identical to the one in figure 13.

The lake capability uses a generalization of the Hoshen-Kopelman algorithm (Hoshen and Kopelman, 1976; Al-Futaisi and Patzek, 2002) to identify clusters on regular or irregular grids. Thus, the lake capability can be used with REGULAR, BLOCKWISE, or LAYERED SUTRA meshes. LAYERED meshes need not be logically rectangular but must have the same (regular or irregular) two-dimensional structure within each layer (Voss and Provost, 2002).

\subsubsection{Lake Hierarchy as a Binary Tree}

The lake capability assumes that when a lake divides, it splits into exactly two children. In other words, as the lake stage falls, it cannot encounter two sills within the same lake simultaneously; it must encounter one of them before the other. This poses no dilemma for division of lakes: one division can be followed immediately by a second, effectively splitting one lake into three. If the two sills are distinct but close in elevation, it generally does not make much practical difference which one is encountered first.

When the lake stage is rising, however, which sill is encountered first can have a significant effect on the exchange of water between lakes. Consider the situation shown in figure 20, in which the sill on the right is slightly lower than the sill on the left and is therefore encountered first by the rising stage in the middle lake.

When the stage rises to the elevation of the right-hand sill, the middle lake begins to spill into the right-hand lake, and it continues to do so until the right-hand lake is filled. The middle and right-hand lakes then coalesce and rise together. When their stage rises to the elevation of the left-hand sill, they begin to spill into the left-hand lake. If, instead, the left-hand sill had been slightly lower than the right-hand sill, the sequence would have been reversed: the left-hand lake would have filled first, then the right-hand lake. Even if the elevations of the two sills had been equal, the lake capability would have encountered one of them first in its search algorithm, and the corresponding lake would have been designated to receive the spillover.

In a real system, the lake stage necessarily rises above the sill elevation when one lake is spilling into another. All else being equal, the greater the rate of spillover and the narrower the channel between the lakes, the higher the stage rises above the sill. In fact, it is possible for the lake stage to be above two or more sills simultaneously, and thus for a lake to spill into two or more lakes at the same time (fig. 21). One of the sills may begin spilling over first, but that does not necessarily preclude others from spilling over as well, as the stage continues to rise.

This points out a limitation of the binary lake hierarchy used in the lake capability. Of the three physically possible scenarios - middle lake spills into right lake first, middle lake spills into left lake first, and middle lake spills into right and left

\begin{abstract}
11111111111111111111111111111
1111111111111111111111111111111

1111111111111111111111111111111

1111111111111111111111111111111

111111111111111111111111111111

11111111111111111111111111111

1111111111111111111111111111111

1111111111111111111111111111111

11111111111111111111111111111

1111111111111111111111111111111

1111111111111111111111111111111
\end{abstract}

A

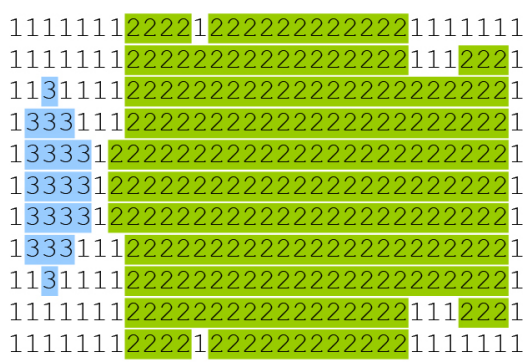

$B$

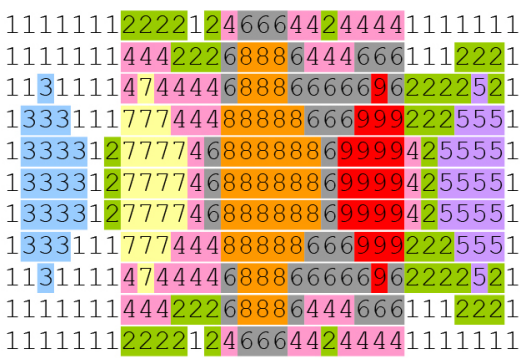

C

Figure 19. The lake capability identifies potential lakes by tracking the formation of distinct clusters of contiguous, submerged nodes on the top surface of the model as the water stage varies from the highest to the lowest elevation on the surface. This example shows a regular, rectangular grid of surface nodes. Numerals indicate the cluster number with which each node is identified, and colors aid in distinguishing the clusters: $A$, With the water stage at the maximum elevation, all nodes belong to one large cluster (cluster 1); $B$, At a lower water stage, only the colored nodes are submerged, and cluster 1 splits into two distinct clusters ( 2 and 3 ); and $C$, When the water stage reaches the surface node that has the lowest elevation, all possible clusters (lakes) have been identified. 


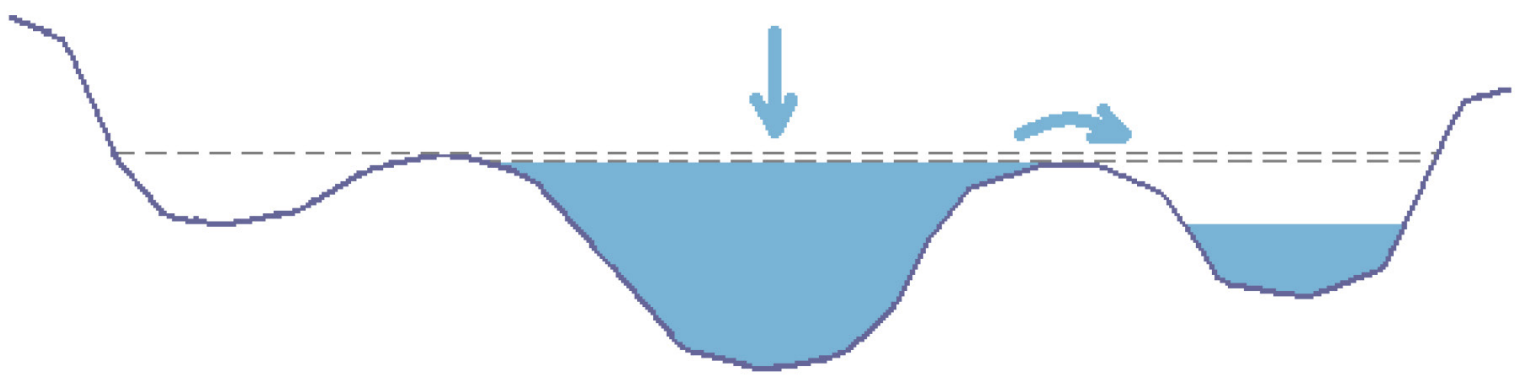

Figure 20. The middle lake spills into the right-hand lake first because the right-hand sill is lower than the left-hand sill. The spilling process (overland flow) is not modeled explicitly, and the stage in the middle lake remains fixed at the level of the right-hand sill until the right-hand lake is filled. Arrows indicate inflow and spillover of water.

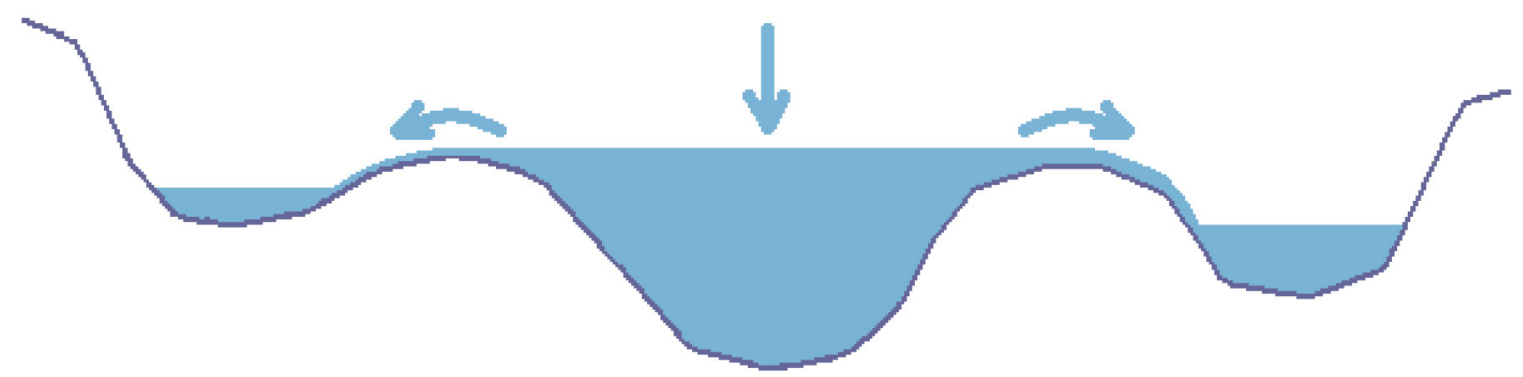

Figure 21. In reality, a sufficiently strong source to the middle lake can cause it to spill over into the two side lakes simultaneously. This cannot be simulated by the SUTRA lake capability. Arrows indicate inflow and spillover of water.

lakes simultaneously — only the first two can be simulated by the lake capability; the third cannot. In the present lake capability paradigm, each lake has but one sibling, and spillover is routed only to that one sibling (or an active descendant thereof). Users should remain mindful of this limitation when formulating their models and interpreting results. If a lake has two sills of equal elevation, the sill chosen by SUTRA as the sill that separates the lake from its sibling might or might not be the sill that the user would choose to begin spilling over first. In cases in which this limitation has a significant effect on the outcome of the simulation, small adjustments to the surface topography by the user may help to force a model to choose the most important exchanges of water between lakes.

\subsubsection{Determining the Fate of Spillover Using Steepest Descent}

When a lake fills to capacity, any additional net inflow of water spills over into the lake's sibling. If the sibling lake is not active at the time (because it is split into its children), the spillover is rerouted to one of the sibling's children. This rerouting continues down the lake hierarchy until an active descendant of the sibling lake is found.

Because the details of the surface-water flow that distributes the spillover are not modeled, a simple search algorithm is used to decide how spillover is routed down the lake hierarchy. The underlying assumption is that the surface flow follows a path of steepest descent from node to node.

The search begins at the node that is the sill between the spilling lake and its sibling. It then moves to the neighboring node (on the sibling's side of the sill) that provides the steepest drop in elevation. The search continues in a like manner, moving from node to neighboring node according to the steepest-descent criterion, until a childless lake (a lake at the bottom of the hierarchy) is reached. The path traversed by the search determines the sequence of lakes to which spillover from the original lake is routed until an active descendant lake is encountered.

A topographic depression can be optionally eliminated from the lake hierarchy because it is too small to warrant treatment as an independent lake, as described in section 3.3.2, "Lake-Bottom Elevations." Any spillover that is routed into such a depression by the steepest-descent algorithm is rerouted by treating the depression (for this purpose only) as a lake that is full and spilling over its sill. Spillover that enters the depression immediately exits at the sill and resumes following a path of steepest descent. 


\subsubsection{Drying and Rewetting}

The groundwater-flow equation is solved and exchanges of water between groundwater and lakes are computed before mass balance calculations are performed on the lakes. Thus, the net outflow (total of all outflows from less the total of all inflows to a lake) of water from a lake on a given time step can exceed the amount of water in the lake. In that case, the water in the lake is "overdrawn" on that time step, and the overdraft is reported as a water mass balance error. Similarly, the groundwater-transport equation is solved and exchanges of solute mass or energy between groundwater and lakes are computed before solute-mass or energy balance calculations are performed on the lakes. If the net outflow of solute mass from a lake on a given time step exceeds the solute mass in the lake, the solute in the lake is "overdrawn" on that time step, and the overdraft is reported as a solute mass balance error. Thermal energy is not subject to overdraft, and no limit is imposed on the lake-water temperature.

A lake from which all water has been removed is said to be dry. A dry lake rewets if there is net inflow into the lowest node in the lake. Note that inflows can include runoff of external sources and groundwater discharge, as illustrated, for example, in figure 15 .

\subsection{Lake-Related Output Files}

The lake number for each surface node is output in the ".lkn" file. The binary tree that represents the lake hierarchy is written to the ".lkh" file.

Fluid and solute or energy budget information is reported for lake-related nodes in the SUTRA ".Ist" output file. It follows a format similar to that used for other budget items in the ".Ist" file.

Budget information for individual lakes is reported in the ".lkbu" lake-budget output file:

- Status (coalesced, split, full, and so forth).

- Stage and its rate of change with time.

- Water volume and mass and their rates of change with time.

- Solute mass and concentration and their rates of change with time (solute transport only).

- Thermal energy content and temperature and their rates of change with time (energy transport only).

- Rates of water mass and solute mass or energy loss to lake-area limits.

- Rates of water mass gain, loss, and net exchange with groundwater, external sources and sinks, runoff, and other lakes.

- Rates of solute mass gain, loss, and net exchange with groundwater, external sources and sinks, runoff, and other lakes (solute transport only).

- Rates of thermal energy gain, loss, and net exchange with groundwater, external sources and sinks, runoff, and other lakes (energy transport only).

Lake stage and depth information is output to the ".lkst" file. This file has a format similar to that of the SUTRA ".nod" file. For inactive lakes and top-surface nodes at which lake water is absent, a user-specified marker value (RNOLK in dataset 1 of the ".Ikin" input file) is printed. The lake capability is compatible with the SUTRA restart capability. Lake-related restart information is written to the ".lkrs" file.

\subsection{Assumptions and Limitations}

The following is a summary of the assumptions and limitations inherent in SUTRA's lake capability:

- Lakes exchange fluid mass and solute mass or energy with groundwater, with each other, and with external sources or sinks. Lakes influence the groundwater simulation by interacting with user-specified flow and transport boundary conditions on the top surface of the model. (See p. 25.)

- Lakes form on top of the surface topography defined by the top layer of nodes in the SUTRA model, or, optionally, by user-specified lake-bottom elevations. (See section 3.1.1.)

- Because the lake capability requires an identifiable "top layer" of nodes, its use is restricted to 3D REGULAR, BLOCKWISE, and LAYERED meshes. LAYERED meshes need not be logically rectangular but must have the same (regular or 
irregular) two-dimensional structure within each layer (Voss and Provost, 2002). The lake capability cannot presently be used with 3D IRREGULAR meshes, nor with 2D meshes of any type. (See section 3.1.1 .)

- SUTRA automatically identifies the lakes that can form on the model surface and arranges them in a numbered hierarchy that represents the splitting and coalescence of lakes as the surface-water stage changes. Because the lake numbering is generally not known by the user a priori, formulation of lake specifications, such as initial lake stages, can involve trial and error over multiple model runs. An option to associate lake specifications with surface-node numbers instead of lake numbers is available to facilitate the process in the early stages of modeling. (See section 3.1.1 and dataset 3 of the “.Ikin" input file in appendix 3.)

- Each surface node is overlain by a "lake cell" that can hold lake water. The total volume of water in a lake is the sum of the volumes of water held in the lake cells associated with that lake. For the purpose of volume calculations, the lakebottom elevation is assumed to be uniform within each lake cell. (See section 3.1.2.)

- The rate at which the lake stage increases as the volume of water in the lake increases is inversely proportional to the surface area of the lake. For the purpose of lake-stage calculations, the surface area of the lake is the sum of the areas associated with all the submerged lake cells in the lake. Thus, lake stage is a continuous, piecewise-linear function of volume. (See section 3.1.2.)

- The groundwater-flow equation includes exchanges of water with lakes via groundwater-flow boundary conditions. Exchanges are based on lake stages from the previous time step or nonlinearity iteration.

- The groundwater-transport equation includes exchanges of solute mass or energy with lakes via groundwater-flow and transport boundary conditions. Exchanges are based on lake concentrations or temperatures from the previous time step or nonlinearity iteration.

- The water-mass balance equations for the lakes include exchanges of water with the groundwater-flow system. To conserve water mass in the simulation, exchanges are consistent with those used in solving the groundwater-flow equation provided there is sufficient water in each lake to satisfy the computed exchanges. If water is overdrawn from a lake on a given time step, the overdraft is reported as a lake water mass-balance error.

- The solute-mass or energy balance equations for the lakes include exchanges of solute mass or energy with the groundwater-flow system. To conserve solute mass or energy in the simulation, exchanges are consistent with those used in solving the groundwater-transport equation provided there is sufficient solute mass in each lake to satisfy the computed exchanges. If solute mass is overdrawn from a lake on a given time step, the overdraft is reported as a lake solute massbalance error.

- Rates of fluid exchange with groundwater and external sources and sinks are assumed to remain constant throughout each time step.

- The volume of water in each lake, which in turn determines the stage, is computed from the mass of water under the approximation of constant density. This introduces error into the volumetric calculations but does not compromise the conservation of mass. (See section 3.2.1.3.)

- Lakes act as well-mixed tanks. There is no stratification of concentration or temperature within a lake. (See section 3.2.2.)

- The user can specify the set of surface nodes at which lakes may form. This set of nodes can comprise only a portion of the top surface of the model but must form a single, contiguous region such that potential lakes are all contained within a single hierarchy. (See section 3.3.1.)

- The lake hierarchy is a binary tree. When a lake divides, it splits into exactly two children. As a result, a lake that is filled to capacity cannot spill over into two or more lakes simultaneously. (See section 3.4.2.)

- Spillover from one lake to another occurs by a surface-water process that is not explicitly modeled and is assumed to occur instantaneously; excess water is simply reallocated from the lake to its sibling. (See section 3.2.1.1.)

- If the sibling of a lake that is spilling over is not active, the spillover is routed to an active lake lower in the hierarchy that is determined using a discrete steepest-decent algorithm. (See section 3.4.3.) 


\subsection{Example Problem: Lakes}

\subsubsection{Physical Setup}

This problem involves interaction of 3D groundwater flow with lakes and transport of solute between groundwater and lakes. The model domain covers a $10-\mathrm{km}-$ by-20-km rectangular area and is approximately $100 \mathrm{~m}$ deep, with a variable surface topography that corresponds to the top surface of the groundwater model, which includes three topographic depressions (fig. 22). Initially, no lake water is on the surface of the model. As topographically driven groundwater flow recharges at higher elevations and discharges at lower elevations, lakes form in the three topographic depressions. A source of solute at the model surface enters the groundwater and discharges into one of the lakes. As the lake stages rise, the lakes coalesce, and their waters mix. Eventually, one large lake forms. Subsequent withdrawal of lake water causes the lake stage to fall, and the large lake splits into the three original lakes. At the end of the simulation, the groundwater-lake flow system is near steady state.

\subsubsection{Objectives}

1. Demonstrate the interaction of groundwater with lakes simulated using the SUTRA lake capability.

2. Demonstrate solute transport in groundwater and lakes simulated using the SUTRA lake capability.

\subsubsection{Simulation Setup}

The mesh (fig. 23) consists of 40 by 20 elements horizontally and 10 elements vertically, resulting in a total of 9,471 nodes $(\mathrm{NN}=9,471)$ and 8,000 elements $(\mathrm{NE}=8,000)$. Each element is $500 . \mathrm{m}$ by $500 . \mathrm{m}$ horizontally and between approximately 7 . and $10 . \mathrm{m}$ vertically. The bottom of the model is at $0 \mathrm{~m}$ elevation, and the top-surface elevation, $z_{\text {top }}[\mathrm{m}]$, is given by

$$
z_{\text {top }}=100-\frac{15}{1+\left(r_{3} / 1500\right)^{4}}-\frac{20}{1+\left(r_{4} / 2000\right)^{4}}-\frac{30}{1+\left(r_{5} / 3000\right)^{4}}
$$

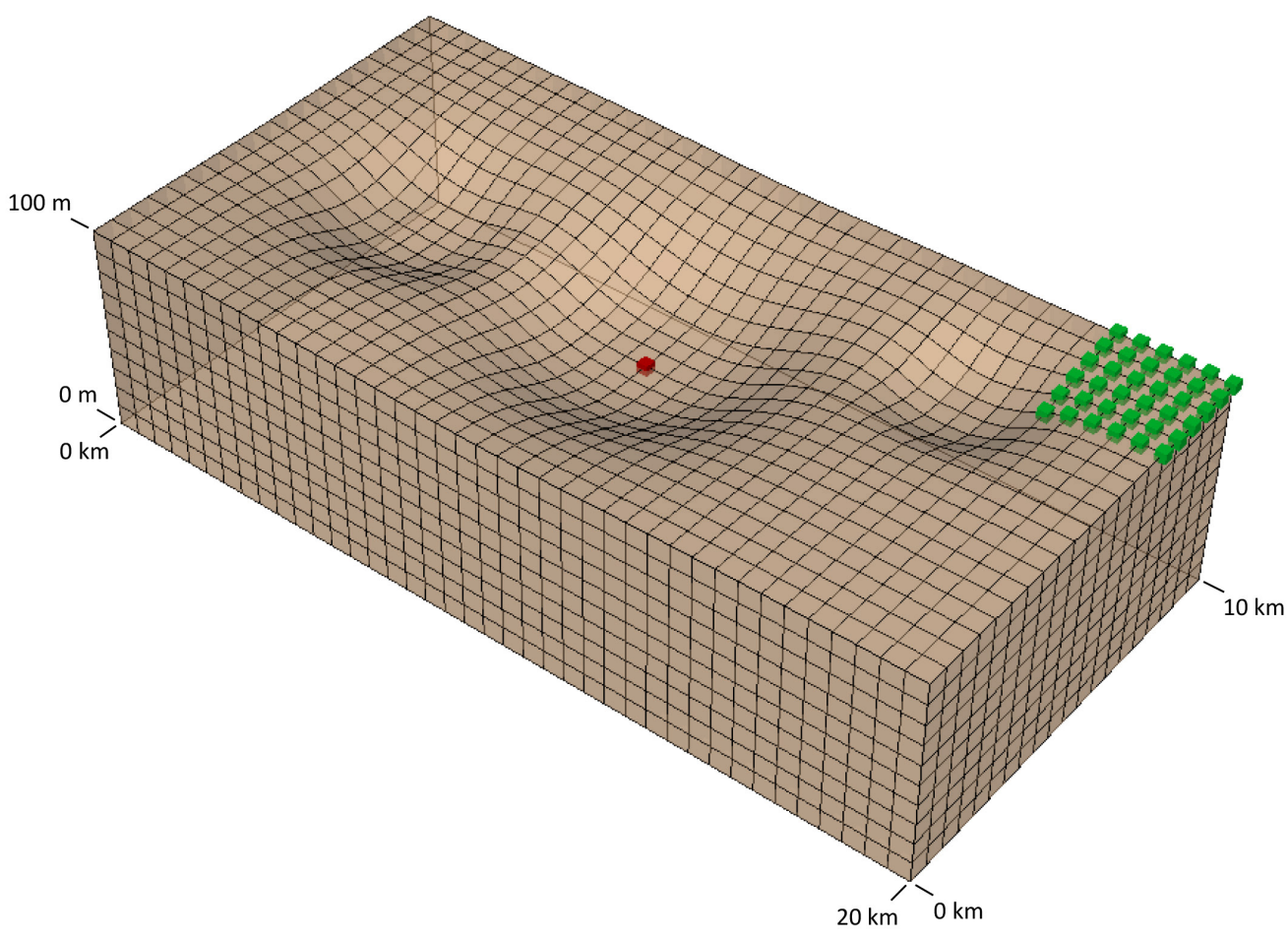

Figure 22. Finite-element mesh for the lake example. Green cubes denote specifiedpressure nodes that act as solute sources. Red cube denotes a fluid sink node that withdraws lake water. (50X vertical exaggeration; $m$, meter; km, kilometer) 
where

$$
\begin{aligned}
& r_{3}=\sqrt{(x-16000)^{2}+(y-7000)^{2}} \\
& r_{4}=\sqrt{(x-4000)^{2}+(y-5000)^{2}}
\end{aligned}
$$

and

$$
r_{5}=\sqrt{(x-10000)^{2}+(y-5000)^{2}}
$$

Based on this surface topography, the SUTRA lake capability identified and reported the lake hierarchy shown in figure 23. Lakes 3, 4, and 5 correspond to the right, left, and middle topographic depressions in figure 23. Coalescence of lakes 4 and 5 forms lake 2, and coalescence of lakes 2 and 3 forms lake 1.

Groundwater flow is fully saturated and of constant density. Concentration [dimensionless] is expressed on a relative scale of 0 . to 1 . The run is transient in both pressure and concentration. The time step size is $\Delta t=6.048 \times 10^{5} \mathrm{~s}$ (1. week). The simulation consists of 500 time steps. The total simulation time is $3.024 \times 10^{8} \mathrm{~s}(500$. weeks). The CG solver is used for groundwaterflow solutions and the GMRES solver is used for groundwater-transport solutions. Groundwater-flow solutions required no more than five solver iterations to converge to a tolerance of $1 \times 10^{-8}$. Groundwater-transport solutions required no more than 13 solver iterations to converge to a tolerance of $1 \times 10^{-10}$.

\subsubsection{Parameters}

$$
\begin{array}{ll}
\alpha=1.0 \times 10^{-8} \mathrm{~m} \cdot \mathrm{s}^{2} / \mathrm{kg} & \beta=4.47 \times 10^{-10} \mathrm{~m} \cdot \mathrm{s}^{2} / \mathrm{kg} \\
\begin{array}{ll}
\text { (The } \left.\alpha \text { and } \beta \text { values imply that } S_{o p}=9.0447 \times 10^{-9} \mathrm{~m} \cdot \mathrm{s}^{2} / \mathrm{kg} .\right) \\
k=1.0 \times 10^{-10} \mathrm{~m}^{2} & \varepsilon=0.1 \\
\rho=1000 . \mathrm{kg} / \mathrm{m}^{3} & \mu=1.0 \times 10^{-3} \mathrm{~kg} /(\mathrm{m} \cdot \mathrm{s}) \\
\mathrm{g}=9.81 \mathrm{~m} / \mathrm{s}^{2} & \alpha_{L}=\left\{\begin{array}{l}
4000 . \mathrm{m} \text { for horizontal flow } \\
20 . \mathrm{m} \text { for vertical flow }
\end{array}\right. \\
D_{m}=1.0 \times 10^{-9} \mathrm{~m}^{2} / \mathrm{s} & \alpha_{T}=10 . \mathrm{m}
\end{array}
\end{array}
$$

Here, $\alpha$ and $\beta$ are compressibilities of the porous matrix and the fluid, respectively, $S_{o p}$ is specific pressure storativity, $k$ is permeability, $\varepsilon$ is porosity, $\rho$ is fluid density, $\mu$ is fluid viscosity, $g$ is the acceleration of gravity, $D_{m}$ is apparent molecular diffusivity, $\alpha_{L}$ is longitudinal dispersivity, and $\alpha_{T}$ is transverse dispersivity. These physical properties are defined and discussed in more detail in Voss and Provost (2002).

\subsubsection{Boundary Conditions}

No flow occurs across the vertical and bottom boundaries. Atmospheric (zero) pressure is specified at all nodes on the top surface, and all nodes on the top surface are eligible to form lakes. The fraction of discharge that runs off from inactive lake nodes to lakes is set to zero. At time $t=30$ weeks, the concentration associated with inflow to the model is changed from 0 . to 1 . (expressed in arbitrary units) at 36 specified-pressure nodes in the upper-right corner of the model area (fig. 23). At 100 weeks, lake-water withdrawal from a single surface node (fig. 23) is begun at a constant rate of $1.6 \times 10^{4} \mathrm{~kg} / \mathrm{s}$. 


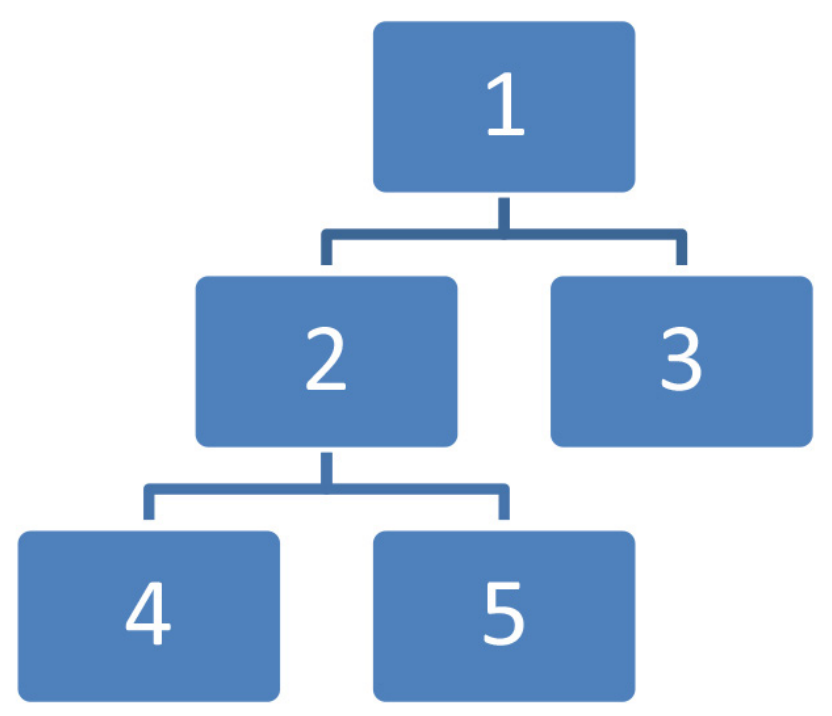

Figure 23. Hierarchy of five lakes identified in the lake example. Lakes 3, 4, and 5 correspond to the right, left, and middle topographic depressions (fig. 23).

\subsubsection{Initial Conditions}

Initially, the groundwater flow is steady state, with no lakes on the surface of the model (fig. 24). Steady-state pressures are obtained through an extra initial simulation. Initial concentrations are zero throughout the model.

\subsubsection{Results}

Figure 25 shows areas of the model surface covered by lake water at a sequence of times during the simulation. Figure 26 shows how lake-water concentrations change with time.

At the start of the simulation, no lakes are on the surface of the model. Topographically driven, fresh groundwater discharges into the topographic depressions and starts to fill them with fresh lake water. By 30 weeks (fig. 26A), lakes 3 (right) and 4 (left) are both full and are spilling over into lake 5 (middle). At this time, the concentration associated with recharge from nodes in the upper-right corner of the model area (fig. 23) changes from 0 . to 1. [dimensionless], creating a source of solute to the model. Solute-containing recharge discharges into lake 3, which in turn spills over into lake 5, and the concentration in both lakes increases (yellow and red curves in fig. 27).

At 47 weeks, lakes 4 and 5 coalesce to form lake 2 (convergence of blue and red curves to form the purple curve in fig. 27). The water in lake 2 is a mixture of the fresh water from lake 4 and the solute-containing water from lake 5 . Because the volume of lake 5 is much larger than that of lake 4, the resulting concentration in lake 2 is close to that of lake 5 . Figure $26 B$ shows the areas covered by lakes 2 and 3 at 60 weeks. At 92 weeks, lakes 2 and 3 coalesce to form lake 1 (convergence of purple and yellow lines to form the black curve in fig. 27). The concentration in lake 1 results from mixing of the water in lake 2 with the smaller but more concentrated volume of water in lake 3.

Figure $26 C$ shows the area of the model surface covered by lake 1 at 100 weeks. At this time, lake-water withdrawal begins, and the lake stage starts to decrease. At 119 weeks, lake 1 splits into its children-lakes 2 and 3 (splitting of the black curve into the yellow and purple curves in fig. 27). Lake-water withdrawal continues from lake 2 . At 346 weeks, lake 2 splits into its children-lakes 4 and 5 (splitting of the purple curve into the blue and red curves in fig. 27). Thereafter, the concentration in lake 4 decreases as the water in lake 4 is flushed out by discharge of fresh groundwater into the lake. Lakes 3 and 4 are full and are spilling over into lake 5 as the stage in lake 5 declines due to continued lake-water withdrawal. As the stage in lake 5 decreases, the head gradient driving groundwater discharge into the lake increases, and steady-state flow is approached as inflows into the lake balance withdrawals. Figure $26 D$ shows the areas covered by lakes 3 , 4, and 5 at 500 weeks, when the flow system is near steady state. 


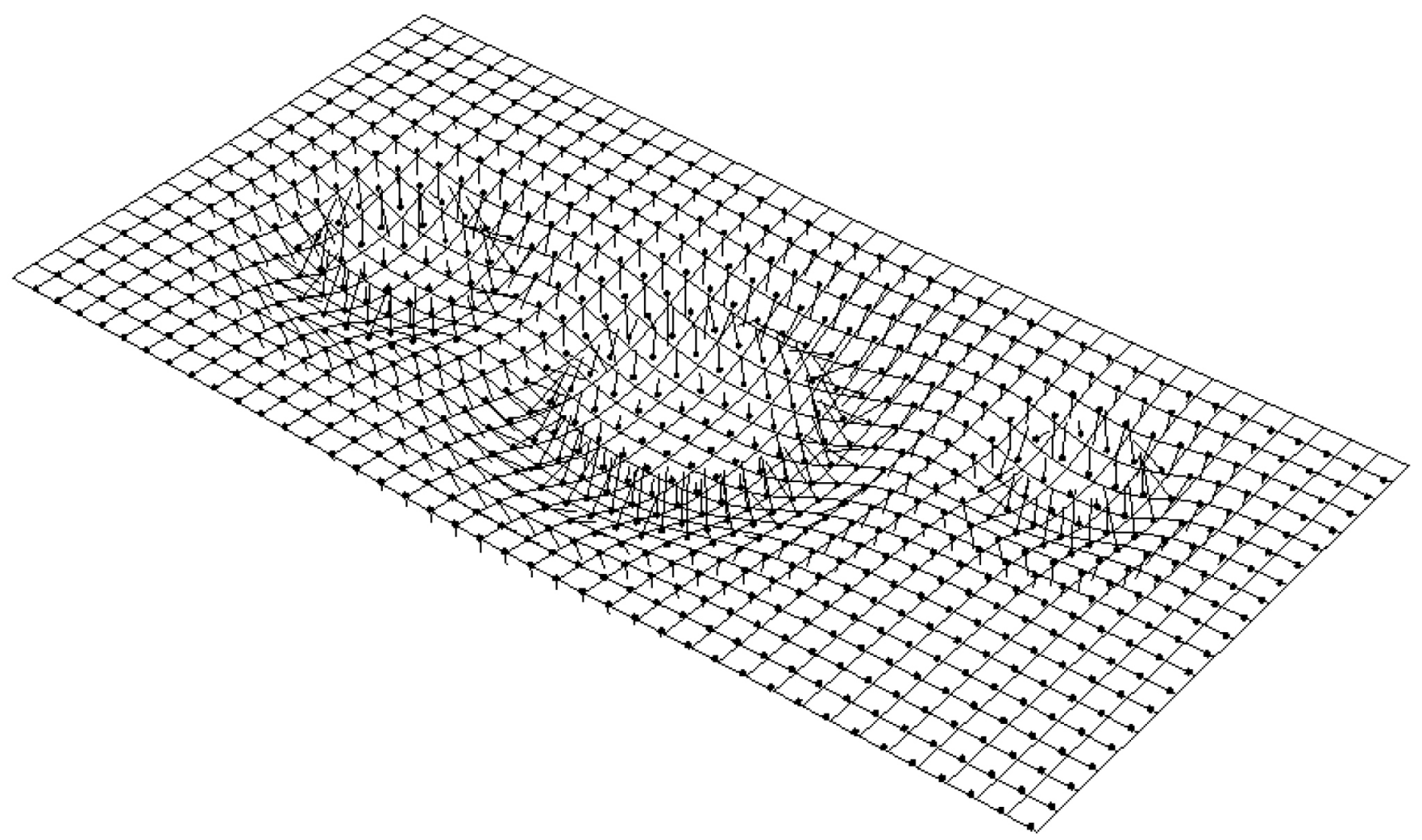

Figure 24. Initial groundwater-flow velocity vectors in the top layer of elements for the lake example. Grid lines show the top surface of the model. Dots indicate element centroids. Velocity vectors point away from element centroids. The direction of each vector indicates the direction of flow at the element centroid, and the length of each vector is proportional to the magnitude of the velocity. (50X vertical exaggeration) 

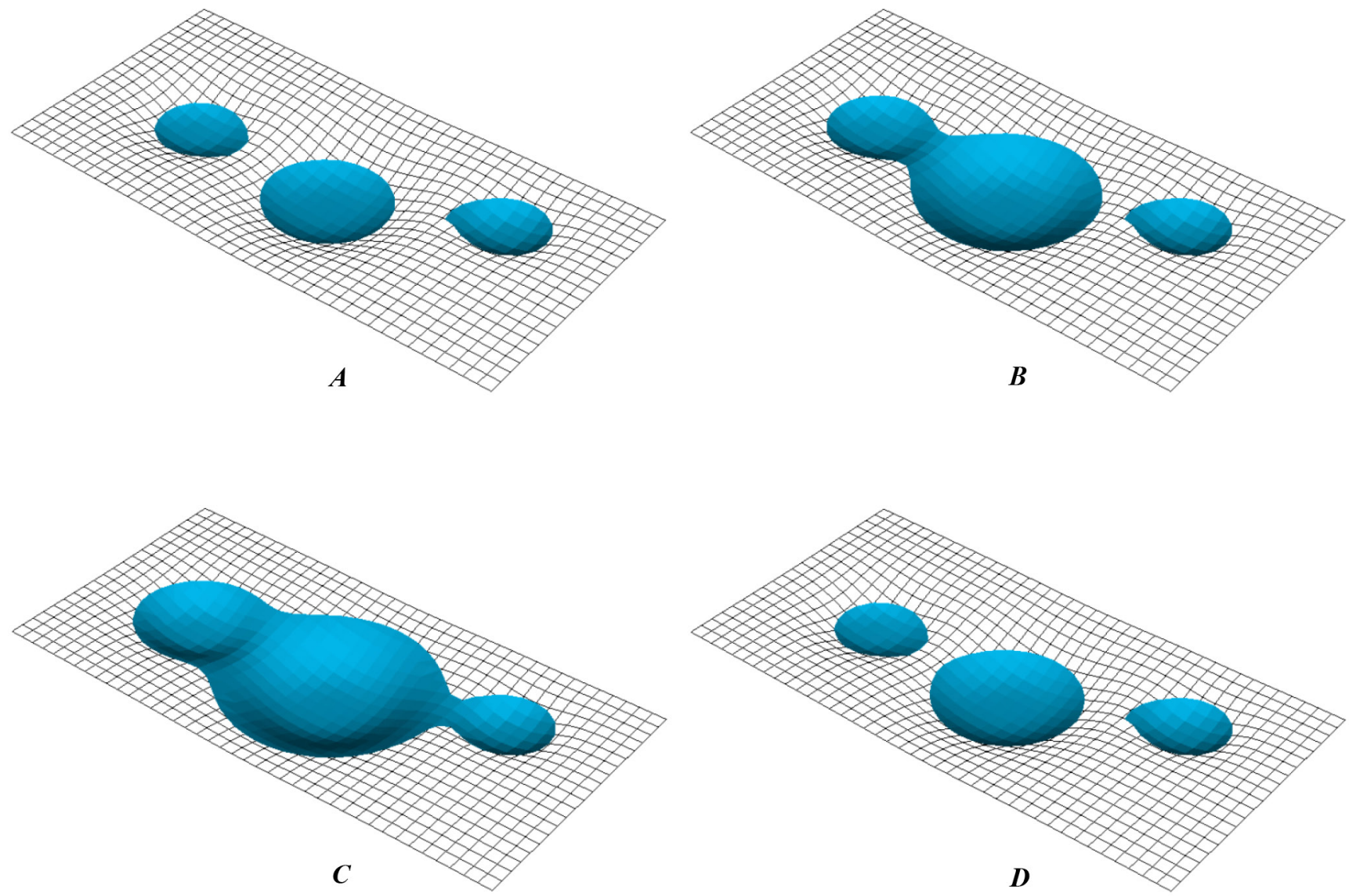

Figure 25. Areas of the model surface covered by lake water (shaded blue) in the lake example. Groundwater flow recharges at higher elevations and discharges at lower elevations (fig. 25), supplying water to form lakes in the topographic depressions. $A, B y$ 30 weeks, lakes 3 (right) and 4 (left) are full and are spilling over onto lake 5 (middle). $B$, By 60 weeks, lakes 4 and 5 are coalesced into their parent, lake 2. C, By 100 weeks, all lakes are coalesced into one large lake (lake 1), and lake-water withdrawal begins. $D$, By 500 weeks, lake stages have declined such that there are once again three distinct lakes, and inflows nearly balance outflows in each lake, so the flow system is near steady state. (50X vertical exaggeration) 


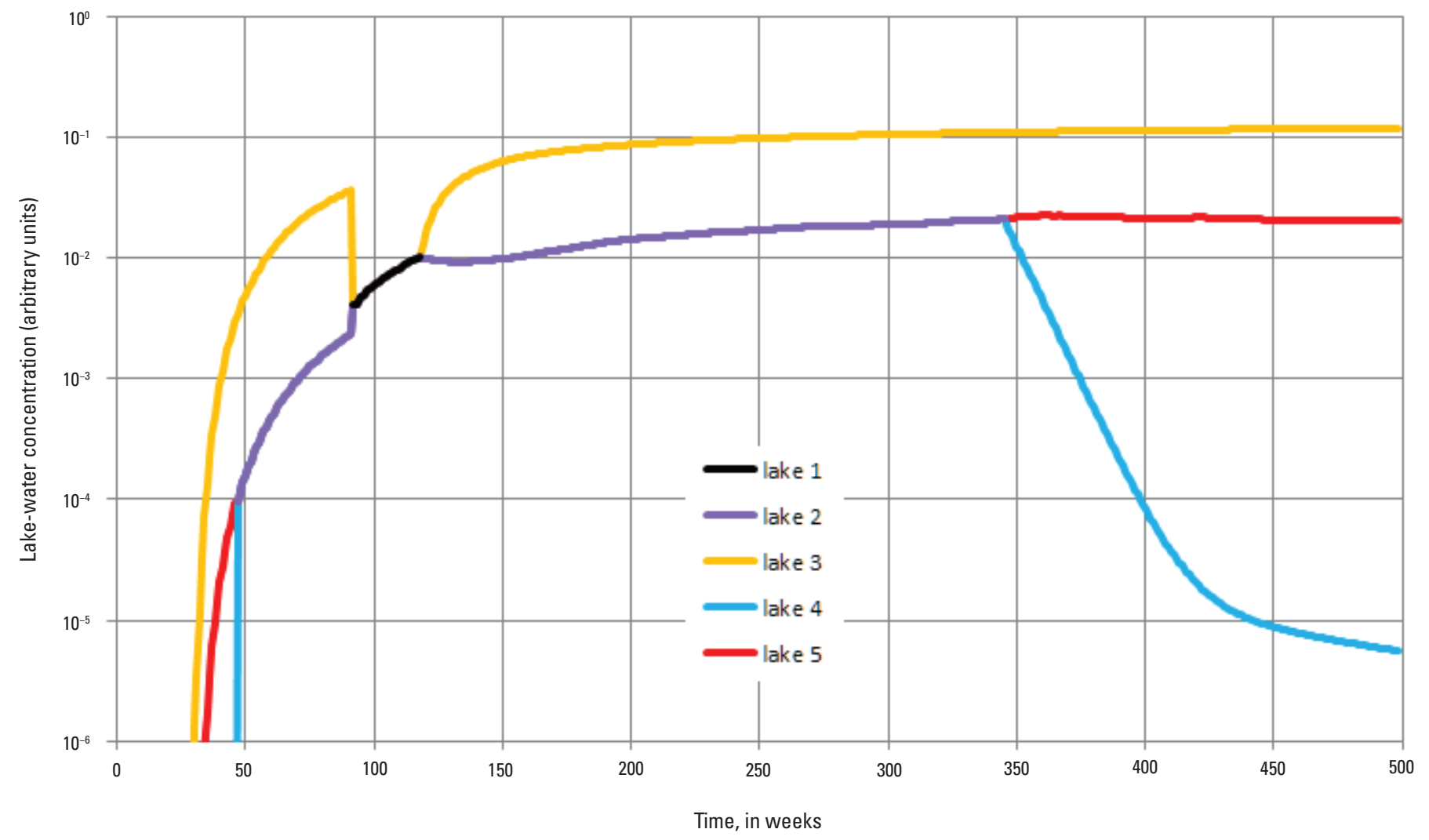

Figure 26. Lake-water concentration as a function of time in the lake example. Concentration is expressed in arbitrary units in which the maximum source concentration is 1 . When two lakes coalesce (lakes 4 and 5 at 47 weeks, and lakes 2 and 3 at 92 weeks), the water in the parent lake is a mixture of the concentrations in the two child lakes. When a lake splits into its children (lake 1 at 119 weeks, and lake 2 at 346 weeks), the concentration in each child lake is initially the concentration from the parent lake. Over time, the concentrations in the two child lakes diverge.

\section{Acknowledgments}

This work was funded in part by Strategic Environmental Research and Development Program (SERDP) grant RC2111. The authors are grateful to the technical reviewers of this report, which include Delwyn Oki and Richard Yager of the U.S. Geological Survey.

\section{References Cited}

Al-Futaisi, A., and Patzek,T.W., 2002, Extension of the Hoshen-Kopelman algorithm to non-lattice environments, Physica A 321, p. 665-678.

Freeze, R.A., and Cherry, J.A., 1979, Groundwater: Englewood Cliffs, N.J., Prentice Hall.

Harbaugh, A.W., 2005, MODFLOW-2005, The U.S. Geological Survey modular ground-water model- the Ground-Water Flow Process: U.S. Geological Survey Techniques and Methods, book 6, chap. A16, variously paginated, at http://pubs.usgs.gov/ $\mathrm{tm} / 2005 / \mathrm{tm} 6 \mathrm{~A} 16 /$.

Hoshen, J., and Kopelman, R., 1976, Percolation and cluster distribution. I. Cluster multiple labeling technique and critical concentration algorithm: Physical Review B, v. 14, no. 8, p. 3438-3445.

Muskat, M., 1937, The flow of homogeneous fluids through porous media: New York, McGraw Hill. 
Polubarinova-Kochina, P., 1962, Theory of ground water movement: Princeton, N.J., Princeton Univ. Press. (Translated into English from the Russian by J.M. Roger de Wiest.)

Van Genuchten, M.Th., 1980, A closed-form equation for predicting the hydraulic conductivity of unsaturated soils: Soil Science Society of America Journal, v. 44, no. 5, p. 892-898.

Voss, C.I., and Provost, A.M., 2002 (Version of September 22, 2010), SUTRA, A model for saturated-unsaturated variabledensity ground-water flow with solute or energy transport: U.S. Geological Survey Water-Resources Investigations Report 02-4231, 291 p., at http://pubs.er.usgs.gov/publication/wri024231.

Winston, R.B., and Voss, C.I., 2004, SutraGUI, a graphical user interface for SUTRA, a model for ground-water flow with solute or energy transport: U.S. Geological Survey Open-File Report 03-285, 114 p., at http://pubs.er.usgs.gov/publication/ofr03285. 



\section{Appendix 1. List of Symbols}

The symbols used in this report are listed below. For each mathematical symbol, the listing includes the equation or section of the text in which the symbol was introduced, the units associated with the symbol, and a brief description of the quantity represented by the symbol.

\section{Generic Units}

[1]

$[\mathrm{E}]$

$[\mathrm{M}]$

[Ms]

\section{Units}

$\left[{ }^{\circ} \mathrm{C}\right]$

[hr]

$[\mathrm{kg}]$

[m]

[s] dimensionless

energy units, or $\left[\mathrm{M} \cdot \mathrm{L}^{2} / \mathrm{s}^{2}\right]$

length units

fluid mass units

solute mass units

degrees Celsius

hours

kilograms

meters

seconds

\section{Special Notation \\ $\sum_{j \neq i}$}

\section{Greek Lowercase}

$\alpha$

$\alpha_{L}$

$\alpha_{T}$

$\beta$

$\varepsilon$

$\eta_{p}$

$\theta$

$\mu$

$v_{p}$

$\rho$

$\varphi$

\section{Greek Uppercase}

$\Delta H_{\text {vap }}$

Roman Lowercase

$a$

$\S 1.10 .4$

(21)

$\S 1.4 .6$ summation over neighbors of node $i$, not including node $i$ itself

$\begin{array}{ll}\S 1.10 .4 & {\left[\mathrm{M} /\left(\mathrm{L} \cdot \mathrm{s}^{2}\right)\right]^{-1}} \\ \S 3.7 .4 & {[\mathrm{~L}]} \\ \S 3.7 .4 & {[\mathrm{~L}]} \\ \S 1.10 .4 & {\left[\mathrm{M} /\left(\mathrm{L} \cdot \mathrm{s}^{2}\right)\right]^{-1}} \\ \S 1.10 .4 & {[1]} \\ (25) & {[1]} \\ \S 1.4 .2 & {\left[{ }^{\circ}\right]} \\ (5) & {[\mathrm{M} /(\mathrm{L} \cdot \mathrm{s})]} \\ (22) & {[\mathrm{L} \cdot \mathrm{s}]} \\ (1) & {\left[\mathrm{M} / \mathrm{L}_{\mathrm{f}}^{3}\right]} \\ \S 3.2 .3 .1 & {[1]}\end{array}$

[E/M] sure conditions in SUTRA 3.0
Latent heat of vaporization of water

Porous matrix compressibility

Longitudinal dispersivity

Transverse dispersivity

Fluid compressibility

Porosity

Extremely large number used in implementing specified-pres-

Angle above horizontal at which a conductive layer is inclined

Fluid viscosity

Symbol for the parameter GNUP used to control enforcement of specified-pressure conditions in previous versions of SUTRA

Fluid density

User-specified ratio of runoff to flow in or out of the groundwater model at a boundary node

Van Genuchten model parameter; see equations (2.8) and (2.21) of Voss and Provost (2002)

Diagonal element in row $i$ of the coefficient matrix of the discretized flow equation 
$\tilde{a}_{i}$

$a_{i j}$

$d_{r i v}$

g

$\underline{g}$

$g_{n}$

$h$

$h_{M}$

$h_{T}$

$k$

$\stackrel{k}{=}$

$k_{r}$

l

n

n

$p$

$p_{1}$

$p_{2}$

$p_{B C}$

$p_{i}$

$p_{j}$

$p_{\text {ext }}$

$p_{w t}$

$p(z)$

$p_{i}^{(0)}$

(6)

$\S 1.1$
[L-s]

$[\mathrm{M} / \mathrm{s}]$ or $\left[\mathrm{E} /\left({ }^{\circ} \mathrm{C} \cdot \mathrm{s}\right)\right]$

$[\mathrm{M} / \mathrm{s}]$

$\left[\mathrm{M}_{\mathrm{s}} / \mathrm{s}\right]$ or [E/s]

$\S 1.4 .6$

$\left[\mathrm{E} /\left(\mathrm{M} \cdot{ }^{\circ} \mathrm{C}\right)\right]$

[L]

[L]

[L]

(1) $\left[\mathrm{L} / \mathrm{s}^{2}\right]$

(A1)

$\S 1.10 .7$

$\S 1.10 .4$

$\S 1.10 .7$

$\S 1.10 .4$

(A2)

$\S 1.2$

$\S 1.2$

$\$ 3.2 .3 .2$
$\left[\mathrm{L} / \mathrm{s}^{2}\right]$

$\left[\mathrm{L} / \mathrm{s}^{2}\right]$

[L]

$\left[\mathrm{M}_{\mathrm{s}} /\left(\mathrm{L}^{2} \cdot \mathrm{s}\right)\right]$

$\left[\mathrm{E} /\left(\mathrm{L}^{\left.2 .{ }^{\circ} \mathrm{C} \cdot \mathrm{s}\right)}\right]\right.$

$\left[\mathrm{L}^{2}\right]$

$\left[\mathrm{L}^{2}\right]$

[1]

[L]

[1]

[L]

$\left[\mathrm{M} /\left(\mathrm{L} \cdot \mathrm{s}^{2}\right)\right]$

$\left[\mathrm{M} /\left(\mathrm{L} \cdot \mathrm{s}^{2}\right)\right]$

$\left[\mathrm{M} /\left(\mathrm{L} \cdot \mathrm{s}^{2}\right)\right]$

$\left[\mathrm{M} /\left(\mathrm{L} \cdot \mathrm{s}^{2}\right)\right]$

$\left[\mathrm{M} /\left(\mathrm{L} \cdot \mathrm{s}^{2}\right)\right]$

$\left[\mathrm{M} /\left(\mathrm{L} \cdot \mathrm{s}^{2}\right)\right]$

$\left[\mathrm{M} /\left(\mathrm{L} \cdot \mathrm{s}^{2}\right)\right]$

$\left[\mathrm{M} /\left(\mathrm{L} \cdot \mathrm{s}^{2}\right)\right]$

$\left[\mathrm{M} /\left(\mathrm{L} \cdot \mathrm{s}^{2}\right)\right]$

$\left[\mathrm{M} /\left(\mathrm{L} \cdot \mathrm{s}^{2}\right)\right]$
Diagonal element in row $i$ of the coefficient matrix of the discretized transport equation

Element in row $i$ and column $j$ of the coefficient matrix of the discretized flow equation

Element in row $i$ and column $j$ of the coefficient matrix of the discretized transport equation

$i$ th element of the right-hand side vector of the discretized flow equation in the absence of a specified-pressure condition at node $i$

$i$ th element of the right-hand side vector of the discretized transport equation in the absence of a specified-concentration or specified-temperature condition at node $i$

Specific heat of water

Extinction depth, below which the rate of fluid loss by evapotranspiration is zero

Depth above which the rate of fluid loss by evapotranspiration is at its maximum (most negative) value

Depth of river water

Gravitational acceleration (magnitude of the gravity vector)

Gravity vector

Gravitational acceleration normal to a conductive layer (normal component of the gravity vector)

Height of water on the downstream side of the dam in the seepage-face example problem

Mass-transfer coefficient

Heat-transfer coefficient

Permeability

Permeability tensor

Relative permeability

Dam width in the seepage-face example problem

Van Genuchten model parameter; see equations (2.8) and (2.21) of Voss and Provost (2002)

Coordinate normal to the surface of a conductive layer

Fluid pressure

First of two pressure values that define a generalized-flow condition

Second of two pressure values that define a generalized-flow condition

Specified pressure

Computed pressure at node $i$

Computed pressure at node $j$

Pressure at an external point that is separated from the model boundary by a conductive layer

Pressure at the water table (assumed to be zero)

Estimated pressure at a boundary-condition node at elevation $z$

Pressure computed at node $i$ under the temporary assumption that $Q_{i}^{P B C}=0$ 


$\begin{array}{lll}p_{i}^{B C} & (21) & {\left[\mathrm{M} /\left(\mathrm{L} \cdot \mathrm{s}^{2}\right)\right]} \\ q & (\mathrm{~A} 1) & {\left[\mathrm{M} /\left(\mathrm{L} \cdot \mathrm{s}^{2}\right)\right]} \\ q_{n} & (\mathrm{~A} 2) & {\left[\mathrm{M} /\left(\mathrm{L}^{2} \cdot \mathrm{s}\right)\right]} \\ q_{E T}^{\max } & (14) & {\left[\mathrm{M} /\left(\mathrm{L}^{2} \cdot \mathrm{s}\right)\right]} \\ r_{3} & (35) & {[\mathrm{L}]} \\ r_{4} & (36) & {[\mathrm{L}]} \\ r_{s} & (37) & {[\mathrm{L}]} \\ t & (31) & {[\mathrm{s}]} \\ t_{0} & (31) & {[\mathrm{s}]} \\ u & \S 3.2 .2 & {\left[\mathrm{M}_{s} / \mathrm{M}\right] \text { or }} \\ & & {\left[{ }^{\circ} \mathrm{C}\right]} \\ u_{l} & (33) & {\left[\mathrm{M}_{s} / \mathrm{M}\right] \text { or }} \\ u_{k} & (33) & {\left[{ }^{\circ} \mathrm{C}\right]} \\ & & {\left[\mathrm{M}_{s} / \mathrm{M}\right] \text { or }} \\ u_{l}^{b c, i n} & (33) & {\left[{ }^{\circ} \mathrm{C}\right]} \\ x & (35) & {\left[\mathrm{M}_{s} / \mathrm{M}\right] \text { or }} \\ y & (35) & {\left[{ }^{\circ} \mathrm{C}\right]} \\ y & (1) & {[\mathrm{L}]} \\ z & (34) & {[\mathrm{L}]} \\ z_{\text {top }} & (1) & {[\mathrm{L}]} \\ z_{w t} & & {[\mathrm{~L}]} \\ & & {[\mathrm{L}]}\end{array}$

\section{Roman Uppercase}

A

$C_{\text {lay }}$

C

$C_{1}$

$C_{2}$

$C_{\text {ext }}$

$C_{\text {sat }}$

$D_{m}$

$F_{l, l^{\prime}}^{\text {spill }}$

$F_{k, l}^{s p i l l}$

$F_{l}^{b c, i n}$

$F_{l}^{b c, o u t}$
$\left[\mathrm{L}^{2}\right]$

$\left[\mathrm{L}^{2} / \mathrm{s}\right]$

$\left[\mathrm{M}_{\mathrm{s}} / \mathrm{M}\right]$

$\left[\mathrm{M}_{\mathrm{s}} / \mathrm{M}\right]$

$\left[\mathrm{M}_{\mathrm{s}} / \mathrm{M}\right]$

$\left[\mathrm{M}_{\mathrm{s}} / \mathrm{M}\right]$

$\left[\mathrm{M}_{\mathrm{s}} / \mathrm{M}\right]$

$\left[\mathrm{L}^{2} / \mathrm{s}\right]$

[M/s]

$[\mathrm{M} / \mathrm{s}]$

$[\mathrm{M} / \mathrm{s}]$

$[\mathrm{M} / \mathrm{s}]$
Specified pressure at boundary node $i$

Mass flux vector

Component of the mass flux vector normal to the surface of a conductive layer

Maximum (most negative) evapotranspiration (ET) flux

Distance (radius) defined for the lakes example problem

Distance (radius) defined for the lakes example problem

Distance (radius) defined for the lakes example problem

Time

Time at which the current time step began

Concentration or thermal energy content

Concentration or thermal energy content in lake $l$

Concentration or thermal energy content in lake $k$

Concentration or thermal energy content of inflow to lake $l$ from groundwater-flow boundary conditions

$x$ coordinate

$y$ coordinate

$z$ coordinate (elevation)

Top-surface elevation in the lakes example problem

Water-table elevation

Area associated with a boundary-condition node

Conductance of a conductive layer that separates an external point from the model boundary

Solute concentration (mass fraction) in the fluid (mass of solute per total mass of fluid)

First of two concentrations that define a generalized-transport condition for solute transport

Second of two concentrations that define a generalized-transport condition for solute transport

Concentration at an external point that is separated from the model boundary by a mass-transfer boundary layer

Concentration of saturated brine

Apparent molecular diffusivity of solute in solution in a porous medium, including tortuosity effects

Rate of spillover from lake $l$ to its sibling, lake $l$ '

Rate of spillover from lake $k$ to lake $l$

Rate of inflow to lake $l$ from groundwater-flow boundary conditions

Rate of outflow from lake $l$ to groundwater-flow boundary conditions 


\begin{tabular}{|c|c|c|}
\hline$F_{l}^{l i m}$ & (32) & {$[\mathrm{M} / \mathrm{s}]$} \\
\hline$F_{l}^{\text {net }}$ & (31) & {$[\mathrm{M} / \mathrm{s}]$} \\
\hline$G_{l}^{b c, i n}$ & (33) & $\begin{array}{l}{\left[\mathrm{M}_{\mathrm{s}} / \mathrm{M}\right]} \\
{[\mathrm{E} / \mathrm{s}]}\end{array}$ \\
\hline$G_{l}^{b c, \text { out }}$ & (33) & $\begin{array}{l}{\left[\mathrm{M}_{\mathrm{s}} / \mathrm{M}\right]} \\
{[\mathrm{E} / \mathrm{s}]}\end{array}$ \\
\hline$H$ & $\S 1.10 .7$ & {$[\mathrm{~L}]$} \\
\hline$K$ & (4) & {$[\mathrm{L} / \mathrm{s}]$} \\
\hline$L$ & (4) & {$[\mathrm{L}]$} \\
\hline$M_{l}$ & (31) & {$[\mathrm{M}]$} \\
\hline$M_{l}^{0}$ & $(31)$ & {$[\mathrm{M}]$} \\
\hline$N A L$ & $(32)$ & {$[1]$} \\
\hline$Q$ & $\S 1.1$ & {$[\mathrm{M} / \mathrm{s}]$} \\
\hline$Q_{1}$ & $\S 1.2$ & {$[\mathrm{M} / \mathrm{s}]$} \\
\hline$Q_{2}$ & $\S 1.2$ & {$[\mathrm{M} / \mathrm{s}]$} \\
\hline$Q_{d a m}$ & $\S 1.10 .7$ & {$\left[\mathrm{~L}^{3} / \mathrm{s}\right.$ per unit thickness $]$} \\
\hline$Q_{f d}$ & (3) & {$[\mathrm{M} / \mathrm{s}]$} \\
\hline$Q_{I N}$ & $\S 3.2 .3 .1$ & {$[\mathrm{M} / \mathrm{s}]$} \\
\hline$Q_{i n f}$ & (15) & {$[\mathrm{M} / \mathrm{s}]$} \\
\hline$Q_{\max }$ & (9) & {$[\mathrm{M} / \mathrm{s}]$} \\
\hline$Q_{P B C}$ & $\S 3.2 .3 .2$ & {$[\mathrm{M} / \mathrm{s}]$} \\
\hline$Q_{P B G}$ & $\S 3.2 .3 .3$ & {$[\mathrm{M} / \mathrm{s}]$} \\
\hline$Q_{P B G 1}$ & $\S 1.2$ & {$[\mathrm{M} / \mathrm{s}]$} \\
\hline$Q_{P B G 2}$ & $\S 1.2$ & {$[\mathrm{M} / \mathrm{s}]$} \\
\hline$Q_{r i v}$ & (9) & {$[\mathrm{M} / \mathrm{s}]$} \\
\hline$Q_{U I N C}$ & $\S 3.2 .3 .5$ & $\begin{array}{l}{\left[\mathrm{M}_{\mathrm{s}} / \mathrm{s}\right] \text { or }} \\
{[\mathrm{E} / \mathrm{s}]}\end{array}$ \\
\hline$Q^{U}$ & $\S 1.6$ & $\begin{array}{l}{\left[\mathrm{M}_{\mathrm{s}} / \mathrm{s}\right] \text { or }} \\
{[\mathrm{E} / \mathrm{s}]}\end{array}$ \\
\hline$Q_{1}^{U}$ & $\S 1.6$ & $\begin{array}{l}{\left[\mathrm{M}_{\mathrm{s}} / \mathrm{s}\right] \text { or }} \\
{[\mathrm{E} / \mathrm{s}]}\end{array}$ \\
\hline$Q_{2}^{U}$ & $\S 1.6$ & $\begin{array}{l}{\left[\mathrm{M}_{\mathrm{s}} / \mathrm{s}\right] \text { or }} \\
{[\mathrm{E} / \mathrm{s}]}\end{array}$ \\
\hline$Q_{i}^{P B C}$ & $(21)$ & {$[\mathrm{M} / \mathrm{s}]$} \\
\hline$Q_{i}^{U B C}$ & $\S 2.3$ & $\begin{array}{l}{\left[\mathrm{M}_{\mathrm{s}} / \mathrm{s}\right] \text { or }} \\
{[\mathrm{E} / \mathrm{s}]}\end{array}$ \\
\hline
\end{tabular}

Rate of outflow from lake $l$ due to lake-area limitations

Net rate of inflow of water to or outflow of water from lake $l$

Rate of inflow of solute mass or energy to lake $l$ from groundwater-transport boundary conditions

Rate of outflow of solute mass or energy from lake $l$ to groundwater-transport boundary conditions

Height of water on the upstream side of the dam in the seepageface example problem

Hydraulic conductivity

Thickness of a conductive layer

Mass of water in lake $l$ at time $t$

Mass of water in lake $l$ at time $t_{0}$

Number of active lakes

Rate of fluid-mass gain or loss (flow)

First of two rates of fluid-mass gain or loss (flow) that define a generalized-flow condition

Second of two rates of fluid-mass gain or loss (flow) that define a generalized-flow condition

Discharge through the dam in the seepage-face example problem

Rate of free (gravity-driven) drainage of fluid across a conductive layer

Rate of fluid-mass gain or loss (flow) at a fluid source or sink node

Fluid-mass infiltration rate associated with a seepage-face boundary condition

Maximum rate of fluid-mass gain or loss (flow) associated with a river boundary condition

Rate of fluid-mass gain or loss (flow) at a specified-pressure node

Rate of fluid-mass gain or loss (flow) at a generalized-flow node

Symbol used to represent $Q_{l}$ in input datasets that define generalized-flow conditions

Symbol used to represent $Q_{2}$ in input datasets that define generalized-flow conditions

Rate of fluid-mass gain or loss (flow) driven by the head supplied by a column of river water

Rate of gain or loss of solute mass or energy at a solute mass or energy source/sink node

Rate of gain or loss of solute mass or energy

First of two rates of gain or loss of solute or energy that define a generalized-transport condition

Second of two rates of gain or loss of solute or energy that define a generalized-transport condition

Rate of gain or loss of fluid mass associated with a specifiedpressure condition at node $i$

Rate of gain or loss of solute or energy associated with a specified-concentration or specified-temperature condition at node $i$ 


\begin{tabular}{|c|c|c|}
\hline$Q_{U B C}^{U}$ & $\$ 3.2 .3 .6$ & $\begin{array}{l}{\left[\mathrm{M}_{\mathrm{s}} / \mathrm{s}\right] \text { or }} \\
{[\mathrm{E} / \mathrm{s}]}\end{array}$ \\
\hline$Q_{U B G}^{U}$ & $\$ 3.2 .3 .7$ & $\begin{array}{l}{\left[\mathrm{M}_{\mathrm{s}} / \mathrm{s}\right] \text { or }} \\
{[\mathrm{E} / \mathrm{s}]}\end{array}$ \\
\hline$Q_{U B G I}^{U}$ & $\S 1.6$ & $\begin{array}{l}{\left[\mathrm{M}_{\mathrm{s}} / \mathrm{s}\right] \text { or }} \\
{[\mathrm{E} / \mathrm{s}]}\end{array}$ \\
\hline$Q_{U B G 2}^{U}$ & $\S 1.6$ & $\begin{array}{l}{\left[\mathrm{M}_{\mathrm{s}} / \mathrm{s}\right] \text { or }} \\
{[\mathrm{E} / \mathrm{s}]}\end{array}$ \\
\hline$S_{o p}$ & $\S 1.10 .4$ & {$\left[\mathrm{M} /\left(\mathrm{L} \cdot \mathrm{s}^{2}\right)\right]^{-1}$} \\
\hline$S_{w}$ & $\S 1.10 .4$ & [1] \\
\hline$S_{\text {wres }}$ & $\S 1.10 .4$ & [1] \\
\hline$T$ & (16) & {$\left[{ }^{\circ} \mathrm{C}\right]$} \\
\hline$T_{1}$ & (17) & {$\left[{ }^{\circ} \mathrm{C}\right]$} \\
\hline$T_{2}$ & (17) & {$\left[{ }^{\circ} \mathrm{C}\right]$} \\
\hline$T_{e x t}$ & (16) & {$\left[{ }^{\circ} \mathrm{C}\right]$} \\
\hline$U$ & (1.6) & $\begin{array}{l}{\left[{ }^{\circ} \mathrm{C}\right] \text { or }} \\
{\left[\mathrm{M}_{s} / \mathrm{M}\right]}\end{array}$ \\
\hline$U_{1}$ & $\S 1.6$ & $\begin{array}{l}{\left[{ }^{\circ} \mathrm{C}\right] \text { or }} \\
{\left[\mathrm{M}_{\mathrm{s}} / \mathrm{M}\right]}\end{array}$ \\
\hline$U_{2}$ & $\S 1.6$ & $\begin{array}{l}{\left[{ }^{\circ} \mathrm{C}\right] \text { or }} \\
{\left[\mathrm{M}_{\mathrm{s}} / \mathrm{M}\right]}\end{array}$ \\
\hline$U_{B C}$ & $\$ 3.2 .3 .6$ & $\begin{array}{l}{\left[{ }^{\circ} \mathrm{C}\right] \text { or }} \\
{\left[\mathrm{M}_{\mathrm{s}} / \mathrm{M}\right]}\end{array}$ \\
\hline$U_{B G 1}$ & $\S 1.6$ & $\begin{array}{l}{\left[{ }^{\circ} \mathrm{C}\right] \text { or }} \\
{\left[\mathrm{M}_{s} / \mathrm{M}\right]}\end{array}$ \\
\hline$U_{B G 2}$ & $\S 1.6$ & $\begin{array}{l}{\left[{ }^{\circ} \mathrm{C}\right] \text { or }} \\
{\left[\mathrm{M}_{s} / \mathrm{M}\right]}\end{array}$ \\
\hline$U_{i}$ & $\S 2.3$ & $\begin{array}{l}{\left[{ }^{\circ} \mathrm{C}\right] \text { or }} \\
{\left[\mathrm{M}_{s} / \mathrm{M}\right]}\end{array}$ \\
\hline$U_{j}$ & (28) & $\begin{array}{l}{\left[{ }^{\circ} \mathrm{C}\right] \text { or }} \\
{\left[\mathrm{M}_{s} / \mathrm{M}\right]}\end{array}$ \\
\hline$U_{i}^{(0)}$ & (28) & $\begin{array}{l}{\left[{ }^{\circ} \mathrm{C}\right] \text { or }} \\
{\left[\mathrm{M}_{s} / \mathrm{M}\right]}\end{array}$ \\
\hline$U_{i}^{B C}$ & $\S 2.3$ & $\begin{array}{l}{\left[{ }^{\circ} \mathrm{C}\right] \text { or }} \\
{\left[\mathrm{M}_{\mathrm{s}} / \mathrm{M}\right]}\end{array}$ \\
\hline
\end{tabular}

Rate of gain or loss of solute mass or energy at a specifiedconcentration or specified-temperature node

Rate of gain or loss of solute mass or energy at a generalizedtransport node

Symbol used to represent $Q_{1}^{U}$ in input datasets that define generalized-transport conditions

Symbol used to represent $Q_{2}^{U}$ in input datasets that define generalized-transport conditions

Specific pressure storativity

Water saturation (saturation) (volume of water per volume of voids)

Residual water saturation

Fluid temperature

First of two temperatures that define a generalized-transport condition for energy transport

Second of two temperatures that define a generalized-transport condition for energy transport

Fluid temperature at an external point that is separated from the model boundary by a thermal boundary layer

Solute concentration or temperature

First of two concentrations or temperatures that define a generalized-transport condition

Second of two concentrations or temperatures that define a generalized-transport condition

Specified concentration or temperature

Symbol used to represent $U_{l}$ in input datasets that define generalized-transport conditions

Symbol used to represent $U_{2}$ in input datasets that define generalized-transport conditions

Computed concentration or temperature at node $i$

Computed concentration or temperature at node $j$

Concentration or temperature computed at node $i$ under the temporary assumption that $Q_{i}^{U B C}=0$

Specified concentration or temperature at boundary node $i$ 


\section{Appendix 2. Flow Across a Conductive Layer}

The mass flux vector for groundwater flow within the conductive layer, $\underline{q}\left[\mathrm{M} /\left(\mathrm{L}^{2} \cdot \mathrm{s}\right)\right]$, is given by

$$
\underline{q}=-\frac{\rho \underline{\underline{k}}}{\mu}(\underline{\nabla p}+\rho \underline{g})
$$

where $\rho$ is fluid density $\left[\mathrm{M} / \mathrm{L}^{3}\right], \mu$ is fluid viscosity $[\mathrm{M} /(\mathrm{L} \cdot \mathrm{s})], k$ is the permeability tensor $\left[\mathrm{L}^{2}\right]$ within the layer, $g$ is the gravity vector $\left[\mathrm{L} / \mathrm{s}^{2}\right]$, and $p$ is pressure $\left[\mathrm{M} /\left(\mathrm{L} \cdot \mathrm{s}^{2}\right)\right]$. If the layer is assume $\overline{\bar{y}}$ to be isotropic, and permeability, density, viscosity, and gravity can be considered uniform throughout the layer, the component of the flux normal to the surface of the layer, $q_{n}$, can be written as

$$
q_{n}=-\frac{\rho k}{\mu}\left(\frac{\partial p}{\partial n}+\rho g_{n}\right)
$$

and integrated across the thickness of the layer to give

$$
q_{n} L=-\frac{\rho k}{\mu}\left(p_{e x t}-p+\rho g_{n} L\right)
$$

Here, $n$ is the coordinate [L] in the normal direction, $L$ is the thickness [L] of the layer, $k$ is the isotropic permeability, $g_{n}$ is the component of gravity normal to the surface of the layer, $p\left[\mathrm{M} /\left(\mathrm{L} \cdot \mathrm{s}^{2}\right)\right]$ is the pressure on the side of the layer adjacent to the model boundary, and $p_{\text {ext }}\left[\mathrm{M} /\left(\mathrm{L} \cdot \mathrm{s}^{2}\right)\right]$ is the "external" pressure on the other side of the layer. Multiplication of both sides of (A3) by the area, $A\left[\mathrm{~L}^{2}\right]$, associated with the boundary node and rearrangement yields an expression for the total mass flow rate of groundwater through the layer, $Q[\mathrm{M} / \mathrm{s}]$ :

$$
Q=\frac{k A \rho}{\mu L}\left(p_{\text {ext }}-p\right)+\frac{k A \rho^{2} g_{n}}{\mu}
$$

which can be rewritten as (3)-(6). If permeability, density, viscosity, or gravity varies spatially within the intervening medium, choosing a representative, constant value preserves the linear form of equation (A4). 


\section{Appendix 3. Input Data List}

This section describes SUTRA input datasets that are new or have been modified in Version 3.0. The datasets described here follow the general rules for input described in the SUTRA documentation (Voss and Provost, 2002). A complete, up-to-date description of all SUTRA input datasets is maintained on the USGS Web site at https://doi.org/10.5066/P9PPEHHM.

\section{List of New or Modified Input Data for the Main Input File (.inp)}

\section{Model Version: SUTRA 3.0}

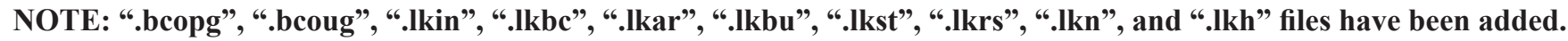

The file "SUTRA.FIL" contains file assignments (one line for each assignment) in the following format:

\begin{tabular}{|c|c|c|}
\hline Variable & Type & Description \\
\hline \multirow[t]{25}{*}{ FTYPE } & Character & File type (within single quotes ' " as shown below). Valid values are as follows: \\
\hline & & 'INP' = “.inp” input file (main input) \\
\hline & & 'BCS' = “.bcs" input file (time-dependent sources and boundary conditions) \\
\hline & & 'ICS' = “.ics” input file (initial conditions) \\
\hline & & 'LKIN' = “.lkin” input file (lake main input) \\
\hline & & 'LKBC' = “.lkbc" input file (lake-boundary condition interactions) \\
\hline & & 'LKAR'= “.lkar” input file (lake-area nodes) \\
\hline & & 'LST' = “.Ist”" output file (main output listing) \\
\hline & & 'RST' = “.rst” output file (restart conditions) \\
\hline & & 'NOD' = “.nod” output file (nodewise results) \\
\hline & & 'ELE’ = “.ele” output file (elementwise results) \\
\hline & & 'OBS’ = “.obs” output file (observations) \\
\hline & & 'OBC' = “.obc" output file (observations) \\
\hline & & 'BCOF' = “.bcof” output file (specifications and results at fluid-source/sink nodes) \\
\hline & & 'BCOS' = “.bcos" output file (specifications and results at solute/energy-source/sink nodes) \\
\hline & & 'BCOP' = “.bcop” output file (specifications and results at specified-pressure nodes) \\
\hline & & $\begin{array}{l}\text { 'BCOU' }=\text { “.bcou” output file (specifications and results at specified-concentration/temperature } \\
\text { nodes) }\end{array}$ \\
\hline & & 'BCOPG' = “.bcopg” output file (specifications and results at generalized-flow nodes) \\
\hline & & 'BCOUG' = “.bcoug”' output file (specifications and results at generalized-transport nodes) \\
\hline & & ‘LKBU’ = “.lkbu” output file (lake budgets) \\
\hline & & 'LKST’ = “.lkst” output file (lake stages) \\
\hline & & 'LKRS’ = “.lkrs" output file (lake restart) \\
\hline & & 'LKN' = “.Ikn” output file (lake numbers for surface nodes) \\
\hline & & 'LKH’ = “.lkh” output file (lake hierarchy) \\
\hline & & 'SMY' = “.smy” output file ( simulation summary) \\
\hline IUNIT & Integer & $\begin{array}{l}\text { FORTRAN unit number to be assigned to the file. If IUNIT is not a valid FORTRAN unit number } \\
\text { or if it is already assigned to another file, SUTRA will assign the next available unit number after } \\
\text { IUNIT. (Unit numbers less than } 11 \text { are assumed to be unavailable.) }\end{array}$ \\
\hline FNAME & Character & Full name of the file (within single quotes " ' as shown below). \\
\hline
\end{tabular}




\section{Notes:}

Assignments for the “.bcs", “.nod”, “.ele”, “.obs”, “.obc”, “.bcof”, “.bcos”, “.bcop”, “.bcou”, and ".lkst” files are optional. If any of these assignments are omitted, the corresponding output files will not be created by SUTRA. Assignment for the ".smy" file is also optional - if not assigned, it will receive the file name "SUTRA.SMY" and an automatically generated unit number, by default. Assignment for the ".rst" file is required if ISTORE $\neq 0$ in dataset 4, and assignment for the ".Ikrs" file is required in addition if the lake capability is used. Assignments for the ".inp", ".ics", and ".Ist" files are always required. Assignments for the ".lkin", “.lkbc", ".lkbu”, “.lkn”, and ".lkh" files are always required when the lake capability is used. Assignment for the ".lkar" file is optional - if the lake capability is used and the ".lkar" file is not assigned, all nodes on the top surface of the model are eligible to form lakes. Assignments may be listed in any order. Assignment of unit numbers is performed by SUTRA in the order in which the files are listed, except for the ".obs" and ".obc" files. The latter are always assigned last by SUTRA.

For the observation output files (".obs" and ".obc"), FNAME is a base filename from which the actual filenames are automatically derived by SUTRA. SUTRA generates one observation output file for each combination of schedule and output format that appears in the observation specifications in dataset 8D of the main input (“.inp”) file. For an example of this, see the description of dataset $8 \mathrm{D}$.

Multiple ".bcs" files may be assigned. At the beginning of each time step, SUTRA checks each ".bcs" file and reads in any boundary condition specifications that pertain to that time step. The ".bcs" files are checked in the order in which they are listed in "SUTRA.FIL". If the ".bcs" files contain multiple specifications of the same kind, at the same node, on the same time step, the specification read in last overrides any previous specifications.

\section{Example:}

\begin{tabular}{|c|c|c|}
\hline 'INP' & 50 & 'project.inp' \\
\hline 'BCS' & 52 & 'project.bcs' \\
\hline 'ICS' & 55 & 'project.ics' \\
\hline 'LST' & 60 & 'project.1st' \\
\hline 'RST' & 66 & 'project.rst' \\
\hline 'NOD' & 70 & 'project.nod' \\
\hline 'ELE' & 75 & 'project.ele' \\
\hline 'OBS' & 80 & 'project.obs' \\
\hline 'OBC' & 85 & 'project.obc' \\
\hline 'BCOF' & 91 & 'project.bcof' \\
\hline 'BCOS' & 93 & 'project.bcos' \\
\hline 'BCOP' & 92 & 'project.bcop' \\
\hline 'BCOU' & 94 & 'project.bcou' \\
\hline 'BCOPG' & 95 & 'project.bcopg' \\
\hline 'BCOUG' & 96 & 'project.bcoug' \\
\hline 'SMY' & 98 & 'project.smy' \\
\hline 'LKIN' & 40 & 'project.lkin' \\
\hline 'LKBC' & 41 & 'project.lkbc' \\
\hline 'LKAR' & 42 & 'project.lkar' \\
\hline 'LKBU' & 43 & 'project.lkbu' \\
\hline 'LKST' & 44 & 'project.lkst' \\
\hline 'LKRS' & 45 & 'project.lkrs' \\
\hline 'LKN' & 46 & 'project.lkn' \\
\hline 'LKH' & 47 & 'project.lkh' \\
\hline
\end{tabular}


DATASET 3: Simulation Control Numbers (one line)

NOTE: Input variables NPBG and NUBG have been added.

\begin{tabular}{lll}
\hline \multicolumn{1}{c}{ Variable } & \multicolumn{1}{c}{ Type } & \multicolumn{1}{c}{ Description } \\
\hline NN & Integer & Exact number of nodes in finite element mesh. \\
NE & Integer & Exact number of elements in finite element mesh. \\
NPBC & Integer & Exact number of nodes at which pressure is a specified constant value or function of time. \\
NUBC & Integer & $\begin{array}{l}\text { Exact number of nodes at which temperature or concentration is a specified constant value or } \\
\text { function of time. }\end{array}$ \\
NSOP & Integer & Exact number of nodes at which a fluid source/sink is a specified constant value or function of time. \\
NSOU & Integer & Exact number of nodes at which an energy or solute mass source/sink is a specified constant value or \\
& & function of time. \\
NPBG & Integer & Exact number of nodes at which a generalized-flow condition is specified. \\
NUBG & Integer & Exact number of nodes at which a generalized-transport condition is specified. \\
NOBS & Integer & Exact number of points at which observations will be made. Set to zero for no observations. \\
\hline
\end{tabular}

Note:

The order in which NPBC, NUBC, NSOP, and NSOU are listed above is different from the order in which the corresponding datasets $(19,20,17$, and 18) appear in the ".inp" file.

DATASET 5: Upstream Weighting Parameter (one line)

NOTE: Parameters GNUP and GNUU are no longer needed and have been removed.

\begin{tabular}{lcc}
\hline Variable & \multicolumn{1}{c}{ Type } & \multicolumn{1}{c}{ Description } \\
\hline UP & Real & $\begin{array}{c}\text { Fractional upstream weight for stabilization of oscillations in results due to highly advective } \\
\text { transport or unsaturated flow. UP may be given any value from } 0.0 \text { to }+1.0 \text {. UP }=0.0 \text { implies no } \\
\text { upstream weighting (Galerkin method). UP }=0.5 \text { implies } 50 \% \text { upstream weighting. UP }=1.0 \\
\text { implies full }(100 \%) \text { upstream weighting. Recommended value is zero. }\end{array}$ \\
& $\begin{array}{l}\text { WARNING: Upstream weighting increases the local effective longitudinal dispersivity of the simula- } \\
\text { tion by approximately UP* }(\Delta L L) / 2 \text { where } \Delta L L \text { is the local distance between element sides along } \\
\text { the direction of flow. (See section } 7.2 \text { of the main SUTRA documentation (Voss and Provost, } \\
\text { 2002)). Note that the amount of this increase varies from place to place, depending on flow direc- } \\
\text { tion and element size. Thus, a nonzero value for UP actually changes the value of longitudinal } \\
\text { dispersivity used by the simulation and broadens otherwise sharp concentration, temperature, or } \\
\text { saturation fronts. }\end{array}$ \\
\hline
\end{tabular}

DATASET 6: Temporal Control and Solution Cycling Data

NOTE: The list of input parameters remains unchanged from SUTRA Version 2.2. However, schedule "TIME_STEPS" must now be defined before any other schedules are defined, and time-step numbers and times must now be listed in ascending order within each 'STEP LIST' or 'TIME LIST' schedule. 
DATASET 8E: Output Controls and Options for “.bcof”, “.bcos”, “.bcop”, “.bcou”, “.bcopg”, and “.bcoug” Files (Source and Boundary Condition Specifications and Results Listed in Columns) (one line)

\section{NOTE: Input variables NBGPPR and NBGUPR have been added.}

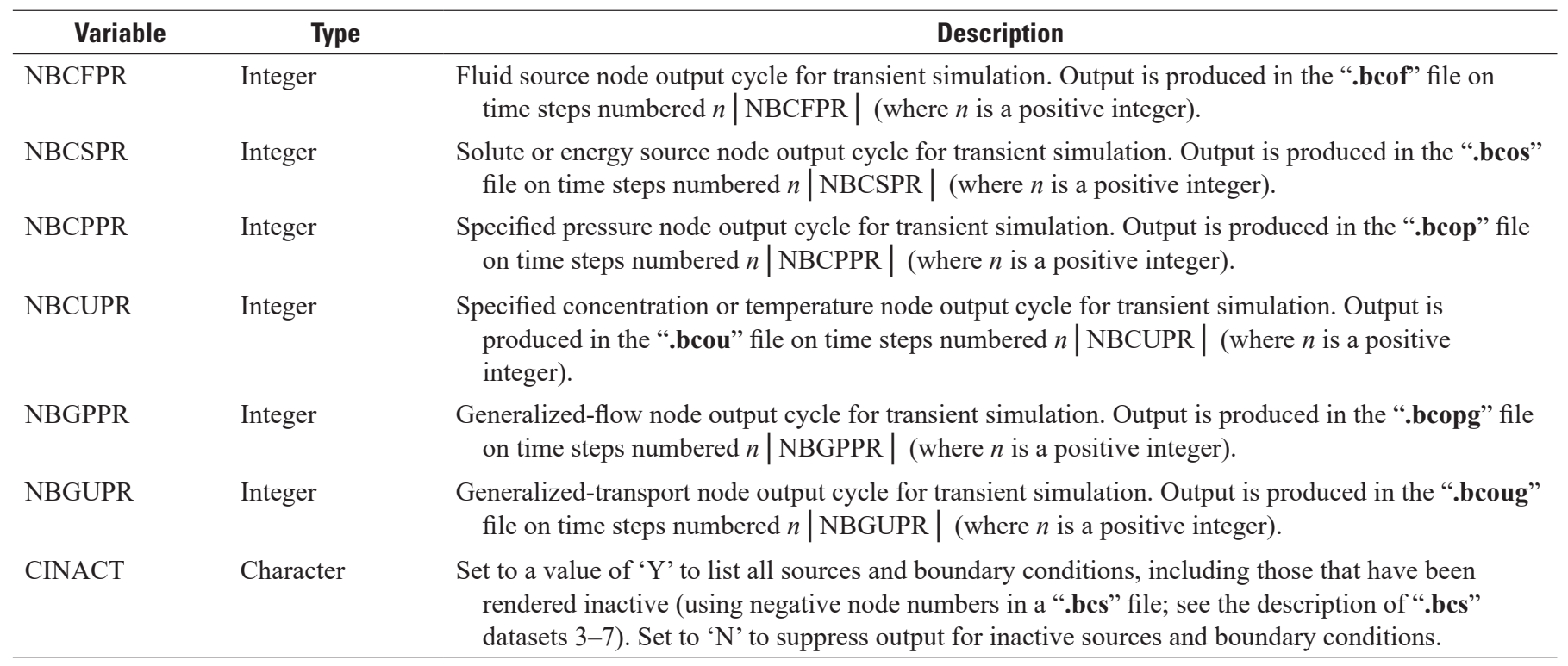

Notes:

For transient simulations, output is also produced on the first and last time steps. For steady-state simulations, output is produced irrespective of the values of the output control variables.

The information that is output to the ".bcof", “.bcos", “.bcop”, and ".bcou” files is described in section 5.9 of the main SUTRA documentation (Voss and Provost, 2002). The information that is output to the ".bcopg" and ".bcoug" files is described in section 1.8 of this document, "Budget Output and Boundary-Condition Output Files."

\section{Example:}

To output source and boundary condition information to the “.bcof”, “.bcos”, “.bcop”, “.bcou”, “.bcopg”, and“.bcoug” files every 10 time steps, suppressing output for inactive sources and boundary conditions, write the following:

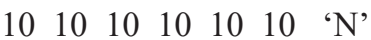


DATASET 21A: Constant Values for Generalized-Flow Nodes (one line for each of NPBG generalized pressure nodes as indicated in dataset 3 , plus one line)

NOTE: This is an entirely new dataset.

$\underline{\mathrm{O} M}$ I T when there are no generalized-flow nodes $(\mathrm{NPBG}=0)$.

Specifications made in this dataset are constant values that are used by SUTRA unless/until they are superseded by timedependent specifications in dataset $7 \mathrm{~A}$ of an optional ".bcs" file.

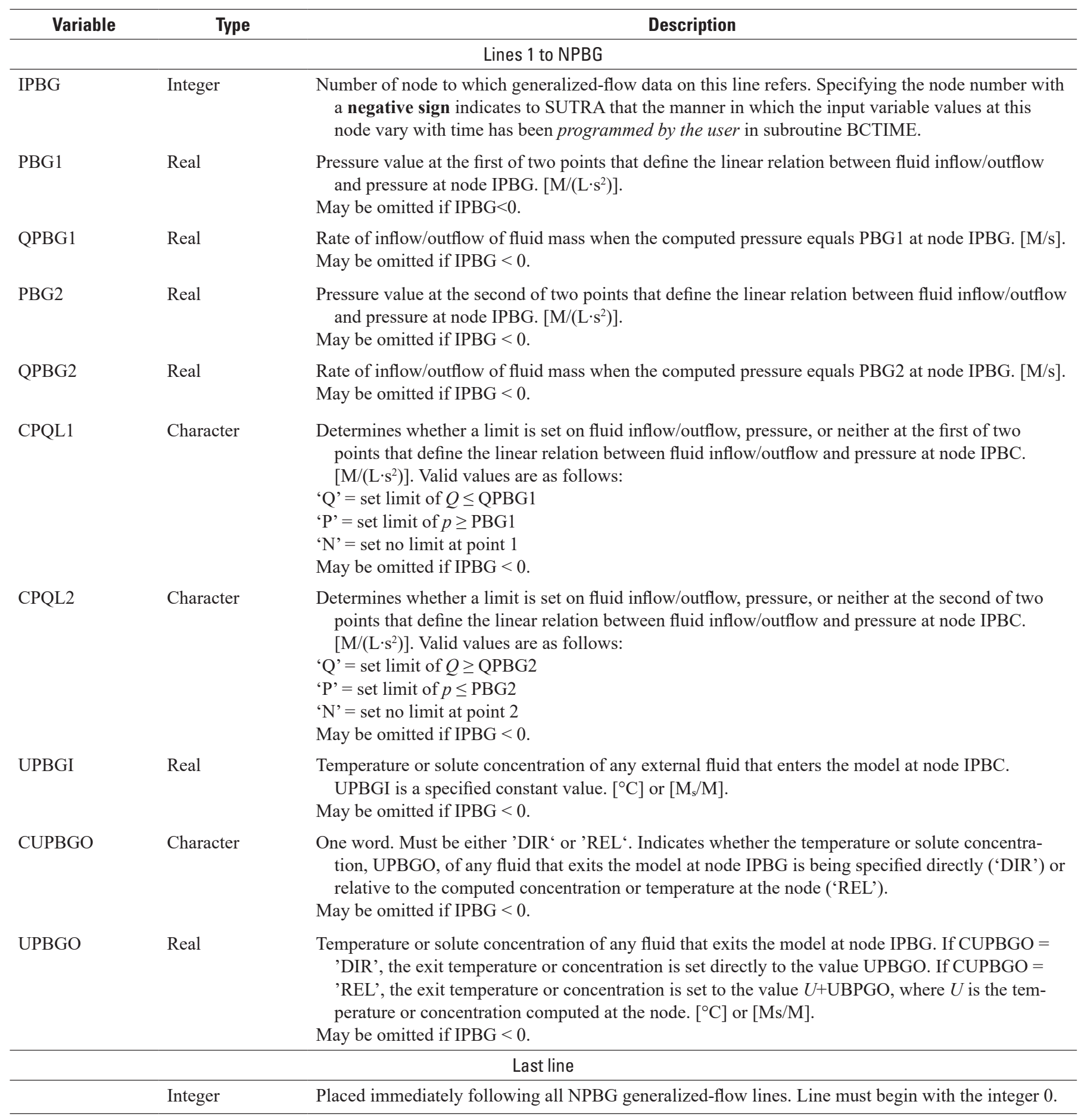


DATASET 21B: Constant Values for Generalized-Transport Nodes (one line for each of NUBG generalized-transport nodes indicated in dataset 3 , plus one line)

NOTE: This is an entirely new dataset.

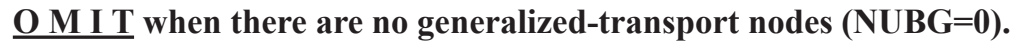

Specifications made in this dataset are constant values that are used by SUTRA unless/until they are superseded by timedependent specifications in dataset 7B of an optional ".bcs" file.

\begin{tabular}{|c|c|c|}
\hline Variable & Type & Description \\
\hline \multicolumn{3}{|r|}{ Lines 1 to NUBG } \\
\hline IUBG & Integer & $\begin{array}{l}\text { Number of node to which generalized-transport data on this line refers. Specifying the node number } \\
\text { with a negative sign indicates to SUTRA that the manner in which the input variable values at } \\
\text { this node vary with time has been programmed by the user in subroutine BCTIME. }\end{array}$ \\
\hline UBG1 & Real & $\begin{array}{l}\text { Concentration or temperature value at the first of two points that define the linear relation be- } \\
\text { tween solute mass or energy inflow/outflow and concentration or temperature at node IUBG. } \\
{\left[\mathrm{M}_{\mathrm{s}} / \mathrm{M} \text { or } \mathrm{C}^{\circ}\right] \text {. }} \\
\text { May be omitted if IUBG }<0 \text {. }\end{array}$ \\
\hline QUBG1 & Real & $\begin{array}{l}\text { Rate of inflow/outflow of solute mass or energy when the computed concentration or temperature } \\
\text { equals UBG1 at node IUBG. }\left[\mathrm{M}_{\mathrm{s}} / \mathrm{s} \text { or E/s]. }\right. \\
\text { May be omitted if IUBG }<0 \text {. }\end{array}$ \\
\hline UBG2 & Real & $\begin{array}{l}\text { Concentration or temperature value at the second of two points that define the linear relation } \\
\text { between solute mass or energy inflow/outflow and concentration or temperature at node IUBG. } \\
{\left[\mathrm{M}_{\mathrm{s}} / \mathrm{M} \text { or } \mathrm{C}^{\circ}\right] \text {. }} \\
\text { May be omitted if IUBG }<0 \text {. }\end{array}$ \\
\hline QUBG2 & Real & $\begin{array}{l}\text { Rate of inflow/outflow of solute mass or energy when the computed concentration or temperature } \\
\text { equals UBG } 2 \text { at node IUBG. }\left[\mathrm{M}_{\mathrm{s}} / \mathrm{s} \text { or E/s]. }\right. \\
\text { May be omitted if IUBG }<0 \text {. }\end{array}$ \\
\hline \multicolumn{3}{|r|}{ Last line } \\
\hline & Integer & $\begin{array}{l}\text { Placed immediately following all NUBG specified temperature or concentration lines. Line must } \\
\text { begin with the integer } 0 .\end{array}$ \\
\hline
\end{tabular}




\section{List of New or Modified Input Data for the Time-Dependent Sources and Boundary Conditions Files (.bcs)}

Model Version: SUTRA 3.0

DATASET 2: Identifier and Time-Dependent Source and Boundary Condition Counts (one line)

NOTE: Input variables NPBG1 and NUBG1 have been added.

Required for each time step on which there is a source or boundary condition specification in the ".bcs" file (that is, for each time step in the controlling schedule specified in dataset 1).

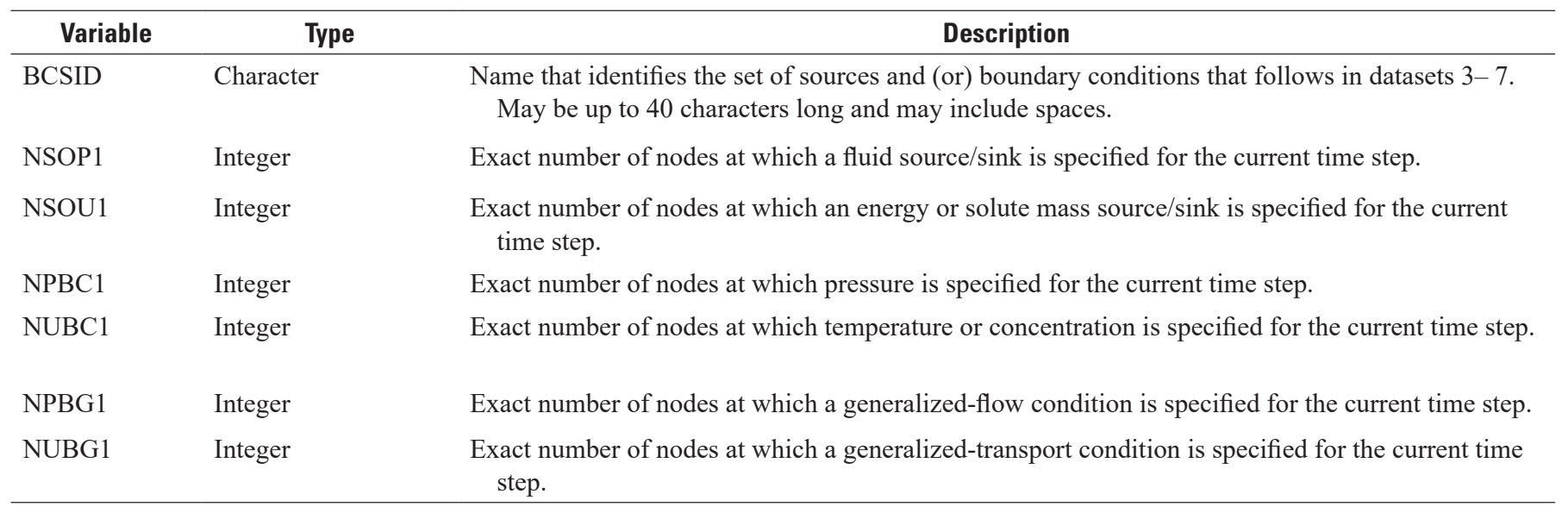

\section{Note:}

The source and boundary condition counts NSOP1, NSOU1, NPBC1, NUBC1, NPBG1, and NUBG1 correspond to ".bcs" datasets 3, 4, 5, 6, 7A, and 7B, respectively, and must be listed in that order. The counts refer to specifications made on the current time step in the current ".bcs" file; specifications made on other time steps and (or) in other files are not included in the counts.

Specifications need be included in ".bcs" files only when they are changing on a given time step. Specifications are persistent once set, they remain in force unless/until superseded by another specification.

If the controlling schedule includes time steps for which no ".bcs" specification is desired, one can simply set NSOP1=NSOU1= $\mathrm{NPBC} 1=\mathrm{NUBC} 1=\mathrm{NPBG} 1=\mathrm{NUBG} 1=0$ on those time steps.

To assist the user in keeping track of where various boundary conditions are set, SUTRA includes the identifier BCSID with each source or boundary condition listed in the “.bcof”, “.bcos”, “.bcop”, “.bcou”, “.bcopg”, and ".bcoug” output files. 
DATASET 7A: Time-Dependent Generalized Flows (one line for each of NPBG1 generalized-flow nodes as indicated in ".bcs" dataset 2, plus one line)

\section{NOTE: This is an entirely new dataset.}

\section{$\underline{\mathrm{O} M}$ I T when there are no generalized flows to be specified for the current time step $(\mathrm{NPBG} 1=0$ in dataset 2$)$.}

Specifications made in this dataset take precedence over those made in ".inp" dataset 21A (and subroutine BCTIME). A specification remains in force unless/until superseded by a corresponding specification on a later time step (or in another ".bcs" file read later on the same time step).

\begin{tabular}{|c|c|c|}
\hline Variable & Type & Description \\
\hline \multicolumn{3}{|r|}{ Lines 1 to NPBG1 } \\
\hline IPBG1 & Integer & $\begin{array}{l}\text { Number of node to which generalized-flow data on this line refers. Specifying the node number with } \\
\text { a negative sign renders the generalized-flow condition inactive (it is not applied) at node IPBG1, } \\
\text { which gives the user the option of suppressing output for the inactive boundary condition by set- } \\
\text { ting CINACT = 'N' in ".inp" dataset } 8 \mathrm{E} \text {. }\end{array}$ \\
\hline PBG11 & Real & $\begin{array}{l}\text { Pressure value at the first of two points that define the linear relation between fluid inflow/outflow } \\
\text { and pressure at node IPBG1. }\left[\mathrm{M} /\left(\mathrm{L} \cdot \mathrm{s}^{2}\right)\right] \text {. } \\
\text { May be omitted if the boundary condition is inactive }(\mathrm{IPBG} 1<0) \text {. }\end{array}$ \\
\hline QPBG11 & Real & $\begin{array}{l}\text { Rate of inflow/outflow of fluid mass when the computed pressure equals PBG11 at node IPBG1. } \\
{[\mathrm{M} / \mathrm{s}] \text {. }} \\
\text { May be omitted if the boundary condition is inactive }(\mathrm{IPBG} 1<0) \text {. }\end{array}$ \\
\hline PBG21 & Real & $\begin{array}{l}\text { Pressure value at the second of two points that define the linear relation between fluid inflow/outflow } \\
\text { and pressure at node IPBG1. }\left[\mathrm{M} /\left(\mathrm{L} \cdot \mathrm{s}^{2}\right)\right] \text {. } \\
\text { May be omitted if the boundary condition is inactive }(\mathrm{IPBG} 1<0) \text {. }\end{array}$ \\
\hline CPQL11 & Character & $\begin{array}{l}\text { Determines whether a limit is set on fluid inflow/outflow, pressure, or neither at the first of two points } \\
\left.\left.\text { that define the linear relation between fluid inflow/outflow and pressure at node IPBG1. [M/(L·s } \mathrm{s}^{2}\right)\right] \text {. } \\
\text { Valid values are as follows: } \\
\text { ' } \mathrm{Q} \text { ' = set limit of } Q \leq \mathrm{QPBG} 11 \\
\text { ' } \mathrm{P} \text { ' = set limit of } p \geq \text { PBG1 } \\
\text { ' } \mathrm{N} \text { ' = set no limit at point } 1 \\
\text { May be omitted if the boundary condition is inactive (IPBG1 }<0) \text {. }\end{array}$ \\
\hline CPQL21 & Character & $\begin{array}{l}\text { Determines whether a limit is set on fluid inflow/outflow, pressure, or neither at the second of two } \\
\text { points that define the linear relation between fluid inflow/outflow and pressure at node IPBG1. } \\
{\left[\mathrm{M} /\left(\mathrm{L} \cdot \mathrm{s}^{2}\right)\right] \text {. Valid values are as follows: }} \\
\text { 'Q' } \mathrm{Q} \text { ' set limit of } Q \geq \mathrm{QPBG} 21 \\
\text { 'P' }=\text { set limit of } p \leq \mathrm{PBG} 21 \\
\text { 'N' = set no limit at point } 2 \\
\text { May be omitted if the boundary condition is inactive (IPBG1 }<0) \text {. }\end{array}$ \\
\hline CUPBGO1 & Character & $\begin{array}{l}\text { One word. Must be either 'DIR' or 'REL'. Indicates whether the temperature or solute concentration, } \\
\text { UPBGO1, of any fluid that exits the model at node IPBG1 is being specified directly ('DIR') or } \\
\text { relative to the computed concentration or temperature at the node ('REL'). } \\
\text { May be omitted if the boundary condition is inactive (IPBG1 }<0 \text { ). }\end{array}$ \\
\hline UPBGO1 & Real & $\begin{array}{l}\text { Temperature or solute concentration of any fluid that exits the model at node IPBG1. If CUPBGO1 } \\
=\text { 'DIR', the exit temperature or concentration is set directly to the value UPBGO1. If CUPBGO1 } \\
=\text { 'REL', the exit temperature or concentration is set to the value } U+U B P G O 1 \text {, where } U \text { is the } \\
\text { temperature or concentration computed at the node. }\left[{ }^{\circ} \mathrm{C}\right] \text { or }\left[\mathrm{M}_{\mathrm{s}} / \mathrm{M}\right] \text {. } \\
\text { May be omitted if the boundary condition is inactive (IPBG1 }<0) \text {. }\end{array}$ \\
\hline
\end{tabular}


Last line

Integer Placed immediately following all NPBG1 specified pressure lines. Line must begin with the integer 0 .

Note:

It is not sufficient to specify only the input variable that is changing on the current time step. For example, if PBG11 is changing but the other input variables (for example, QPBG11) are not, one must still provide a value for each input variable.

DATASET 7B: Time-Dependent Generalized Transport (one line for each of NUBG1 generalized-transport nodes indicated in ".bcs" dataset 2, plus one line)

NOTE: This is an entirely new dataset.

$\underline{\mathrm{O}}$ M I T when there are no generalized-transport nodes to be specified for the current time step (NUBG1 = 0 in dataset 2).

Specifications made in this dataset take precedence over those made in ".inp" dataset 21B (and subroutine BCTIME). A specification remains in force unless/until superseded by a corresponding specification on a later time step (or in another ".bcs" file read later on the same time step).

\begin{tabular}{|c|c|c|}
\hline Variable & Type & Description \\
\hline \multicolumn{3}{|r|}{ Lines 1 to NUBG1 } \\
\hline IUBG1 & Integer & $\begin{array}{l}\text { Number of node to which generalized-transport data on this line refers. Specifying the node number } \\
\text { with a negative sign renders the generalized-transport condition inactive (it is not applied) at } \\
\text { node IUBG1, which gives the user the option of suppressing output for the inactive boundary } \\
\text { condition by setting CINACT = 'N' in ".inp" dataset 8E. } \\
\text { Any node listed in this dataset must also be listed in ".inp" dataset 21B. }\end{array}$ \\
\hline QUBG11 & Real & $\begin{array}{l}\text { Rate of inflow/outflow of solute mass or energy when the computed concentration or temperature } \\
\text { equals UBG11 at node IUBG1. }\left[\mathrm{M}_{\mathrm{s}} / \mathrm{s} \text { or E/s]. }\right. \\
\text { May be omitted if the boundary condition is inactive }(\mathrm{IUBG} 1<0) \text {. }\end{array}$ \\
\hline QUBG21 & Real & $\begin{array}{l}\text { Rate of inflow/outflow of solute mass or energy when the computed concentration or temperature } \\
\text { equals UBG } 21 \text { at node IUBG1. }\left[\mathrm{M}_{\mathrm{s}} / \mathrm{s} \text { or E/s]. }\right. \\
\text { May be omitted if the boundary condition is inactive }(\mathrm{IUBG} 1<0) \text {. }\end{array}$ \\
\hline \multicolumn{3}{|r|}{ Last line } \\
\hline & Integer & $\begin{array}{l}\text { Placed immediately following all NUBG1 specified temperature or concentration lines. Line must } \\
\text { begin with the integer } 0 \text {. }\end{array}$ \\
\hline
\end{tabular}

Note:

It is not sufficient to specify only the input variable that is changing on the current time step. For example, if UBG11 is changing but the other input variables (for example, QUBG11) are not, one must still provide a value for each input variable. 


\section{Input Data for the Main Input File for the Lake Capability (.Ikin)}

\section{Model Version: SUTRA 3.0}

NOTE: This is an entirely new input file.

This input file is optional in general but is required for the lake capability. If this input file is omitted, the lake capability is not used.

DATASET 1: Lake Output Control (one line)

\begin{tabular}{ccc}
\hline Variable & Type & \multicolumn{1}{c}{ Description } \\
NLAKPR & Integer & $\begin{array}{l}\text { Output cycle for lake information during a transient simulation. Output is produced in the lake out- } \\
\text { put files on time steps numbered } n \mid \text { NLAKPR } \mid \text { (where } n \text { is a positive integer). Also, for transient } \\
\text { solutions, output is produced for initial conditions and on the first and last time steps. To cancel } \\
\text { printed output for the first time step of a transient simulation, set NLAKPR to a negative number } \\
\text { (that is, place a minus sign before the desired output cycle). For steady-state solutions, output is } \\
\text { produced irrespective of the value of NLAKPR. }\end{array}$ \\
\hline
\end{tabular}

DATASET 2: Number of lake specifications and default values (one line)

\begin{tabular}{|c|c|c|}
\hline Variable & Type & Description \\
\hline NLSPEC & Integer & Number of lake specifications. Set NLSPEC $=0$ if there are no lake specifications. \\
\hline FRROD & Real & $\begin{array}{l}\text { Default value of the fraction of groundwater recharge diverted as runoff from generalized-flow nodes. (See } \\
\text { section 3.2.3.4, "Runoff to Lakes.") This default value is applied to the basins of all lakes not identified } \\
\text { in the lake specifications in DATASET } 3 \text { below. }\end{array}$ \\
\hline FDROD & Real & $\begin{array}{l}\text { Default value of the fraction of groundwater discharge diverted as runoff from generalized-flow nodes. } \\
\text { (See section 3.2.3.4, "Runoff to Lakes.") This default value is applied to the basins of all lakes not iden- } \\
\text { tified in the lake specifications in DATASET } 3 \text { below. }\end{array}$ \\
\hline RNOLK & Real & $\begin{array}{l}\text { Value output (in place of lake stage) to the ".lkst" output file at nodes not submerged by lake water. May be } \\
\text { set to any real value. }\end{array}$ \\
\hline
\end{tabular}

DATASET 3: Lake specifications (one line for each of NLSPEC optional lake specifications)

\begin{tabular}{|c|c|c|}
\hline Variable & Type & Description \\
\hline CTYPE & Character & One word. Must be either 'LAKE' or 'NODE'. \\
\hline ILON & Integer & $\begin{array}{l}\text { Number of the lake or node to which the specification applies. If CTYPE = 'LAKE', ILON is the number of } \\
\text { the lake to which the specification applies. If CTYPE = 'NODE', ILON is the number of a node within } \\
\text { the basin of the lake to which the specification applies. Node ILON must be on the top surface of the } \\
\text { model. }\end{array}$ \\
\hline STGI & Real & $\begin{array}{l}\text { Initial stage in the lake to which the specification applies. If STGI is below the lowest point in the lake } \\
\text { bathymetry, the lake is initially dry. SUTRA resolves any conflicting initial stage specifications in favor } \\
\text { of the highest stage specified. }\end{array}$ \\
\hline UWI & Real & Initial lake-water concentration or temperature in the lake to which the specification applies. $\left[\mathrm{M}_{s} / \mathrm{M}\right.$ or $\left.\mathrm{C}^{\circ}\right]$ \\
\hline FRRO & Real & $\begin{array}{l}\text { Value of the fraction of groundwater recharge diverted as runoff from generalized-flow nodes within the } \\
\text { basin of the lake to which the specification applies. (See section 3.2.3.4, "Runoff to Lakes.") }\end{array}$ \\
\hline
\end{tabular}


Note:

Lakes are identified and numbered automatically by SUTRA. Therefore, the user generally will not know the lake numbering scheme until a preliminary run is performed. Once the lake numbering is known, CTYPE = 'LAKE' can be used to allow lake specifications to be made conveniently using lake numbers. Until then, the user has the option to make specifications using node numbers by setting CTYPE $=$ 'NODE'. Setting the desired specifications can involve trial and error, especially for complex lake systems.

\section{Input Data for the Boundary-Condition Interaction Input File for the Lake Capability (.Ikbc)}

\section{Model Version: SUTRA 3.0}

\section{NOTE: This is an entirely new input file.}

DATASET 1: Boundary-condition interaction specification counts (one line)

\begin{tabular}{lll}
\hline Variable & \multicolumn{1}{c}{ Type } & \multicolumn{1}{c}{ Description } \\
\hline NBCIF & Integer & Number of interaction specifications for fluid sources/sinks. \\
NBCIS & Integer & Number of interaction specifications for sources/sinks of solute mass or energy. \\
NBCIP & Integer & Number of interaction specifications for specified pressures. \\
NBCIU & Integer & Number of interaction specifications for specified concentrations or temperatures. \\
NBCIPG & Integer & Number of interaction specifications for generalized-flow conditions. \\
NBCIUG & Integer & Number of interaction specifications for generalized-transport conditions. \\
\hline
\end{tabular}

DATASET 2: Boundary-condition interaction specifications for fluid sources/sinks (one line for each of NBCIF specifications)

\begin{tabular}{|c|c|c|}
\hline Variable & Type & Description \\
\hline \multirow[t]{2}{*}{ BCSFNM } & Character & $\begin{array}{l}\text { On the first line, set BCSFNM = 'DEFAULT'. SUTRA applies DEFAULT specifications to all fluid- } \\
\text { source/sink nodes that can form lakes but are not identified as fluid sources/sinks in the optional list of } \\
\text { ".bcs" files that follows. }\end{array}$ \\
\hline & & $\begin{array}{l}\text { On each subsequent line (optional), set BCSFNM to the name of a ".bcs" file that contains fluid sources/ } \\
\text { sinks with which lakes will interact. }\end{array}$ \\
\hline ILKF & Integer & $\begin{array}{l}\text { Effect that the presence or absence of lake water has on the pplication of fluid sources/sinks identified by } \\
\text { BCSFNM. When ILKF }=-1 \text {, a fluid source/sink is applied to a node only when lake water is absent at } \\
\text { that node. When ILKF }=0 \text {, a fluid source/sink is a applied to a node whether lake water is present or ab- } \\
\text { sent at that node. When ILKF=1, a fluid source/sink is applied to a node only when lake water is present } \\
\text { at that node. }\end{array}$ \\
\hline
\end{tabular}


DATASET 3: Boundary-condition interaction specifications for sources/sinks of solute mass or energy (one line for each of NBCIS specifications)

\begin{tabular}{ccc}
\hline Variable & Type & Description \\
\hline BCSFNM & Character & $\begin{array}{l}\text { On the first line, set BCSFNM = 'DEFAULT'. SUTRA applies DEFAULT specifications to all solute mass } \\
\text { or energy-source/sink nodes that can form lakes but are not identified as sources/sinks of solute mass or } \\
\text { energy in the optional list of ".bcs" files that follows. } \\
\text { On each subsequent line (optional), set BCSFNM to the name of a ".bcs" file that contains sources/sinks } \\
\text { of solute mass or energy with which lakes will interact. } \\
\text { Effect that the presence or absence of lake water has on the application of sources/sinks of solute mass or } \\
\text { energy identified by BCSFNM. When ILKS }=-1 \text {, a source/sink of solute or energy is applied to a node } \\
\text { only when lake water is absent at that node. When ILKS = 0, a source/sink of solute or energy is applied } \\
\text { to a node whether lake water is present or absent at that node. When ILKS = 1, a source/sink of solute } \\
\text { or energy is applied to a node only when lake water is present at that node. }\end{array}$ \\
\hline
\end{tabular}

DATASET 4: Boundary-condition interaction specifications for specified pressures (one line for each of NBCIP specifications)

\begin{tabular}{|c|c|c|}
\hline Variable & Type & Description \\
\hline \multirow[t]{2}{*}{ BCSFNM } & Character & $\begin{array}{l}\text { On the first line, set BCSFNM = 'DEFAULT'. SUTRA applies DEFAULT specifications to all specified- } \\
\text { pressure nodes that can form lakes but are not identified as specified-pressure nodes in the optional list } \\
\text { of ".bcs" files that follows. }\end{array}$ \\
\hline & & $\begin{array}{l}\text { On each subsequent line (optional), set BCSFNM to the name of a ".bcs" file that contains specified } \\
\text { pressures with which lakes will interact. }\end{array}$ \\
\hline ILKP & Integer & $\begin{array}{l}\text { Effect that the presence or absence of lake water has on the application of specified pressures identified } \\
\text { by BCSFNM. When ILKP }=-1 \text {, a specified pressure is applied to a node only when lake water is absent } \\
\text { at that node. When ILKP }=0 \text {, a specified pressure is applied to a node whether lake water is present or } \\
\text { absent at that node. When ILKP }=1 \text {, a specified pressure is applied to a node only when lake water is } \\
\text { present at that node. }\end{array}$ \\
\hline
\end{tabular}

DATASET 5: Boundary-condition interaction specifications for specified concentrations/temperatures (one line for each of NBCIU specifications)

\begin{tabular}{|c|c|c|}
\hline Variable & Type & Description \\
\hline \multirow[t]{2}{*}{ BCSFNM } & Character & $\begin{array}{l}\text { On the first line, set BCSFNM = 'DEFAULT'. SUTRA applies DEFAULT specifications to all specified- } \\
\text { concentration/temperature nodes that can form lakes but are not identified as specified-concentration/ } \\
\text { temperature nodes in the optional list of “.bcs” files that follows. }\end{array}$ \\
\hline & & $\begin{array}{l}\text { On each subsequent line (optional), set BCSFNM to the name of a ".bcs" file that contains specified con- } \\
\text { centrations/temperatures with which lakes will interact. }\end{array}$ \\
\hline ILKU & Integer & $\begin{array}{l}\text { Effect that the presence or absence of lake water has on the application of specified concentrations or tem- } \\
\text { peratures identified by BCSFNM. When ILKU }=-1 \text {, a specified concentration or temperature is applied } \\
\text { to a node only when lake water is absent at that node. When ILKU }=0 \text {, a specified concentration or } \\
\text { temperature is applied to a node whether lake water is present or absent at that node. When ILKU }=1 \text {, a } \\
\text { specified concentration or temperature is applied to a node only when lake water is present at that node. }\end{array}$ \\
\hline
\end{tabular}


DATASET 6A: Boundary-condition interaction specifications for generalized-flow conditions (one line for each of NBCIPG specifications)

\begin{tabular}{|c|c|c|}
\hline Variable & Type & Description \\
\hline \multirow[t]{2}{*}{ BCSFNM } & Character & $\begin{array}{l}\text { On the first line, set BCSFNM = 'DEFAULT'. SUTRA applies DEFAULT specifications to all } \\
\text { generalized-flow nodes that can form lakes but are not identified as generalized-flow nodes in } \\
\text { the optional list of “.bcs" files that follows. }\end{array}$ \\
\hline & & $\begin{array}{l}\text { On each subsequent line (optional), set BCSFNM to the name of a ".bcs" file that contains } \\
\text { generalized-flow conditions with which lakes will interact. }\end{array}$ \\
\hline ILKPG & Integer & $\begin{array}{l}\text { Effect that the presence or absence of lake water has on the application of generalized-flow con- } \\
\text { ditions identified by BCSFNM. When ILKPG }=-1 \text {, a generalized-flow condition is applied } \\
\text { to a node only when lake water is absent at that node. When ILKPG }=0 \text {, a generalized-flow } \\
\text { condition is applied to a node whether lake water is present or absent at that node. When } \\
\text { ILKPG }=1 \text {, a generalized-flow condition is applied to a node only when lake water is present } \\
\text { at that node. }\end{array}$ \\
\hline CTIPG & Character & $\begin{array}{l}\text { Type of interaction between the generalized-flow condition and lakes. Select one of the } \\
\text { following: } \\
\text { 'F' = Interaction analogous to that between a fluid source/sink node and a lake } \\
\text { 'P' = Interaction analogous to that between a specified-pressure node and a lake } \\
\text { (See section 3.2.3.3, "Interaction with Generalized-Flow Conditions.") }\end{array}$ \\
\hline
\end{tabular}

DATASET 6B: Boundary-condition interaction specifications for generalized-transport conditions (one line for each of NBCIUG specifications)

\begin{tabular}{|c|c|c|}
\hline Variable & Type & Description \\
\hline BCSFNM & Character & $\begin{array}{l}\text { On the first line, set BCSFNM = 'DEFAULT'. SUTRA applies DEFAULT specifications to all gener- } \\
\text { alized-transport nodes that can form lakes but are not identified as generalized-transport nodes in } \\
\text { the optional list of ".bcs" files that follows. } \\
\text { On each subsequent line (optional), set BCSFNM to the name of a ".bcs" file that contains general- } \\
\text { ized-transport conditions with which lakes will interact. }\end{array}$ \\
\hline ILKUG & Integer & $\begin{array}{l}\text { Effect that the presence or absence of lake water has on the application of generalized-transport con- } \\
\text { ditions identified by BCSFNM. When ILKUG }=-1 \text {, a generalized-transport condition is applied to } \\
\text { a node only when lake water is absent at that node. When ILKUG }=0 \text {, a generalized-transport con- } \\
\text { dition is applied to a node whether lake water is present or absent at that node. When ILKUG }=1 \text {, a } \\
\text { generalized-transport condition is applied to a node only when lake water is present at that node. }\end{array}$ \\
\hline CTIUG & Character & $\begin{array}{l}\text { Type of interaction between the generalized-flow condition and lakes. Select one of the following: } \\
\text { 'S'= Interaction analogous to that between a solute or energy source/sink node and a lake } \\
\text { 'U' = Interaction analogous to that between a specified-concentration or specified-temperature node } \\
\text { and a lake } \\
\text { (See section 3.2.3.7, "Interaction with Generalized-Transport Conditions.") }\end{array}$ \\
\hline
\end{tabular}




\section{Input Data for the Lake-Area Input File for the Lake Capability (.Ikar)}

\section{Model Version: SUTRA 3.0}

NOTE: This is an entirely new input file.

This input file is optional. If the lake capability is used and this input file is omitted, all nodes on the top surface of the model are eligible to form lakes and lake-bottom elevations are based on the top-surface node elevations of the groundwater model.

DATASET 1A: Number of lake nodes and method of determining lake-bottom elevations (one line)

\begin{tabular}{|c|c|c|}
\hline Variable & Type & Description \\
\hline & Character & Line must begin with the word 'LAKE'. \\
\hline NLAN & Integer & Exact number of nodes on the top surface of the model that are eligible to form lakes. \\
\hline
\end{tabular}

DATASET 1B: List of lake nodes (one line for each of NLAN nodes, plus one line)

\begin{tabular}{lll}
\hline Variable & \multicolumn{1}{c}{ Type } & \multicolumn{1}{c}{ Description } \\
\hline IL & $\begin{array}{l}\text { Integer } \\
\text { ELVLB }\end{array}$ & $\begin{array}{l}\text { Number of node that is eligible to form lakes. Node IL must be on the top surface of the model. } \\
\text { User-specified lake-bottom elevation at node IL. May be omitted if lake-bottom elevations are set by default } \\
(\text { CBOT }=\text { 'DEFAULT'). }\end{array}$ \\
\hline & Integer & Placed immediately following all NLAN lake-node lines. Line must begin with the integer 0. \\
\hline
\end{tabular}


Publishing support provided by the U.S. Geological Survey Science Publishing Network, Reston Publishing Service Center

For more information, please contact:

Earth System Processes Division

U.S. Geological Survey

Mail Stop 411

12201 Sunrise Valley Drive

Reston, VA 20192

703-648-5005 
